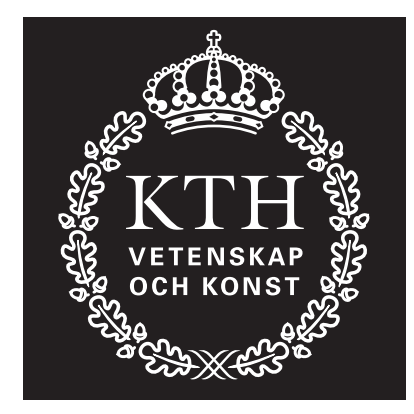

KTH Machine Design

\title{
Kinematic Control of Redundant Knuckle Booms
}

Björn Löfgren 

TRITA - MMK 2004: 1

ISSN 1400-1179

ISRN/KTH/MMK/R-04/1-SE

Kinematic Control of Redundant Knuckle Booms

Björn Löfgren

Licentiate thesis

Academic thesis, which with the approval of Kungliga Tekniska Högskolan, will be presented for public review in fulfilment of the requirements for a Licentiate of Engineering in Machine Design. The public review is held at Kungliga Tekniska Högskolan, Brinellvägen 83, 1 tr, room A325 at 13:00 $13^{\text {th }}$ of February 2004. 


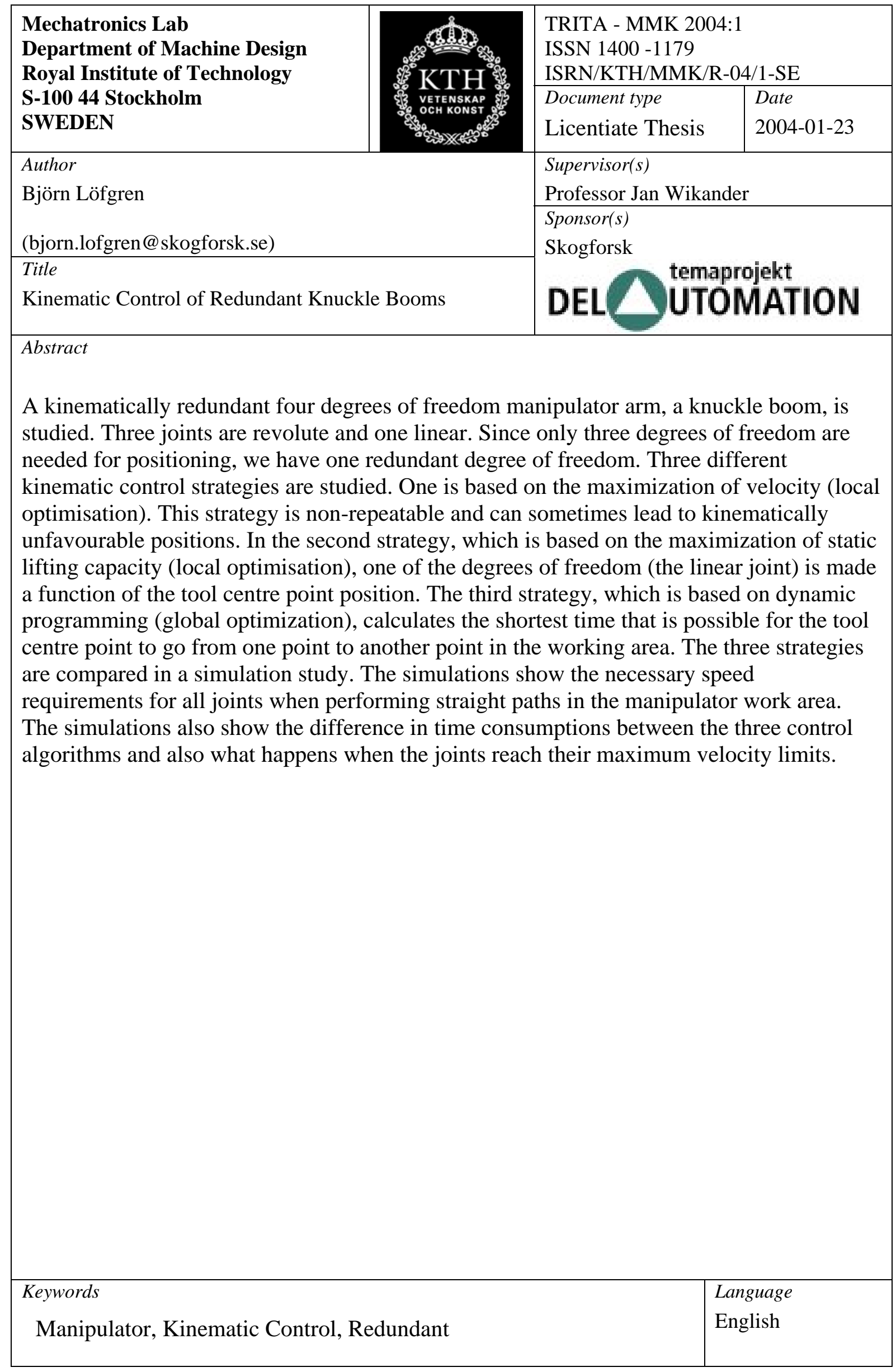





\section{Acknowledgment}

I want to express my deepest love to my wife Ann-Christin and to my two daughters Jenny and Hanna who supported me and made this work possible.

I also wish to express my sincere gratitude to all of those who have supported me and made this work possible. In particular I want to mention the following persons:

Professor Jan Wikander, my main supervisor, for the great freedom I have had when planning my work.

Charles Davidson, $\mathrm{PhD}$, my second supervisor, for skilful and stimulating supervision and especially for good advice on the theoretical part.

Pär Lärkeryd, Partek Forest AB, and Kjell Rönnholm, Cranab AB, who have supported me with all technical data.

Björn Löfgren

January 2004, Stockholm 



\section{Preface}

The Swedish forestry industry competes on an international market and since the raw material is more expensive than in other parts of the world the chain from the stump to the industry needs to be very effective. One part in this chain is cutting down and transporting trees out from the forest to the landing area for further transportation with trucks to the paper or saw mill. When cutting down and transporting trees, forestry machines equipped with booms are used to handle the trees. If we can reduce the boom handling time and thereby increase the productivity by $10 \%$ the Swedish forestry industry can earn up to 250 million Swedish crowns a year. Skogforsk is the research institute of the Swedish forestry sector. We carry out applied research in a variety of different fields; development of technology, environmental and conservation issues, breeding of forestry trees, organisational issues and many other topics.

One way to decrease the boom handling time is to introduce automatization. This thesis describes how to solve the kinematic control of the knuckle booms used on forestry machines if automatization is introduced.

The thesis is a part of my normal research work at The Forestry Research Institute of Sweden within the project Semi Automation. 



\section{Table of Contents}

CHAPTER 1 INTRODUCTION........................................................4

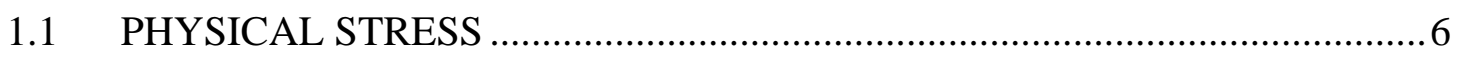

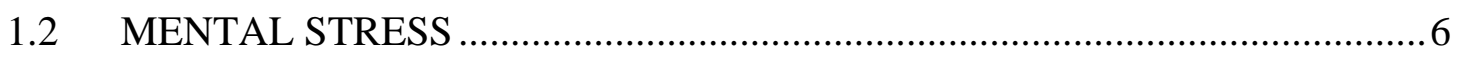

1.3 CONVENTIONAL ARM CONTROL VS. BOOM TIP CONTROL ................6

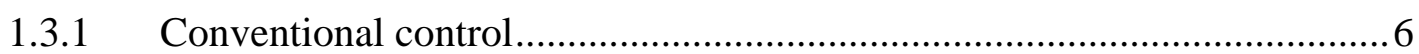

1.3.2 Boom tip control .....................................................................

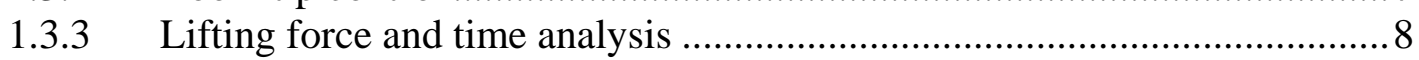

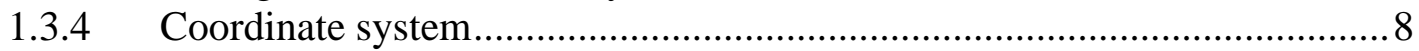

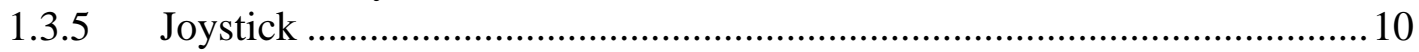

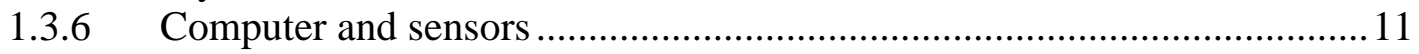

1.4 POTENTIAL ADVANTAGES OF BOOM TIP CONTROL ..........................12

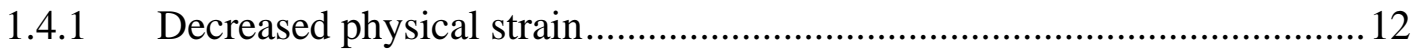

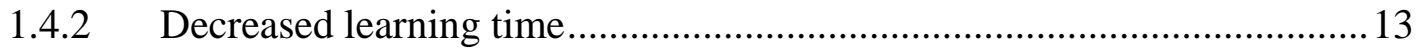

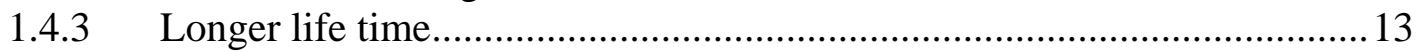

1.5 TARGETED MACHINES AND RESEARCH OBJECTIVE ..........................13

CHAPTER 2 OUTLINE OF THE THESIS ...........................................18

CHAPTER 3 STATE OF THE ART ................................................20

CHAPTER 4 BASIC EQUATIONS.............................................22

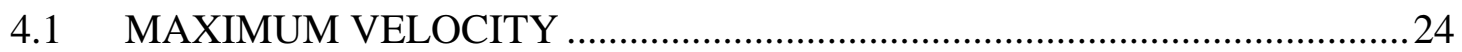

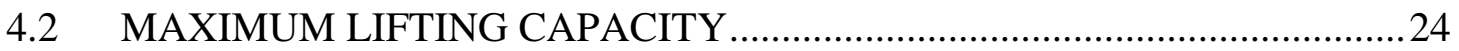

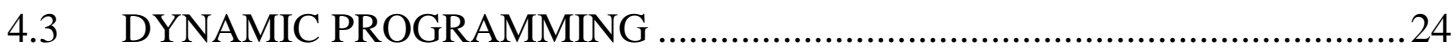

CHAPTER 5 MAXIMUM VELOCITY .......................................26

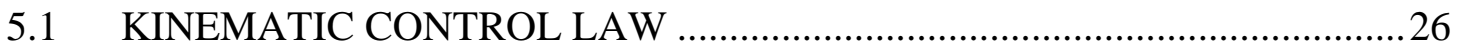

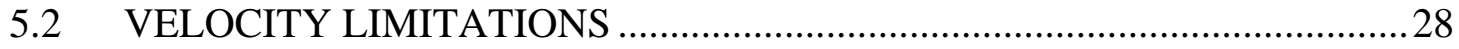

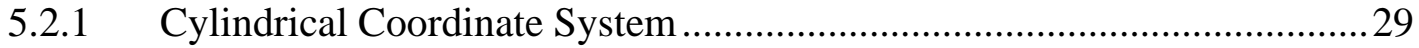

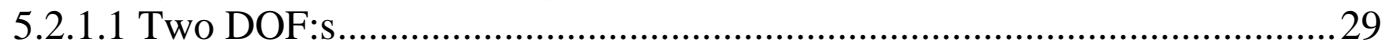




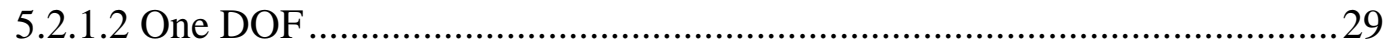

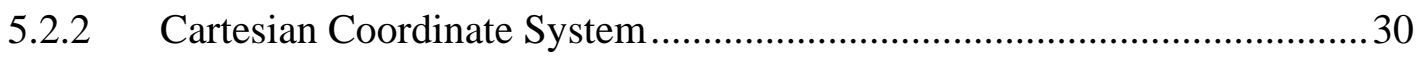

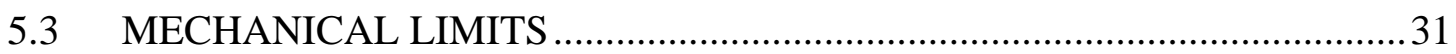

\section{CHAPTER 6 MAXIMUM LIFTING CAPACITY ..........................32}

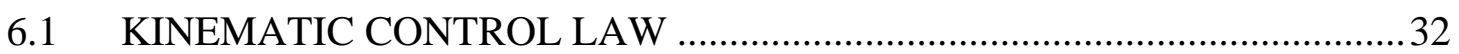

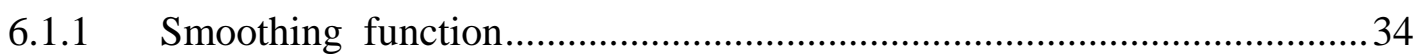

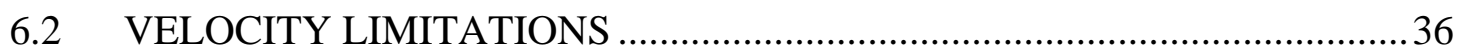

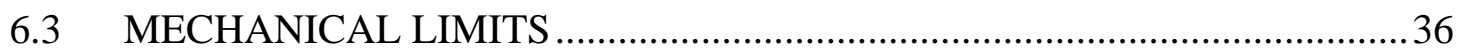

CHAPTER 7 DYNAMIC PROGRAMMING ........................................38

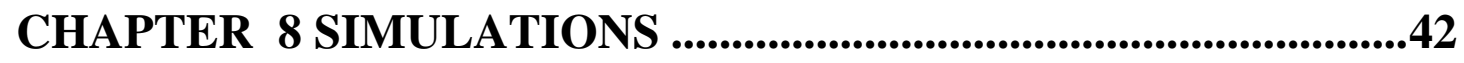

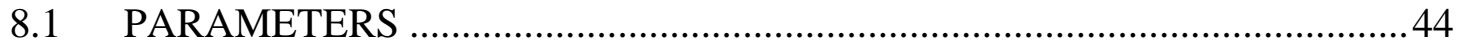

8.2 SIMULATIONS WITH MAXIMUM LIFTING CAPACITY AND

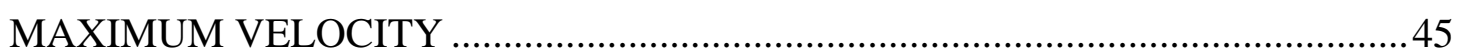

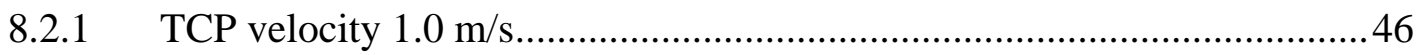

TCP moves from point A to B. ..................................................................... 46

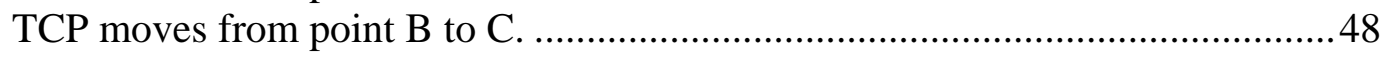

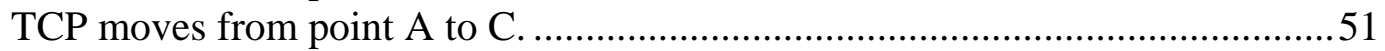

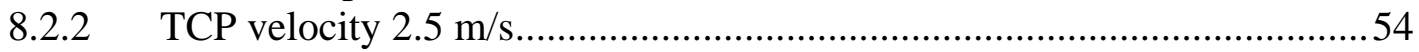

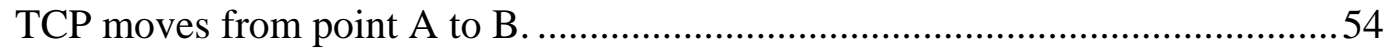

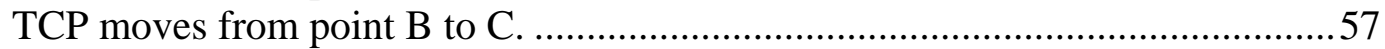

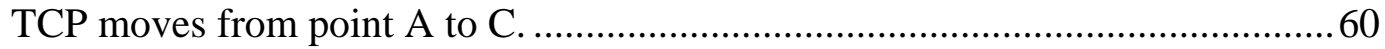

8.3 SIMULATIONS WITH THE DYNAMIC PROGRAMMING ALGORITHM 63

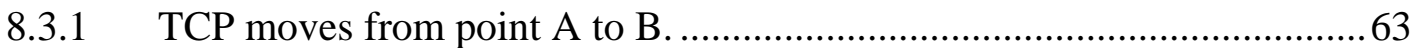

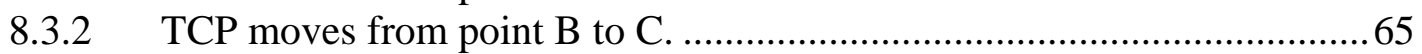

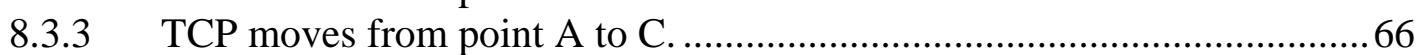

CHAPTER 9 CONCLUSION...........................................................68

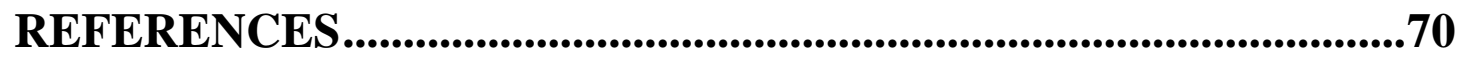

APPENDIX 1: KNUCKLE BOOM MARKET .................................74 


\section{Chapter 1}

\section{INTRODUCTION}

A powerful and a radical mechanisation since the middle of the 1960s has made the Swedish forestry almost $100 \%$ mechanised. This is one of the main explanations to why Swedish forestry could keep its international competitiveness. If this should be possible also in the future the productivity development needs to continue.

The forestry machines of today are high technology units with advanced control engineering. The technology development has resulted in a radical increase in performance. For the driver this has meant a more increased working volume and less natural stops in the ordinary work. At the same time quality content in the drivers work has been changed. It is no longer sufficient to control the machine and its functions. The drivers also have a great responsibility for environmental concerns, planning and follow up of the work. The working environment has through the years improved a lot concerning the physical stress on the driver. But the increased working volume, in combination with many decisions that the driver has to take, has increased the mental stress. The driver could be a bottle neck in new initiatives to increase productivity. By using more automated functions and letting the machine itself take care of repetitive work it is possible for the driver to devote his time for decisions regarding tree selection, wood quality and environmental concern.

The control of the manipulator movements takes most of the drivers working time on a forwarder, se figure 1.1, and a harvester, se figure 1.2. There is a potential to simplify the control of the manipulator, partly to reduce the mental work load and produce a good effect on more important tasks, partly to increase the production. The risk for stress injuries can also be reduced. 


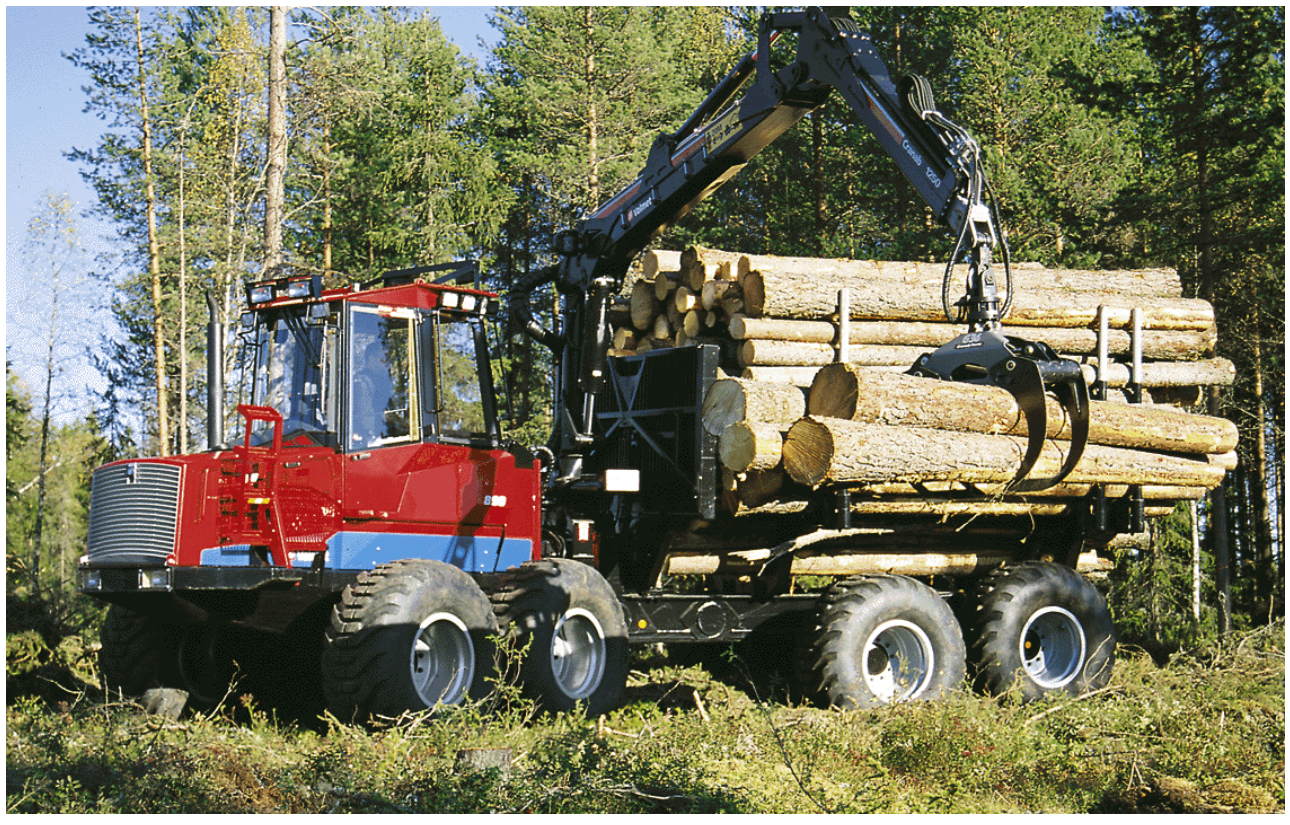

Figure 1.1. Forwarder Valmet 890.

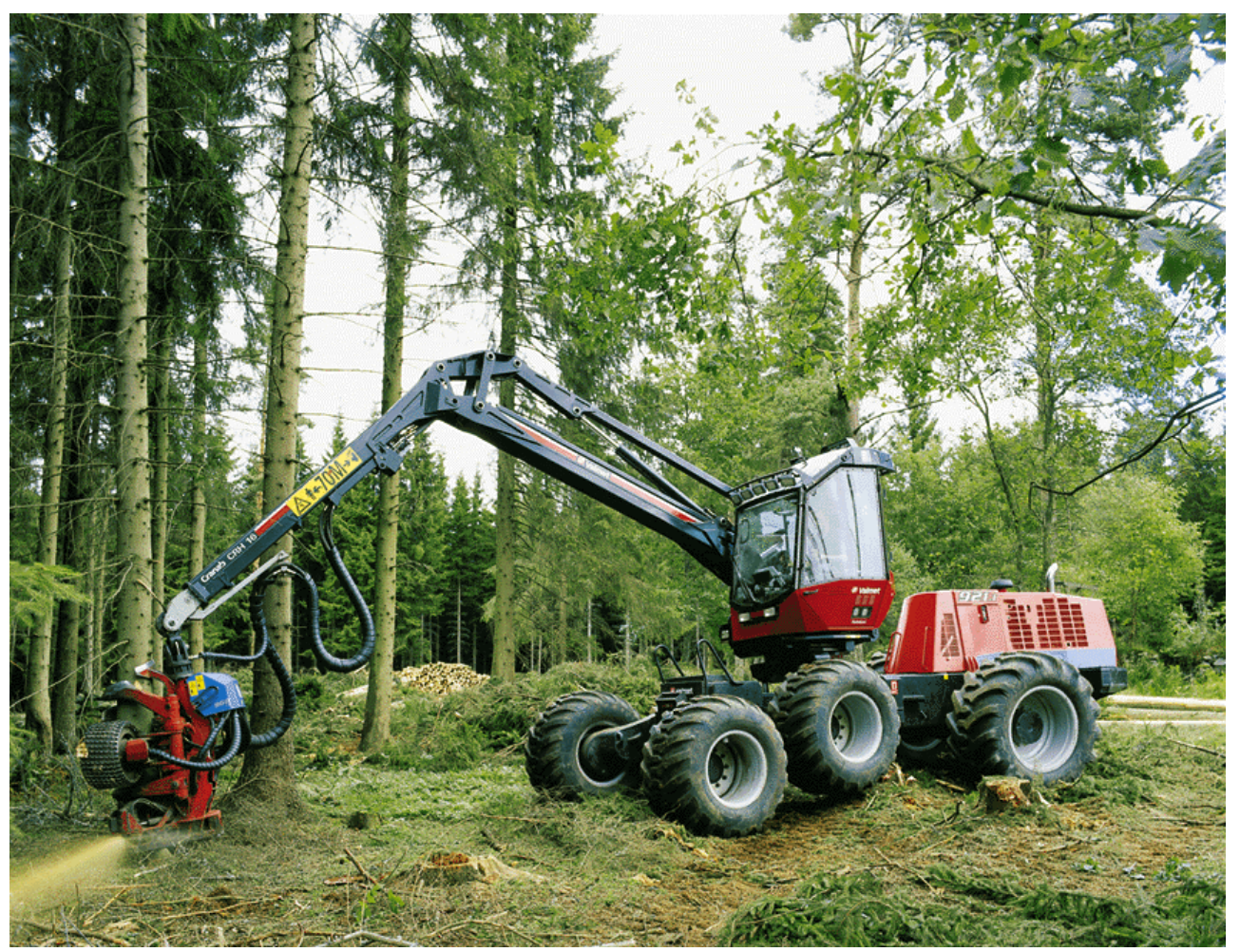

Figure 1.2. Harvester Valmet 921.

The control of the manipulator can be simplified through introduction of manipulator tip control and automated control of certain manipulator movements. 


\subsection{Physical stress}

To control a forestry machine implies almost continuous precision work with the hands. A high production requires intensive precision work. The repetitive work and the high intensity will cause statically tensed muscles or muscle fibres.

Actions that increase blood running through the muscles are of crucial importance to minimize the risk for stress injuries. The work to control the manipulator should therefore be as dynamic as possible, which speaks for many but short pauses. Decreased demands on the precision of the joystick work will give less muscle tension and thereby reduce stress. Technical solutions that will give short pauses in the intensive joystick work are therefore positive $[9,10]$.

\subsection{Mental Stress}

Drivers of forestry machines are exposed for great mental stress during their work. They have to receive and process a large amount of information and make decisions under great time pressure. At the same time, precision work with the hands means by itself a relatively great stress on the brain activity [10].

A natural conclusion of this is that a simplified control of the manipulator can reduce the mental stress on the driver.

\subsection{Conventional arm control vs. boom tip control}

Before one can implement simplified manipulator control one has to make some considerations, i.e. what coordinate system, what kind of joystick controls etc.

\subsubsection{Conventional control}

The forestry machines of today are controlled by two joysticks of different design. With a movement of one joystick in one direction the operator is controlling a specific cylinder out on the boom. This means that the operator has to combine different joystick movements to move the tip of the boom in the desired direction. 


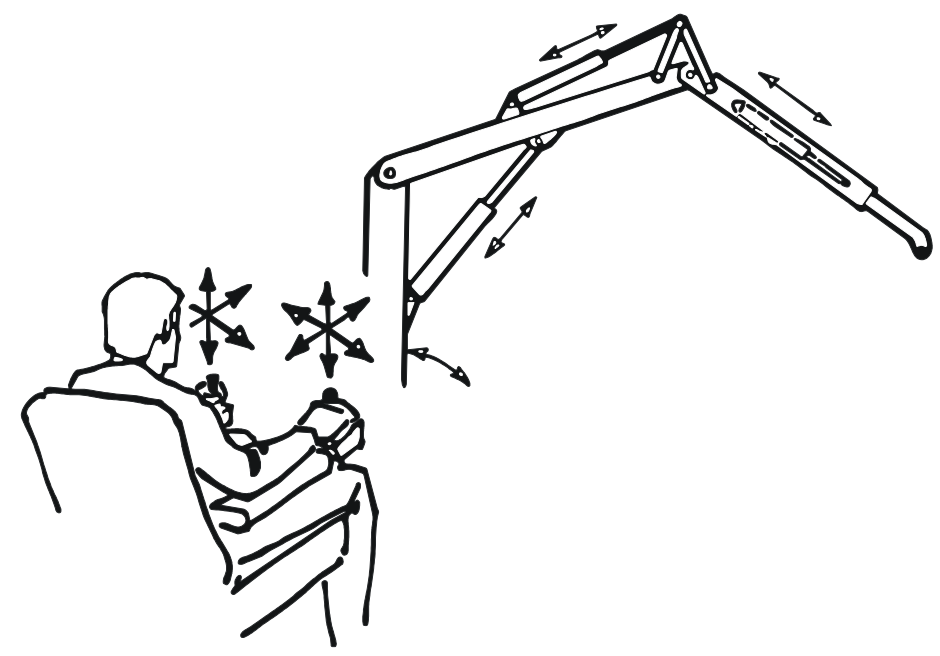

Figure 1.3.1.1. Conventional control.

\subsubsection{Boom tip control}

The concept boom tip control means that the tip of the boom is controlled with only one joystick. Up/down on the joystick corresponds to up/down on the tip of the boom, out/in on the joystick corresponds to out/in on the tip of the boom and left/right corresponds to left/right on the tip of the boom, see figure 1.3.2.1

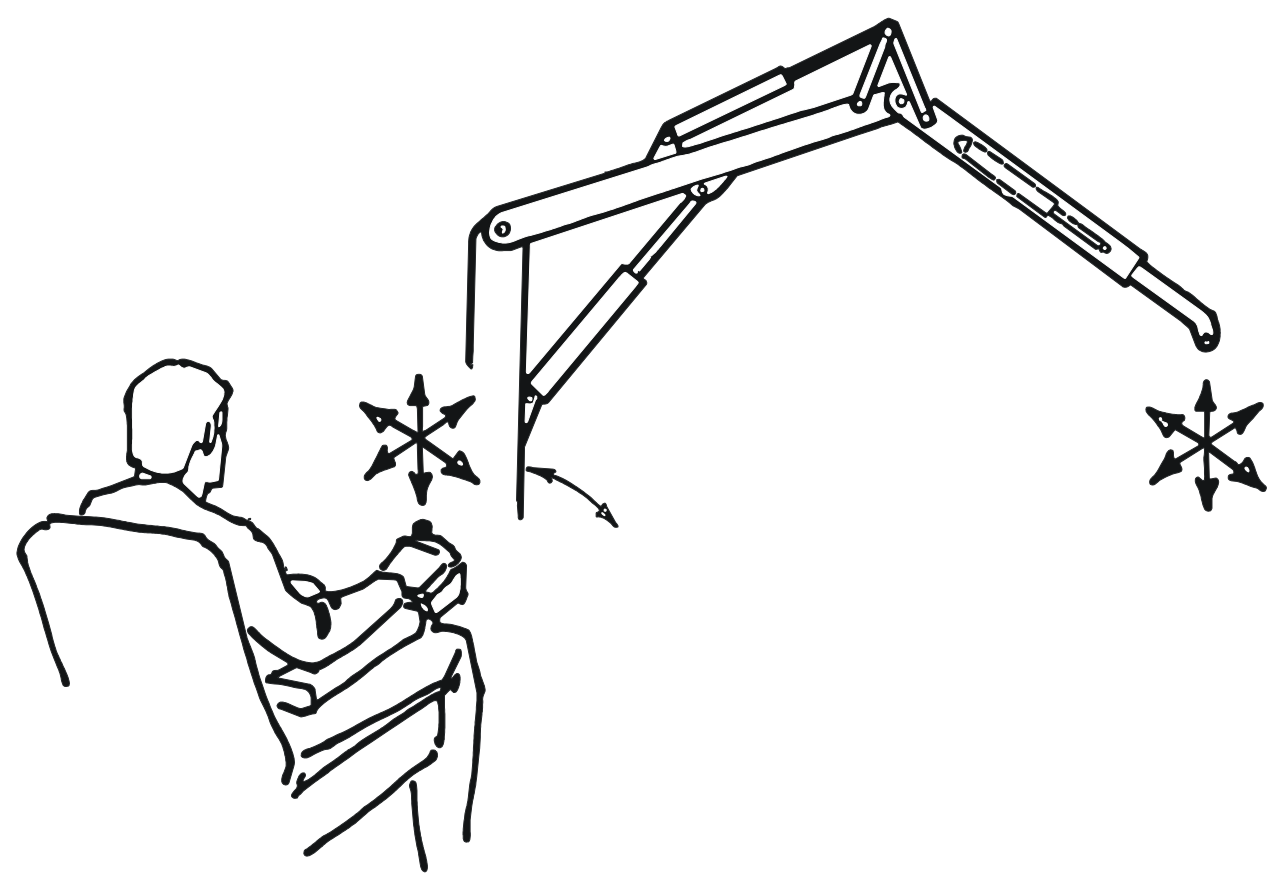

Figure 1.3.2.1. Boom tip control. 


\subsubsection{Lifting force and time analysis}

With the extension, one degree of freedom in the outer boom, in combination with the two rotational degrees of freedom it is possible for the TCP to reach next point on a desired path in a number of ways. In [18] computer analysis shows how the extension affects the speed and the lifting force with different length on the extension. The results show that the extension gives shorter time cycles and that one has better lifting force capacity close to the ground. This means that the extension should be included as much as possible in the kinematic control algorithm for the boom.

\subsubsection{Coordinate system}

There are two types of coordinate systems that are applicable in this case, a Cartesian and a cylindrical coordinate system, see figure 1.3.3.1- 2. This means that the operator driven boom tip control either operates in cylindrical or Cartesian coordinates.

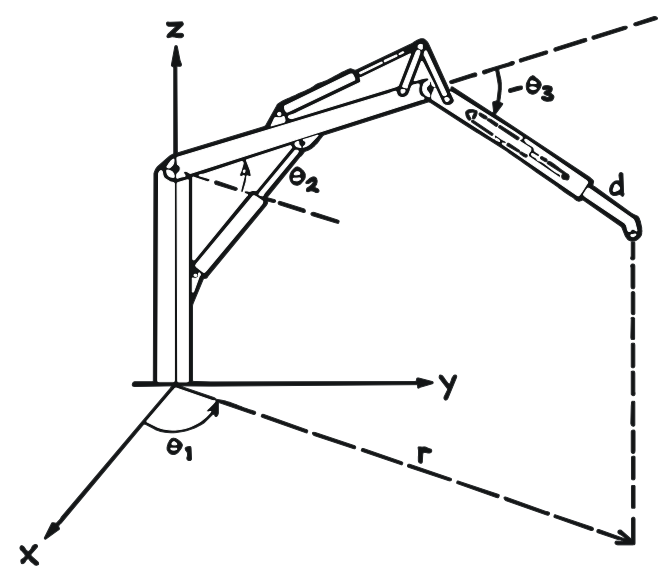

Figure 1.3.3.1. Cartesian coordinate system. 


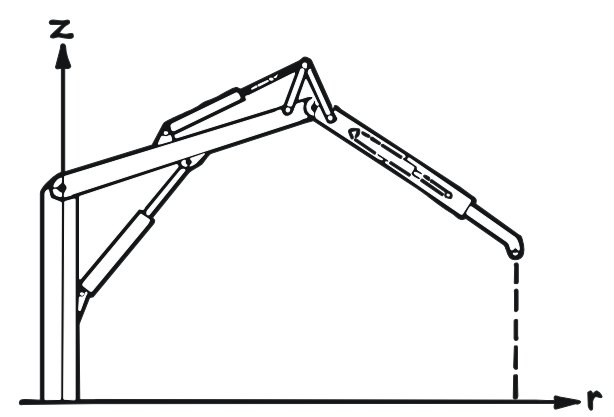

Figure 1.3.3.2. Cylindrical coordinate system.

In both coordinate systems the $\mathrm{z}$-axis coincides with the pillar of the manipulator.

In the Cartesian coordinate system the swing of the manipulator is included in the kinematic control. In boom tip control this means that one has complete analogy between the joystick movements and the tip of the manipulator, the tool centre point (TCP). Forestry machines are articulated steered. On forwarders the manipulator is mounted on the rear chassis and the cab on the front chassis. On harvesters the manipulator is mounted both on the rear and front chassis, depending on model/manufacturer.

In [18] the two different types of coordinate system have been analyzed. The result shows that if one uses the Cartesian coordinate system the articulated steering needs to be involved in the kinematic control algorithm. In clean cutting the driver often needs to move the TCP straight back against the manipulator pillar to avoid collision with the remaining trees, se figure 1.3.3.3. In this case the diver will find it hard to move the joystick in the same angel as the boom. This problem will not occur in a cylindrical coordinate system.

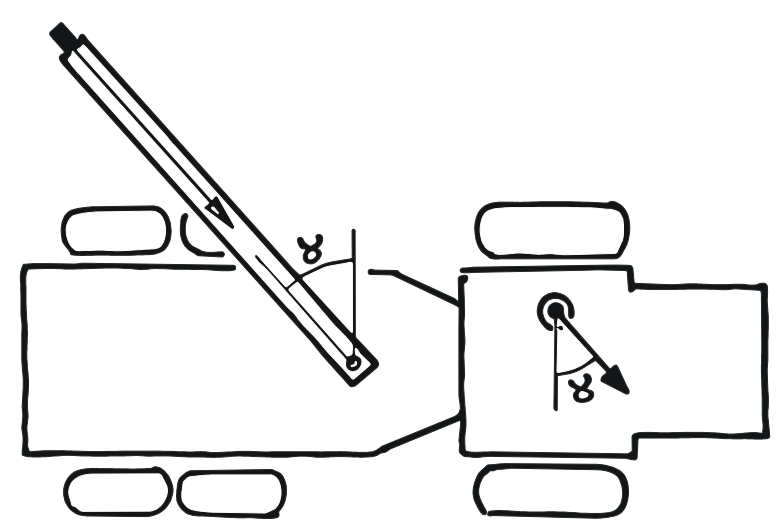

Figure 1.3.3.3. Joystick angle in comparison with manipulator angle.

Another problem which will occur with the Cartesian coordinate system is when the TCP reaches the maximum length of the manipulator. The problem will occur to the driver when he tries to reach a tree, along the straight line, that is out of reach for the TCP of the boom. It is hard for the driver to estimate the range of the boom 
sideways on longer TCP distance. The TCP will then describe an arc of a circle, see figure 1.3.3.4, just like in the cylindrical coordinate system.

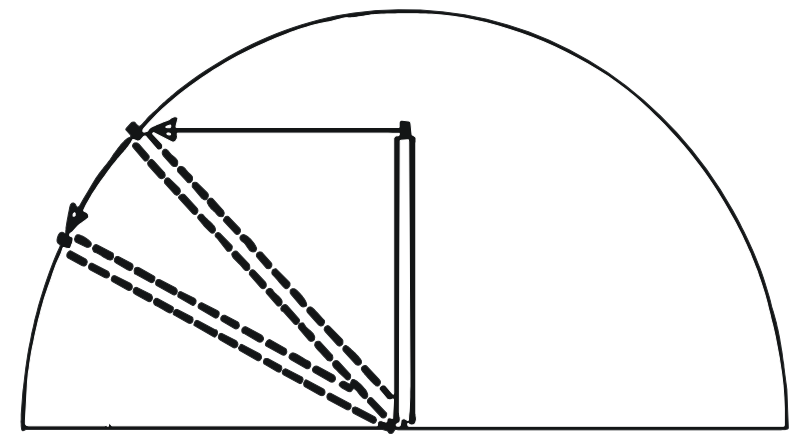

Figure 1.3.3.4. Limitations in the Cartesian coordinate system.

With these limitations in the Cartesian coordinate system the proposed kinematic control algorithms are based on the cylindrical coordinate system.

\subsubsection{Joystick}

As mentioned above, the TCP is controlled with only one joystick. To have as good analogy between the joystick and the manipulator as possible the joystick functions are placed in the following order, se figure 1.3.4.1.
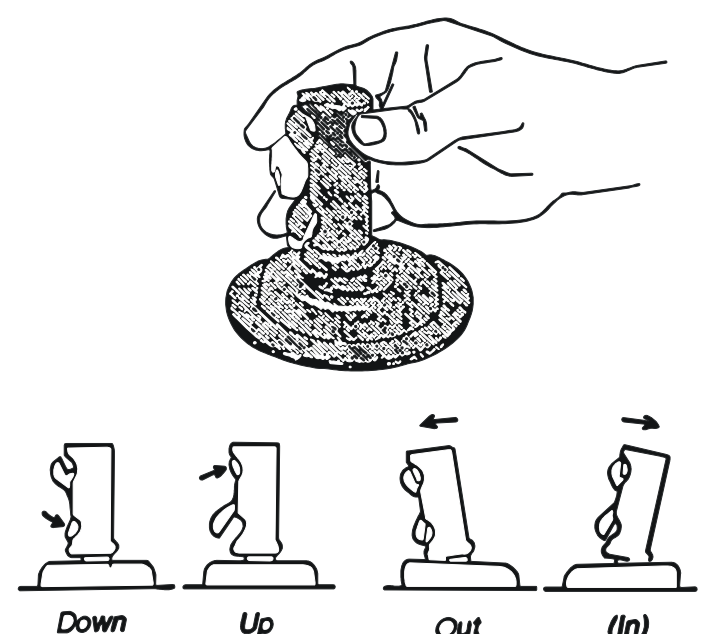

Figure 1.3.4.1. Joystick functions with boom tip control.

The swing function is placed in the left and right directions of the joystick.

The electrical signal from the joystick is transferred via the kinematic control to electrical servo valves in the hydraulic system. The valves are load, pressure and flow compensated. 


\subsubsection{Computer and sensors}

To be able to incorporate boom tip control on a hydraulic manipulator, computer and sensors are needed, see figure 1.3.5.1.

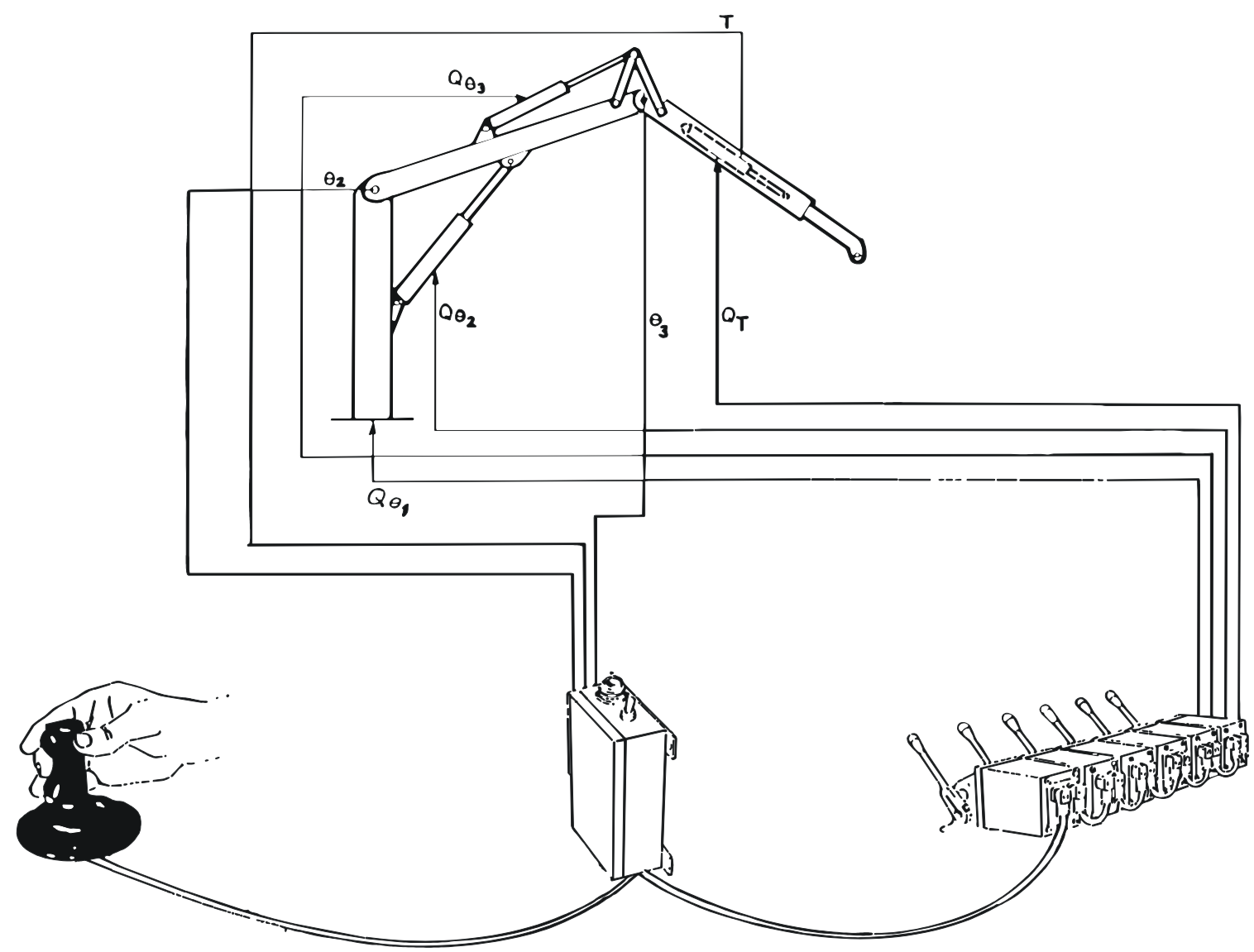

Figure 1.3.5.1. Computer system for boom tip control.

The general demands on the sensors are that they should resist chock and vibrations, they should also resist low temperature and should also be well protected against falling trees.

The sensors give feedback from joint angles on the manipulator. There are in principle two ways to apply sensors on the manipulator.

- One can use angle sensors between the rotating parts

- One can also use sensors in the hydraulic cylinders. 
With sensors in the hydraulic cylinders one has to translate cylinder length to a joint angle. This is rather complicated when the manipulator often has a lot of lever arms, see figure 1.3.5.2.

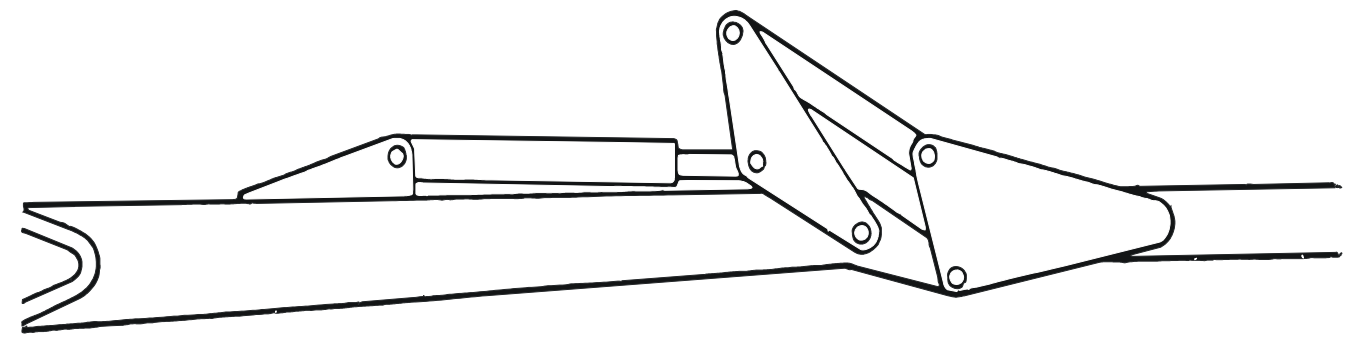

Figure 1.3.5.1. An example of lever arms on a hydraulic manipulator.

\subsection{Potential advantages of boom tip control}

A simplified manipulator control will give the following advantages compared to conventional manipulator control.

- $\quad$ Less physical strain on the driver.

- Decreased learning time.

- Longer life time of the manipulator.

\subsubsection{Decreased physical strain}

Drivers of forestry machines are injured in the neck, shoulders and in the back after some or several years of controlling the manipulator [9]. More than half of all drivers have had problems with the neck, shoulders and back. These problems can be assigned to manipulator control.

It has been shown that drivers unconsciously tense themselves before manipulator control work with increased stress as a consequence [9]. A simplified manipulator control will most likely influence the drivers to control the manipulator in a more relaxed way. 


\subsubsection{Decreased learning time}

Work with conventional control of knuckle booms is very complicated since one can reach every point within the knuckle booms working area in many ways because the knuckle booms are redundant. A simplified control will most likely make it easier to control the knuckle manipulator since the driver does not have to think how he or she should control all degrees of freedom.

Consequently a simplified control will most likely mean that the learning time would decrease substantially [30].

\subsubsection{Longer life time}

There is a big difference between a skilled driver and a non skilled driver [27]. A non skilled driver will control the manipulator in a jerky way which will affect the life time of the manipulator. With a simplified control it is possible to eliminate much of the jerky movements and thereby increase the life time of the manipulator.

\subsection{Targeted machines and research objective}

Most of the manipulators used in forestry are of a type called knuckle boom, see figure 1.5.1 and 1.5.2. They are hydraulically powered and are controlled by hydraulic servo valves. The same types of hydraulic manipulators are commonly used also on trucks and in stationary applications, see figure 1.5.3 and 1.5.4. 


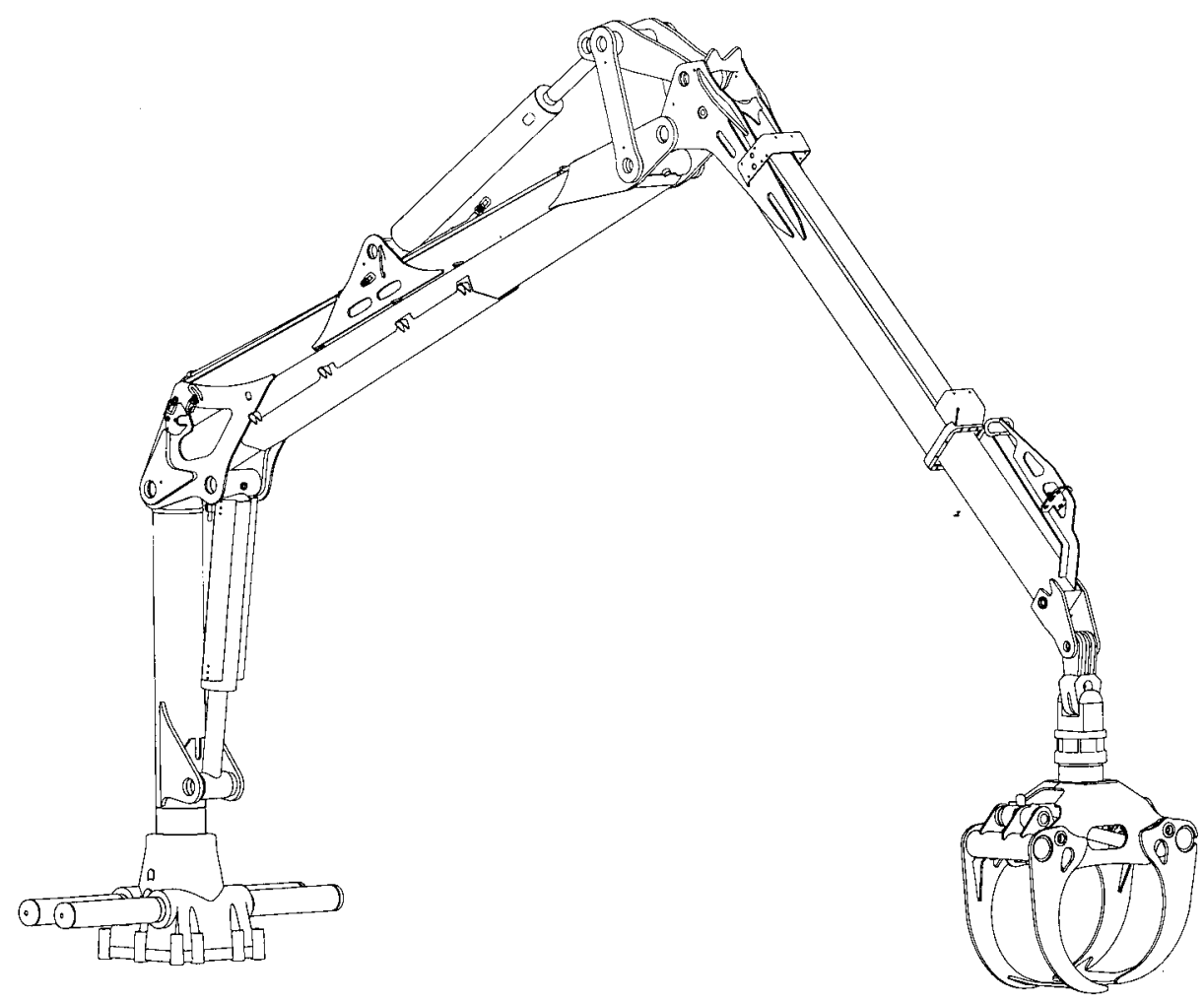

Figure 1.5.1 Knuckle boom Cranab 850.

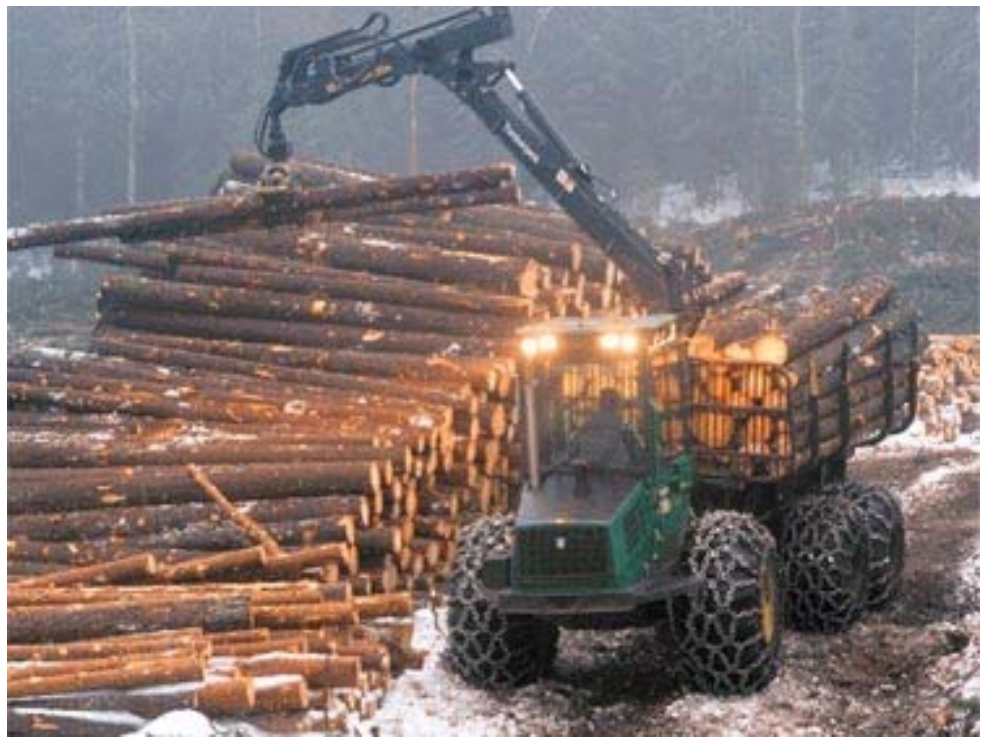

Figure 1.5.2 A knuckle boom Timberjack CF5 mounted on a forwarder Timberjack 1010B. 


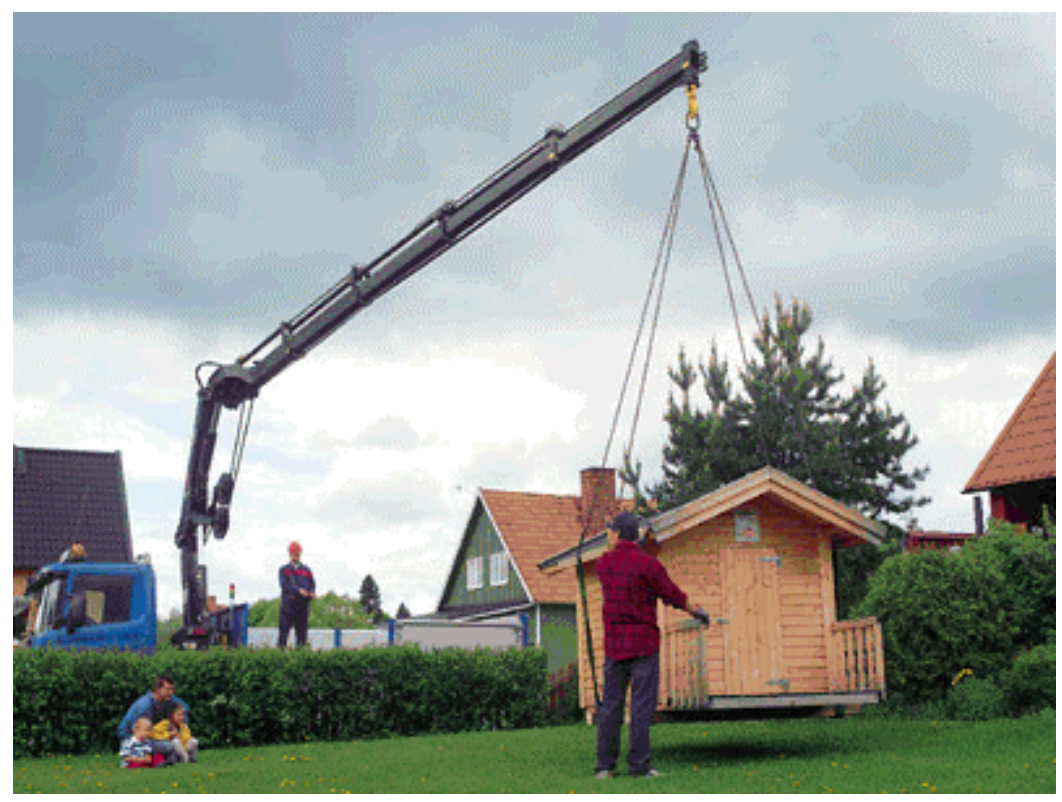

Figure 1.5.3 A knuckle boom HIAB 122XS mounted on a truck.

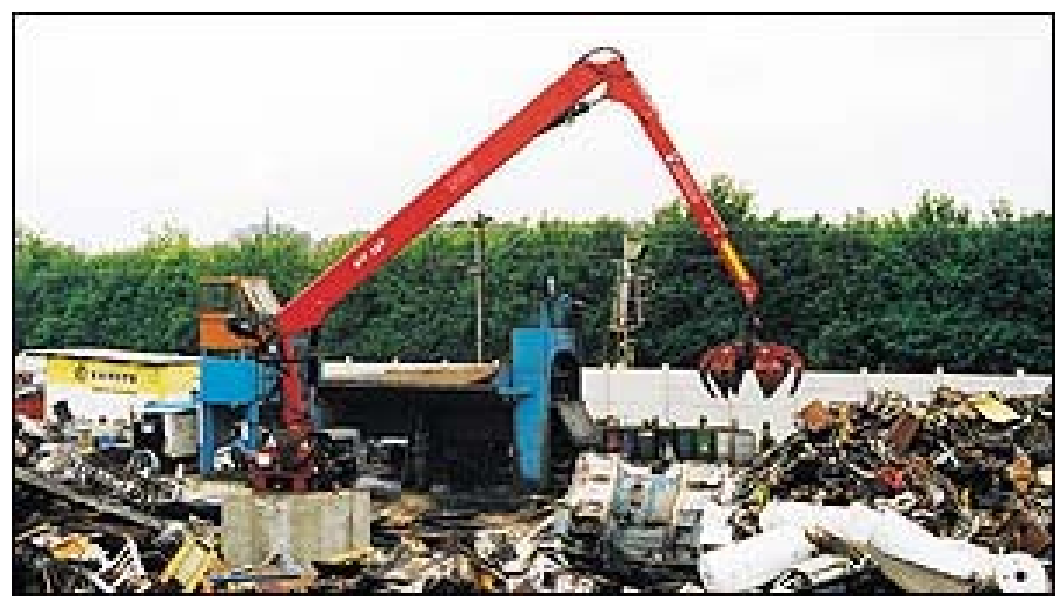

Figure 1.5.4 A knuckle boom (unknown) in a stationary application.

Knuckle booms are often constructed with extra degrees of freedom (DOF). Knuckle booms are thereby redundant manipulators. A redundant manipulator, designed for positioning only, has more than three DOF. In this thesis, a redundant manipulator with three revolute joints and one prismatic joint is studied. 
Why is a redundant DOF introduced? The extra motor, sensor, etc., and the more complicated controller mean extra weight, complexity and cost. Some performance criteria for the redundant DOF are

- Singularity avoidance

- Obstacle avoidance

- Robot dexterity

- Energy minimization

- Manipulator precision

- $\quad$ Lifting capacity

- Velocity of operation

This study was initiated by the introduction of computer control in a manually operated 4 DOF manipulator (a hydraulic crane for forest applications) with configuration as shown in figure 1.5.1.

The objective is to develop and compare three different kinematic control strategies, maximum velocity, maximum lifting capacity and dynamic programming, and thereby find a strategy which is best suited for computer controlled knuckle booms that are redundant. The strategies are compared with respect to time consumption when the manipulator tip moves along a predetermined path. The comparison is made on a knuckle boom used on a forwarder in a forestry application. The knuckle boom has one redundant degree of freedom. The same geometric type of manipulator is used on other forestry machines and also on trucks. 


\section{Chapter 2}

\section{OUTLINE OF THE THESIS}

The following text is divided in three logical parts,

- describing the state of the art,

- presenting three different kinematic control strategies,

- and presenting simulation results and conclusions.

The state of the art regarding manipulators with redundancy is presented in Chapter 3. The fundamental kinematic properties, including kinematic redundancy, are described in Chapter 4.

Chapter 5 deals with a kinematic principle based on maximum velocity (local optimisation). In Chapter 6 a new kinematic control algorithm is introduced, based on geometrical characteristics of the knuckle boom and the hydraulic pressure (maximising static lift capacity). Chapter 7 deals with how dynamic programming theory can be used to achieve minimum time when moving between two known points in the work space (global optimisation).

Results and figures from simulation of a typical forestry work situation are presented in Chapter 8. Conclusions resulting from this simulation study are summarized in Chapter 9.

Manufactures of hydraulic manipulators are presented in Appendix 1. 


\section{Chapter 3}

\section{STATE OF THE ART}

After a review of research made up to this date one can see that there is an increased interest in redundant manipulators since the beginning of 1980s and there is still a great interest in problems about kinematic redundancy in the academic world.

In the industry it was necessary to introduce one or more redundant degrees of freedom to solve complicated applications. The redundancy implies considerably more complicated control algorithms than non redundant manipulators.

Most of the methods used are based on local optimization and use the quite popular pseudo inverse solution. The kinematic equation that describes the relation between manipulator end effector speed and corresponding joint speeds is defined as follows:

$\underline{\dot{x}}=J \underline{\dot{\theta}}$

where $\underline{\dot{x}}$ is an $m \times 1$ velocity vector in Cartesian coordinates for the manipulator end effector, $\underline{\dot{\theta}}$ is the $n \times 1$ joint velocity vector for the joints, $(n>m)$ and $J$ is the $[m \times n]$ Jacobian.

We solve the equation with respect to $\underline{\dot{\theta}}$

$\underline{\dot{\theta}}=J^{\#} \dot{x}$

where

$J^{\#}=J^{T}\left(J J^{T}\right)^{-1}$

$J^{\#}$ is the pseudo inverse of the Jacobian matrix according to the generalized Moore-Penrose inverse [26].

In [14] the problem with joint drift, when one uses only the pseudo inverse control, is analysed when a cyclic task is performed. Despite well developed theory in [15] there is still a problem to make the control conservative. I.e. when repeating a work cycle several times, the joint configurations will not be repeatable and the manipulator can run into unfavourable configurations.

To overcome this drawback a more general solution, by addition of a term, is given by

$\underline{\dot{\theta}}=J^{\#} \underline{\dot{x}}+\left(I-J^{\#} J\right) \underline{\dot{\phi}}$ 
where $\dot{\phi}$ is an arbitrary joint velocity vector and $\left(I-J^{\#} J\right)$ is the null-space projection matrix of $J$. This corresponds to a self motion of the manipulator which has no effect on the velocity of the end effector. The attractiveness with this way is twofold. The first term, $J^{\#} \underline{\dot{x}}$, minimizes $\underline{\dot{\theta}}^{T} \underline{\dot{\theta}}$. Presumably all the joints will be prevented from moving too fast. The second term $\left(I-J^{\#} J\right) \underline{\dot{\phi}}$, can improve the manipulator's configuration by assigning different optimization performance criteria by means of a proper selection of $\dot{\phi}$, for example to achieve singularity avoidance [16].

Other secondary criteria are: obstacle avoidance[13,27], joint torque optimization[11,23,24], joint velocity constraints[2,7,17,20], energy minimization[2,4,12], manipulator precision[12],speed of operation[4], joint limit avoidance[5], maximization of various end-effector dexterity measures[13], multiple performance criteria[6,8,21], global optimization and global versus local optimization[30].

The non-conservative phenomenon is a big problem in robotic applications with repetitive tasks, where high precision is important. In forest applications with manual control, the non-conservative phenomenon is of minor importance, since the operator is able to compensate for the non-conservative phenomenon. Therefore, we will only analyze the"simple” pseudo inverse method according to (3.2) and compare it with the maximum lifting capacity method.

Those who want to get more information about redundant manipulators will find a review in [25] and a tutorial in [29]. 


\section{Chapter 4}

\section{BASIC EQUATIONS}

The manipulator is velocity controlled by means of a 3 DOF joystick, operating in a cylindrical $(\mathrm{r}, \theta, \mathrm{z})$ or Cartesian $(\mathrm{x}, \mathrm{y}, \mathrm{z})$ coordinate system. If we are working in the cylindrical coordinate system, the control of the $\theta_{0}$ - motor is separated from the control of the other motors.

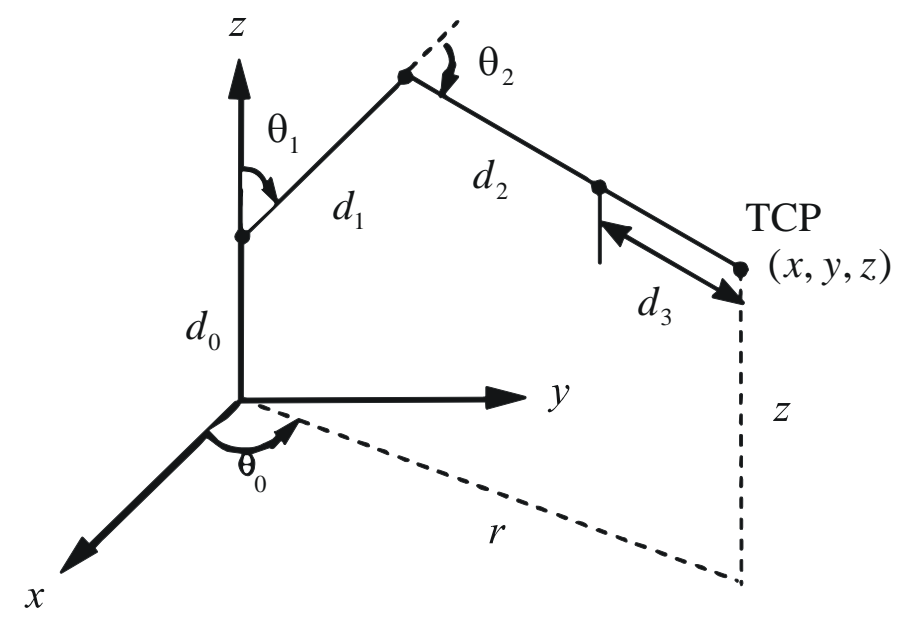

Figure 4.1 Manipulator geometry.

If we are working in the Cartesian coordinate system, with commanded $\dot{x}, \dot{y}$ and $\dot{z}$, we find the commanded $\dot{\theta}_{0}$ by differentiating $\theta_{0}=\arctan (y / x)$ and using

$$
\begin{aligned}
& r=\sqrt{x^{2}+y^{2}} . \\
& \dot{\theta}_{0}=\left(-s_{0} \dot{x}+c_{0} \dot{y}\right) / r
\end{aligned}
$$

where $s_{0}=\sin \theta_{0}, c_{0}=\cos \theta_{0}$

The commanded $\dot{r}$ is found by differentiating $r=\sqrt{x^{2}+y^{2}}$

$$
\dot{r}=c_{0} \dot{x}+s_{0} \dot{y}
$$

We have now expressed increments $\dot{x}$ and $\dot{y}$ in increments $\dot{\theta}_{0}$ and $\dot{r}$, and can concentrate our study on the kinematic control in the r-z-plane, where the redundant DOF is used. 
A vector $\underline{\theta}$ is defined:

$$
\theta=\left[\theta_{1}, \theta_{2}, d_{3}\right]^{T}
$$

The tool center point (TCP, see fig 4.1) coordinates $\mathrm{r}$ and $\mathrm{z}$ defines the vector $\underline{x}$ :

$$
\underline{x}=[r, z]^{T}
$$

Fig. 4.1 gives the following relations:

$$
\begin{aligned}
& r=d_{1} s_{1}+\left(d_{2}+d_{3}\right) s_{12} \\
& Z=d_{0}+d_{1} c_{1}+\left(d_{2}+d_{3}\right) c_{12}
\end{aligned}
$$

where $s_{12}=\sin \left(\theta_{1}+\theta_{2}\right), c_{12}=\cos \left(\theta_{1}+\theta_{2}\right)$.

$$
\begin{aligned}
& \dot{r}=d_{1} c_{1} \dot{\theta}_{1}+\left(d_{2}+d_{3}\right) c_{12}\left(\dot{\theta}_{1}+\dot{\theta}_{2}\right)+s_{12} \dot{d}_{3} \\
& \dot{z}=-d_{1} s_{1} \dot{\theta}_{1}-\left(d_{2}+d_{3}\right) s_{12}\left(\dot{\theta}_{1}+\dot{\theta}_{2}\right)+c_{12} \dot{d}_{3}
\end{aligned}
$$

or in matrix form:

$$
\underline{\dot{x}}=J \underline{\dot{\theta}}
$$

where the Jacobian $\mathrm{J}\left(2 \mathrm{x} 3\right.$ - matrix) has elements $j_{11}, j_{12} \ldots . . j_{23}$ :

$$
\left.\begin{array}{l}
j_{11}=d_{1} c_{1}+\left(d_{2}+d_{3}\right) c_{12} \\
j_{12}=\left(d_{2}+d_{3}\right) c_{12} \\
j_{13}=s_{12} \\
j_{21}=-d_{1} s_{1}-\left(d_{2}+d_{3}\right) s_{12} \\
j_{22}=-\left(d_{2}+d_{3}\right) s_{12} \\
j_{23}=c_{12}
\end{array}\right\}
$$

Since the Jacobian $\mathrm{J}$ is non square, the matrix cannot be directly inverted. The problem can be solved by introducing a constraint.

Three different control strategies will be studied in Sections 5, 6 and 7, as introduced in the following 


\subsection{Maximum velocity}

In some applications the velocity is of major importance. However, it is not possible to have maximum velocity as a constraint, since the operator will not use maximum velocity all the time, but wants to utilize the highest possible velocity only when he/she finds it necessary. The used kinematic control law is based on a weighted pseudo inverse of the Jacobian, plus extra calculations when one or two motors are at their speed or mechanical limits. This strategy is non-conservative, i.e. when repeating same work cycle several times, the joint configurations will not be repeatable and the manipulator can run into unfavourable configurations. The strategy is non conservative in the sense that a closed path of the TCP (end effector) in rectilinear space does not yield a closed path of the joints in joint space.

\subsection{Maximum lifting capacity}

In other applications, velocity is of minor importance, but the static (low velocity) lifting capacity is essential. The kinematic control is for this case based on an optimization study of the lifting capacity [18], based on the force or torque characteristics and the geometrical arrangements of the motors.

\subsection{Dynamic programming}

In some manipulator applications one knows the start point and the end point and one is at the same time free to use the whole work space without taking any concern regarding obstacles. One is also free to use the manipulator joints so one can make an optimal solution by using a global approach. By using dynamic programming one is able to find the minimum time between two points in the workspace. This approach may be useful when more semi or fully automatic functions are introduced on the forestry machines. 


\section{Chapter 5}

\section{MAXIMUM VELOCITY}

\subsection{Kinematic control law}

High velocity is essential in some applications, giving a low cycle time. This means that some of the motors will work at their velocity limits, when maximum velocity is desired. However, the operator does not always want maximum velocity.

Therefore, we need a constraint which gives a solution to the problem with the noninvertible Jacobian when all motors are working below their velocity limits. The quite popular pseudo inverse solution will be used:

Equation (4.9) can be written:

$$
\underline{\dot{\theta}}=J^{\#} \underline{\dot{x}}
$$

with

$$
J^{\#}=J^{T}\left(J J^{T}\right)^{-1}
$$

The pseudo inverse matrix $J^{\#}$ implies that a cost function C is minimized [26]:

$$
C(\underline{\dot{\theta}})=\underline{\dot{\theta}}^{T} \underline{\dot{\theta}}=\dot{\theta}_{1}^{2}+\dot{\theta}_{2}^{2}+\dot{d}_{3}^{2}=\text { minimum }
$$

This is not a reasonable cost function, since, the angle speed $\dot{\theta}_{1}, \dot{\theta}_{2}$ and the prismatic speed $\dot{d}_{3}$ are treated as equivalent, but they do not even have the same dimension. A symmetric, positive definite weighting matrix $\mathrm{W}$ is therefore introduced [7]:

$$
C(\underline{\dot{\theta}}, W)=\underline{\dot{\theta}}^{T} W \underline{\dot{\theta}}
$$

A diagonal matrix is a sound choice here since the joints are independent of each other:

$$
W=\left[\begin{array}{ccc}
w_{11} & 0 & 0 \\
0 & w_{22} & 0 \\
0 & 0 & w_{33}
\end{array}\right]
$$


giving

$$
C(\dot{\theta})=w_{11} \dot{\theta}_{1}^{2}+w_{22} \dot{\theta}_{2}^{2}+w_{33} \dot{d}_{3}^{2}
$$

The choice of diagonal elements in $\mathrm{W}$ is in this case chosen according to equation (5.7):

$$
w_{11} \dot{\theta}_{1 \text { max }}^{2} \approx w_{22} \dot{\theta}_{2 \max }^{2} \approx w_{33} \dot{d}_{3 \max }^{2}
$$

which gives the three motors equal weight when they are working at their maximum velocities $\left(\dot{\theta}_{1 \max }, \dot{\theta}_{2 \max }, \dot{d}_{3 \max }\right)$.

The weighting matrix $\mathrm{W}$ can be position and/or angle dependent:

$$
W=W(\underline{x}, \underline{\theta})
$$

This approach has not been used in the simulations but can be used in a real case.

The weighting matrix $\mathrm{W}$ modifies equation (5.1) and (5.2):

$$
\underline{\dot{\theta}}=Q \underline{\dot{x}}
$$

with (see [7])

$$
Q=W^{-1} J^{T}\left(J W^{-1} J^{T}\right)^{-1}
$$

We find, after some calculations:

$$
\left(J W^{-1} J^{T}\right)^{-1}=\frac{1}{D}\left[\begin{array}{ll}
d_{11} & d_{12} \\
d_{21} & d_{22}
\end{array}\right]
$$

with

$$
\left.\begin{array}{l}
d_{11}=j_{21}^{2} / w_{11}+j_{22}^{2} / w_{22}+j_{23}^{2} / w_{33} \\
d_{12}=-\left(j_{11} j_{21} / w_{11}+j_{12} j_{22} / w_{22}+j_{13} j_{23} / w_{33}\right) \\
d_{22}=j_{11}^{2} / w_{11}+j_{12}^{2} / w_{22}+j_{13}^{2} / w_{33} \\
D=d_{11} d_{22}-d_{12}^{2}
\end{array}\right\}
$$

where $j_{i, j}$ are the elements of $J$ 
and the elements of the Q-matrix are:

$$
\left.\begin{array}{l}
q_{11}=\left(d_{11} j_{11}+d_{12} j_{21}\right) /\left(w_{11} D\right) \\
q_{12}=\left(d_{12} j_{11}+d_{22} j_{21}\right) /\left(w_{11} D\right) \\
q_{21}=\left(d_{11} j_{12}+d_{12} j_{22}\right) /\left(w_{22} D\right) \\
q_{22}=\left(d_{12} j_{12}+d_{22} j_{22}\right) /\left(w_{22} D\right) \\
q_{31}=\left(d_{11} j_{13}+d_{12} j_{23}\right) /\left(w_{33} D\right) \\
q_{32}=\left(d_{11} j_{13}+d_{22} j_{23}\right) /\left(w_{33} D\right)
\end{array}\right\}
$$

\subsection{Velocity limitations}

The motors have maximum velocities $\dot{\theta}_{1 \max }, \dot{\theta}_{2 \max }$ and $\dot{d}_{3 \max }$, respectively. If a motor, e.g. motor no.1, receives a command signal $\dot{\theta}_{1 c}$, with $\left|\dot{\theta}_{1 c}\right|>\dot{\theta}_{1 \max }$, the velocity limitations will cause a position error. This problem is solved in the following way:

Introduce:

$$
\left.\begin{array}{l}
\alpha_{i}=\left|\dot{\theta}_{i c}\right| / \dot{\theta}_{i \max ;} i=1,2 \\
\alpha_{3}=\left|\dot{d}_{3 c}\right| / \dot{d}_{3 \max }
\end{array}\right\}
$$

In a practical case, the geometrical arrangement of the $\theta_{1}$ - and $\theta_{2}$-motors (these revolute joints may be driven by hydraulic cylinders) may cause $\dot{\theta}_{1 \max }$ and $\dot{\theta}_{2 \max }$ to be functions of $\theta_{1}$ and $\theta_{2}$, respectively, and directions. In this case joints speeds are set to equal in both directions. This is due to that for each machine application the hydraulic pressure and flow are different. Therefore the joint speeds are set to suit one typical pressure and flow.

We find the largest $\alpha_{i}$ - value, $\alpha_{\max }$ :

$$
\begin{aligned}
& \alpha_{\max }=\max \left\{\alpha_{i}\right\} \\
& i=1,2,3
\end{aligned}
$$

If $\alpha_{\max } \leq 1$, there are no velocity limitations, and $\underline{\dot{\theta}}$, as determined by equations (5.1) and (5.9), are used. 


\subsubsection{Cylindrical Coordinate System}

\subsubsection{Two DOF:s}

Assume first, that the joystick is working in the cylindrical coordinate system, and that the $\theta_{0}$ - motor is separately controlled.

Assume $\alpha_{1}=\alpha_{\max }>1$

Choose $\dot{\theta}_{1}=\dot{\theta}_{1 \max }$ if $\dot{\theta}_{1}>0$ and $\dot{\theta}_{1}=-\dot{\theta}_{1 \max }$ if $\dot{\theta}_{1}<0$. Since we have lost one DOF, i.e., the system is non-redundant, the calculation of $\dot{\theta}_{2}$ and $\dot{d}_{3}$ is straight forward. ( $r_{c}$ and $z_{c}$ are commanded velocities.)

$$
\left[\begin{array}{c}
\dot{r}_{c} \\
\dot{z}_{c}
\end{array}\right]=J\left[\begin{array}{c} 
\pm \dot{\theta}_{1 \max } \\
\dot{\theta}_{2 c} \\
\dot{d}_{3 c}
\end{array}\right]
$$

giving

$$
\left[\begin{array}{l}
\dot{\theta}_{2 c} \\
\dot{d}_{3 c}
\end{array}\right]=\frac{1}{D_{1}}\left[\begin{array}{cc}
j_{23} & -j_{13} \\
-j_{22} & j_{12}
\end{array}\right] \cdot\left[\begin{array}{l}
\dot{r}_{c} \mp j_{11} \cdot \dot{\theta}_{1 \max } \\
\dot{z}_{c} \mp j_{21} \cdot \dot{\theta}_{1 \max }
\end{array}\right]
$$

with

$$
D_{1}=j_{12} j_{23}-j_{13} j_{22}
$$

\subsubsection{One DOF}

To find out if the new values for $\dot{\theta}_{2 c}$ and $d_{3 c}$ given by (5.17) will exceed their maximum velocities, $\alpha_{2}$ and $\alpha_{3}$ must be calculated again giving $\alpha_{2}^{\prime}, \alpha_{3}^{\prime}$ and $\alpha_{\max }^{\prime}$. If $\alpha_{\max }^{\prime} \leq 1$, control law (5.17) is used. If $\alpha_{\max }^{\prime}>1$, two motors, $\theta_{1}$ and $\theta_{2}$ or $d_{3}$ must be working at their maximum velocities and hence we now have only one DOF, and two DOF:s are necessary to follow a commanded path in the r-z-plane.

$$
\text { Assume that } \alpha_{\max }^{\prime}=\alpha_{2 \max }^{\prime} \text {, i.e. }\left|\dot{\theta}_{2}\right|=\dot{\theta}_{2 \max } \text {. Choose } \dot{\theta}_{2}=\dot{\theta}_{2 \max } \text { if } \dot{\theta}_{2}>0 \text { or }
$$
$\dot{\theta}_{2}=-\dot{\theta}_{2 \max }$ if $\dot{\theta}_{2}<0$. The commanded velocity must be scaled by a factor $\beta<1$ since we can not follow the commanded path with two motors at their maximum speeds, due to that we have lost two DOF:s: 


$$
\beta\left[\begin{array}{l}
\dot{r}_{c} \\
\dot{z}_{c}
\end{array}\right]=\left[\begin{array}{lll}
j_{11} & j_{12} & j_{13} \\
j_{21} & j_{22} & j_{23}
\end{array}\right]\left[\begin{array}{c} 
\pm \dot{\theta}_{1 \max } \\
\pm \dot{\theta}_{2 \max } \\
\dot{d}_{3}
\end{array}\right]
$$

Equation (5.19) has two unknown, $\beta$ and $\dot{d}_{3}$.

We find:

$$
\beta=\frac{j_{23} k_{1}-j_{13} k_{2}}{j_{23} \dot{r}_{c}-j_{13} \dot{z}_{c}}
$$

and

$$
\dot{d}_{3}=\frac{\beta \dot{r}_{c}-k_{1}}{j_{13}}
$$

where

$$
\begin{aligned}
& k_{1}= \pm j_{11} \dot{\theta}_{1 \max } \pm j_{12} \dot{\theta}_{2 \max } \\
& k_{2}= \pm j_{21} \dot{\theta}_{1 \max } \pm j_{22} \dot{\theta}_{2 \max }
\end{aligned}
$$

If instead $\alpha_{\max }^{\prime}=\alpha_{3 \max }^{\prime}$ similar calculations will apply.

Similar calculations will apply also if we have speed limitations in $\theta_{2}$ or $d_{3}$, i.e., $\alpha_{2}=\alpha_{\max }$ or $\alpha_{3}=\alpha_{\max }$.

\subsubsection{Cartesian Coordinate System}

A first step is to check if $\alpha_{o}>1$. If so, scale down the velocity of all motors by dividing by $\alpha_{o} . \alpha_{o}>1$ means, that we cannot reach the commanded velocity.

Then we proceed exactly as in section 5.2.1, but it is necessary to multiply $\dot{\theta}_{0 c}$ by $\beta$ if $\beta<1$. 


\subsection{Mechanical Limits}

If one of the $\theta_{1}-, \theta_{2}-$ or $d_{3}$ - motors reaches a mechanical limit (actually a software limit is acting before the motor has reached a mechanical limit), we are loosing our redundant degree of freedom, but can still follow a desired path (until a second motor reaches a mechanical limit). To solve this, $\underline{\dot{\theta}}$ is first calculated by means of equation (5.9). If the $\theta_{1}$-motor is at a mechanical limit and equation (5.9) shows, that the motor should pass through the mechanical limit, we have to perform a second calculation exactly as in Section 5.2, but now with $\dot{\theta}_{1 \max }$ replaced by 0 . Similar calculations are made for $\theta_{2}$ and $d_{3}$ when they reach their mechanical limits.

In order to avoid large transients when approaching a mechanical limit, the maximum velocity used for calculations is decreased for that motor. 


\section{Chapter 6}

\section{MAXIMUM LIFTING CAPACITY}

\subsection{Kinematic Control Law}

When working with heavy loads, the extra degree of freedom can be used for maximizing the lifting capacity. The kinematic control algorithm is based on computer studies of the lifting capacity [18], as a function of $\theta_{1}, \theta_{2}$, and $d_{3}$, using the hydraulic cylinder characteristics and the geometrical arrangements of the hydraulic cylinders. From the studies it is possible to analyse how the lifting capacity is dependent on the prismatic function $d_{3}$.

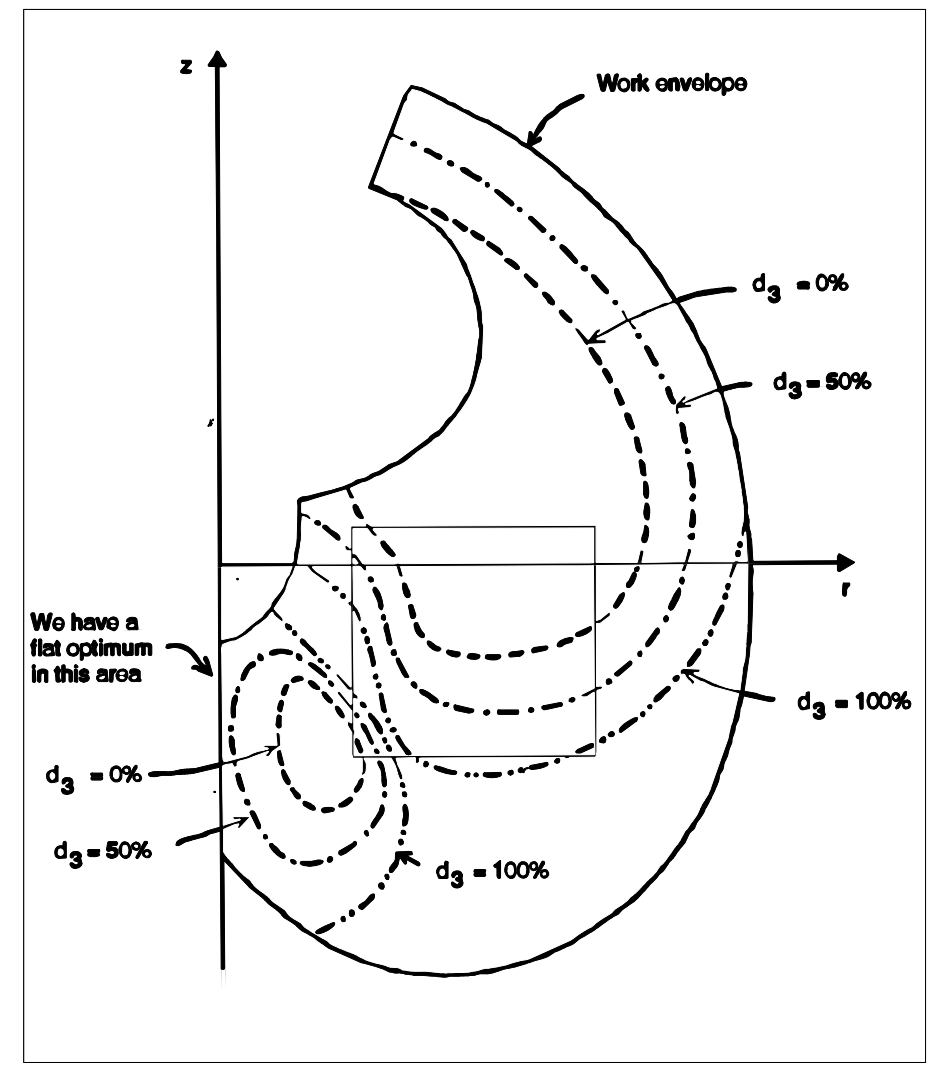

Figure 6.1 Selection $d_{3}$ for maximum lifting capacity.

Figure 6.1 shows how $d_{3}$ should be chosen for maximum lifting capacity for a specific manipulator. Except for the lower left and upper middle part of the work 
area, the three curves ( $d_{3}=0,50,100 \%$ ) can be approximated by circles. In other cases, where the $d_{3}$-curves are more complicated, a look-up table for $d_{3}=d_{3}(r, z)$ plus interpolation can be used.

In order to avoid unnecessarily large accelerations in $d_{3}$, some "smoothing" of the optimal $d_{3}(\mathrm{r}, \mathrm{z})$ function may be introduced, especially in areas in the r-z-plane where the optimum is flat, i.e., where the effect of $d_{3}$ on the lifting capacity is small. The proposed kinematic control function of $d_{3}$ is shown in figure 6.2.

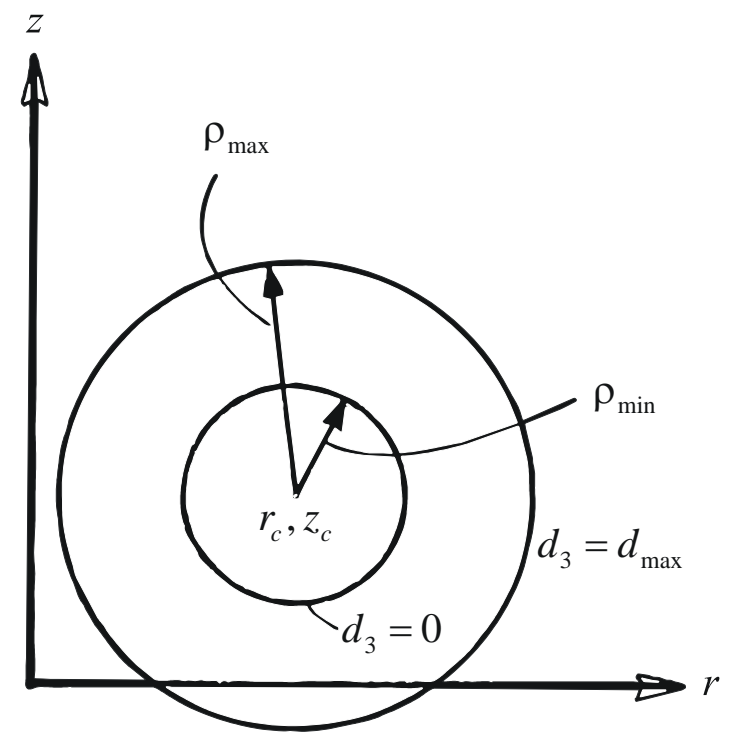

Figure 6.2. $d_{3}$ as a function of TCP's position.

Figure 6.2. gives:

$$
\rho=\sqrt{\left(r-r_{c}\right)^{2}+\left(z-z_{c}\right)^{2}}
$$

where $r_{c}$ and $z_{c}$ are the coordinates for the centre point of the circles in the proposed kinematic control function.

The approach to describe the transition between $\rho_{\min }$ and $\rho_{\max }$ should be expressed as a "smooth" function. The choice of the coordinates for $r_{c}$ and $z_{c}$ can be done according to figure 6.1 and figure 6.2 and the geometrical data from a specific boom. 


\subsubsection{Smoothing function}

In the zone where $d_{3}$ is active it should vary smoothly without large accelerations. We have chosen a function given in equation (6.2) according to figure 6.1.1. This function has $\frac{d d_{3}}{d \rho}=0$ for $\rho=\rho_{\min }$ and for $\rho=\rho_{\max }$ thus avoiding jumps in $d_{3}: \mathrm{s}$ velocity.

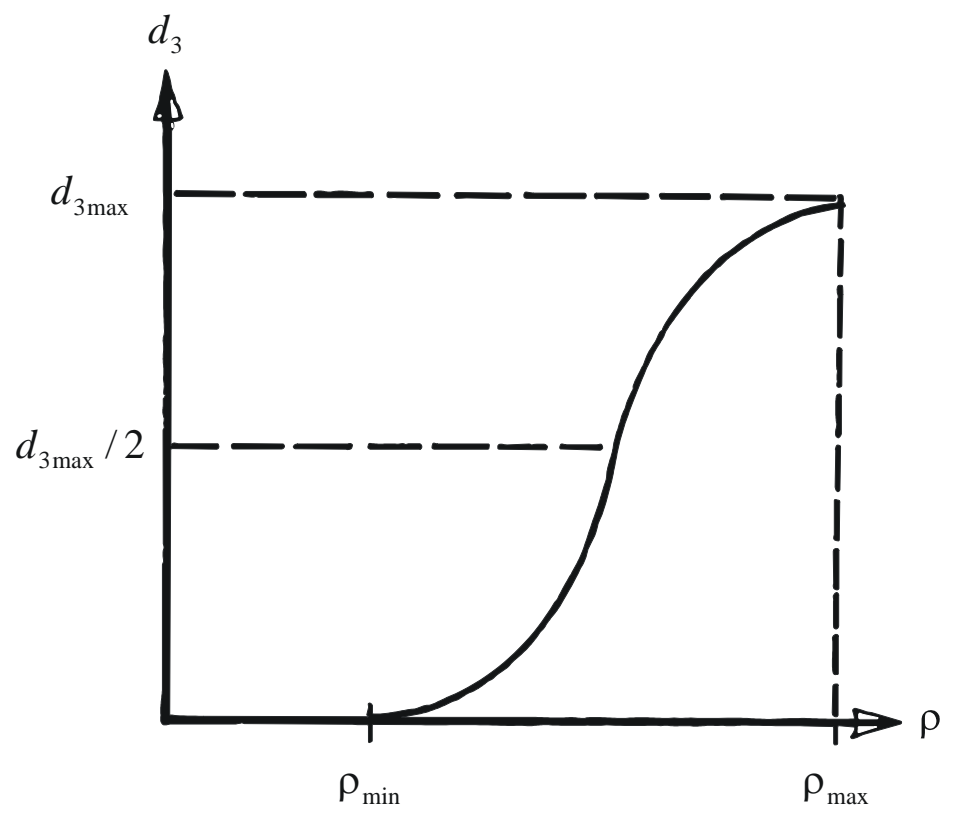

Figure 6.1.1. $d_{3}$ as a function of $\rho$

The smoothing function depicted in figure 6.1.1 is given by equations $6.2-6.4$.

$$
d_{3}=\frac{d_{3 \max }}{2}\left[1+\frac{3(\rho-p)}{2 q}-\frac{(\rho-p)^{3}}{2 q^{3}}\right]
$$

with

$$
\begin{aligned}
& p=\frac{\rho_{\text {max }}+\rho_{\text {min }}}{2} \\
& q=\frac{\rho_{\text {max }}-\rho_{\text {min }}}{2}
\end{aligned}
$$

Differentiating equation (6.2) gives

$$
\dot{d}_{3}=f(r, \rho) \dot{r}+g(z, \rho) \dot{z}
$$


with

$$
\begin{array}{ccc}
f(r, \rho)=c\left(r-r_{c}\right) / \rho & \rho_{\min } \leq \rho \leq \rho_{\max } \\
g(z, \rho)=c\left(z-z_{c}\right) / \rho & \text { for } \quad \rho_{\min } \leq \rho \leq \rho_{\max } \\
f(r, \rho)=g(z, \rho)=0 & & \rho<\rho_{\min } ; \rho>\rho_{\max }
\end{array}
$$

where

$$
c=\frac{3 d_{\max }}{4 q}\left[1-\frac{(\rho-p)^{2}}{2 q^{2}}\right]
$$

Independent of what characteristics we use for $d_{3}$ we can simplify our notations: $f(r, \rho)=f, g(z, \rho)=g$.

Using $\dot{d}_{3}$ from equation (6.5) in equation (4.9) gives:

$$
\left[\begin{array}{c}
\dot{r} \\
\dot{z}
\end{array}\right]=\left[\begin{array}{lll}
j_{11} & j_{12} & j_{13} \\
j_{21} & j_{22} & j_{23}
\end{array}\right] \cdot\left[\begin{array}{c}
\dot{\theta}_{1} \\
\dot{\theta}_{2} \\
f \dot{r}+g \dot{z}
\end{array}\right]
$$

Rewriting equation (6.8) gives

$$
\left[\begin{array}{ll}
j_{11} & j_{12} \\
j_{21} & j_{22}
\end{array}\right] \cdot\left[\begin{array}{l}
\dot{\theta}_{1} \\
\dot{\theta}_{2}
\end{array}\right]=\left[\begin{array}{cc}
1-j_{13} f & -j_{13} g \\
-j_{23} f & 1-j_{23} g
\end{array}\right] \cdot\left[\begin{array}{c}
\dot{r} \\
\dot{z}
\end{array}\right]
$$

or

$$
\left[\begin{array}{c}
\dot{\theta}_{1} \\
\dot{\theta}_{2}
\end{array}\right]=\left[\begin{array}{ll}
j_{11} & j_{12} \\
j_{21} & j_{22}
\end{array}\right]^{-1} \cdot\left[\begin{array}{cc}
1-j_{13} f & -j_{13} g \\
-j_{23} f & 1-j_{23} g
\end{array}\right] \cdot\left[\begin{array}{c}
\dot{r} \\
\dot{z}
\end{array}\right]
$$

Equations (6. 5), (6.10) and (4.10) give, after some calculations, the kinematic control law:

$$
\underline{\dot{\theta}}=P \underline{\dot{x}}
$$

where the (3x2) P-matrix has the following elements: 


$$
\left.\begin{array}{l}
p_{11}=\left(s_{12}-f\right) /\left(d_{1} s_{2}\right) \\
p_{12}=\left(c_{12}-g\right) /\left(d_{1} s_{2}\right) \\
p_{21}=\left[d_{1} f\left(c_{2} f-s_{1}\right) /\left(d_{2}+d_{3}\right)-s_{12}\right] /\left(d_{1} s_{2}\right) \\
p_{22}=\left[d_{1} g\left(c_{2} g-c_{1}\right) /\left(d_{2}+d_{3}\right)-c_{12}\right] /\left(d_{1} s_{2}\right) \\
p_{31}=f \\
p_{32}=g
\end{array}\right\}
$$

A singularity appears for $\theta_{2}=0^{\circ}$,i.e., "straight elbow”, and is caused by the applied constraint on $d_{3}$. With a kinematic control law using the pseudo inverse matrix, this singularity will not exist within the workspace, only on the work envelope.

\subsection{Velocity limitations}

If one of the motors reaches its maximum velocity, a simple "scaling" (cf. section 5.2) of the command signals is necessary, if we want to follow the specified path in the workspace.

\subsection{Mechanical limits}

If one of the $\theta_{1}-, \theta_{2}-$ or $d_{3}$ - motors reaches a mechanical limit (actually a software limit is acting before the motor has reached a mechanical limit), we are loosing our redundant degree of freedom, but can still follow a desired path (until a second motor reaches a mechanical limit). See section 5.3. 


\section{Chapter 7}

\section{DYNAMIC PROGRAMMING}

In some manipulator applications one knows the start point and the end point and one is at the same time free to use the whole work space without taking any concern regarding obstacles. One is also free to use the manipulator joints to make an optimal solution by using a global approach. In [3] the idea with dynamic programming is presented. Dynamic programming is a problem solving approach that proceeds by combining the solutions to sub-problems which are not independent of each other (i.e. they share common sub-sub-problems). A dynamic programming algorithm stores the optimal solutions to sub-sub-problems, thereby avoiding computing them several times. If we transform these ideas to our example when the manipulator TCP moves from one known point to another known point in the workspace, see figure 7.1, we can find the shortest time between two points.

Since dynamic programming is based on numerical calculations, the straight path in the work area is discretized into $\mathrm{N}$ steps, $(\Delta r, \Delta z)$ and we introduce $\mathrm{N}+1$ stages, $\mathrm{S}_{0}$, $\mathrm{S}_{1}, \ldots, \mathrm{S}_{\mathrm{N}}$, representing the positions $(r, z),(r+\Delta r, z+\Delta z), \ldots,(r+N \Delta r, z+N \Delta z)$; see Figure 7.1. Also one of the DOF:s will be discretized into M steps. We choose $d_{3}$, with the values $d_{3 \min }, d_{3 \min }+\Delta d_{3}, \ldots, d_{3 \min }+M \Delta d_{3}\left(=d_{3 \max }\right)$. Between two stages, $d_{3}$ can change $-q \Delta d_{3},-(q-1) \Delta d_{3}, \ldots, 0, \ldots,(q-1) \Delta d_{3}$ or $q \Delta d_{3}$, where $q$ is a given integer. The selection of $\Delta d_{3}, \Delta r, \Delta z$ and $\mathrm{q}$ is important. Small increments ( $\Delta d_{3}, \Delta r, \Delta z$ ) and a large $q$ are necessary for reaching the optimal solution, but leads to a large computational time. Therefore, empirical tests will give the necessary values of $\Delta d_{3}, \Delta r, \Delta z$ and $\mathrm{q}$.

For pedagogical reason, $q=1$ has been used in Figure 7.1, where only a few nodes are shown.

Each stage $\mathrm{S}_{1} \ldots \mathrm{S}_{\mathrm{N}}$ is associated with $M+1$ nodes. In every node, $\left.T_{i j}, i=0,1, \ldots, n, \ldots N ; j=0,1, \ldots, m, \ldots M\right)$ the coordinates of the three DOF:s must be calculated:

$$
\left.d_{3}(n, m)=d_{3 \min }+m \Delta d_{3} \text { (independent of stage } \mathrm{n}\right)
$$

$\theta_{1}(n, m)$ and $\theta_{2}(n, m)$ are determined by means of equation (4.5) and (4.6) and tedious calculations: 


$$
\theta_{2}(n, m)=\operatorname{atan} 2\left(\frac{\sin \theta_{2}(n, m)}{\cos \theta_{2}(n, m)}\right)
$$

where

$$
\begin{aligned}
& \cos \theta_{2}(n, m)=\left(\frac{(r+n \Delta r)^{2}+(z+n \Delta z)^{2}-d_{1}^{2}-\left(d_{2}+d_{3 \min }+m \Delta d_{3}\right)^{2}}{2 d_{1}\left(d_{2}+d_{3 \min }+m \Delta d_{3}\right)}\right) \\
& \sin \theta_{2}(n, m)=\sqrt{1-\cos ^{2} \theta_{2}(n, m)} \\
& \theta_{1}(n, m)=\operatorname{atan} 2\left(\frac{a(r+n \Delta r)+b(z+n \Delta z)}{-b(r+n \Delta r)+a(z+n \Delta z)}\right)
\end{aligned}
$$

with

$$
\begin{aligned}
& a=d_{1}+\left(d_{2}+d_{3 \min } m \Delta d_{3}\right) \cos \theta_{2}(n, m) \\
& b=\left(d_{2}+d_{3 \min }+m \Delta d_{3}\right) \sin \theta_{2}(n, m)
\end{aligned}
$$

Now we look at one "transition", e.g., from $T_{0, m-1}$ to $T_{1, m}$ :

$\theta_{1}$ and $\theta_{2}$ will have increment

$$
\Delta \theta_{j}(0, m-1 ; 1, m)=\theta_{j}(1, m)-\theta_{j}(0, m-1) ; j=1,2
$$

$d_{3}: s$ increment is

$$
\Delta d_{3}(0, m-1 ; 1, m)=\Delta d_{3}
$$

The shortest time for the three transitions $\Delta \theta_{1}, \Delta \theta_{2}$ and $\Delta d_{3}$ will be

$$
\begin{aligned}
& t_{j}(0, m-1 ; 1, m)=\frac{\Delta \theta_{j}(0, m-1 ; 1, m)}{\dot{\theta}_{j \max }} ; j=1,2 \\
& t_{3}(0, m-1 ; 1, m)=\frac{\Delta d_{3}(0, m-1 ; 1, m)}{\dot{d}_{3 \max }}
\end{aligned}
$$

The shortest time for the transition from $T_{0, m-1}$ to $T_{1, m}$ is determined by the slowest of the three DOF:s:

$$
t_{\text {min }}(0, m-1 ; 1, m)=\max _{j=1,2,3}\left(t_{j}(0, m-1 ; 1, m)\right)
$$


We calculate in a similar way $t_{\text {min }}(0, m ; 1, m)$ and $t_{\text {min }}(0, m+1 ; 1, m)$ and finally we find for the transition from stage 0 to node $T_{1, m}$ the minimum time:

$$
t_{\min }(0 ; 1, m)=\min _{j=-1,0,1}\left[t_{\min }(0, m+j ; 1, m)\right]
$$

This time is assigned, in the memory, to node $T_{1, m}$.

Similar calculations are made for all nodes in stage $S_{1}$ and memorized.

In the calculations for transition from stage $S_{1}$ to stage $S_{2}$, we have to add the minimum transition time assigned to each node, for example:

$$
t_{\min }(1 ; 2, m)=\min _{j=-1,0,1}\left[t_{\min }(0 ; 1, m+j)+t_{\min }(1, m+j ; 2, m)\right]
$$

The calculations are repeated until stage $N$, giving $t_{\text {min }}(N-1 ; N, m)$ for $m=0,1, \ldots, M$.

The optimal (minimum) time for the transition from $S_{0}$ to $S_{N}$ is

$$
t_{\min }=\min _{m=0,1, . ., M}\left[t_{\min }(N-1 ; N, m)\right]
$$

The optimal path from stage $S_{0}$ to each node must be memorized such that we finally can get the optimal path from $(r, z)$ to $(r+N \Delta r, z+N \Delta z)$ 


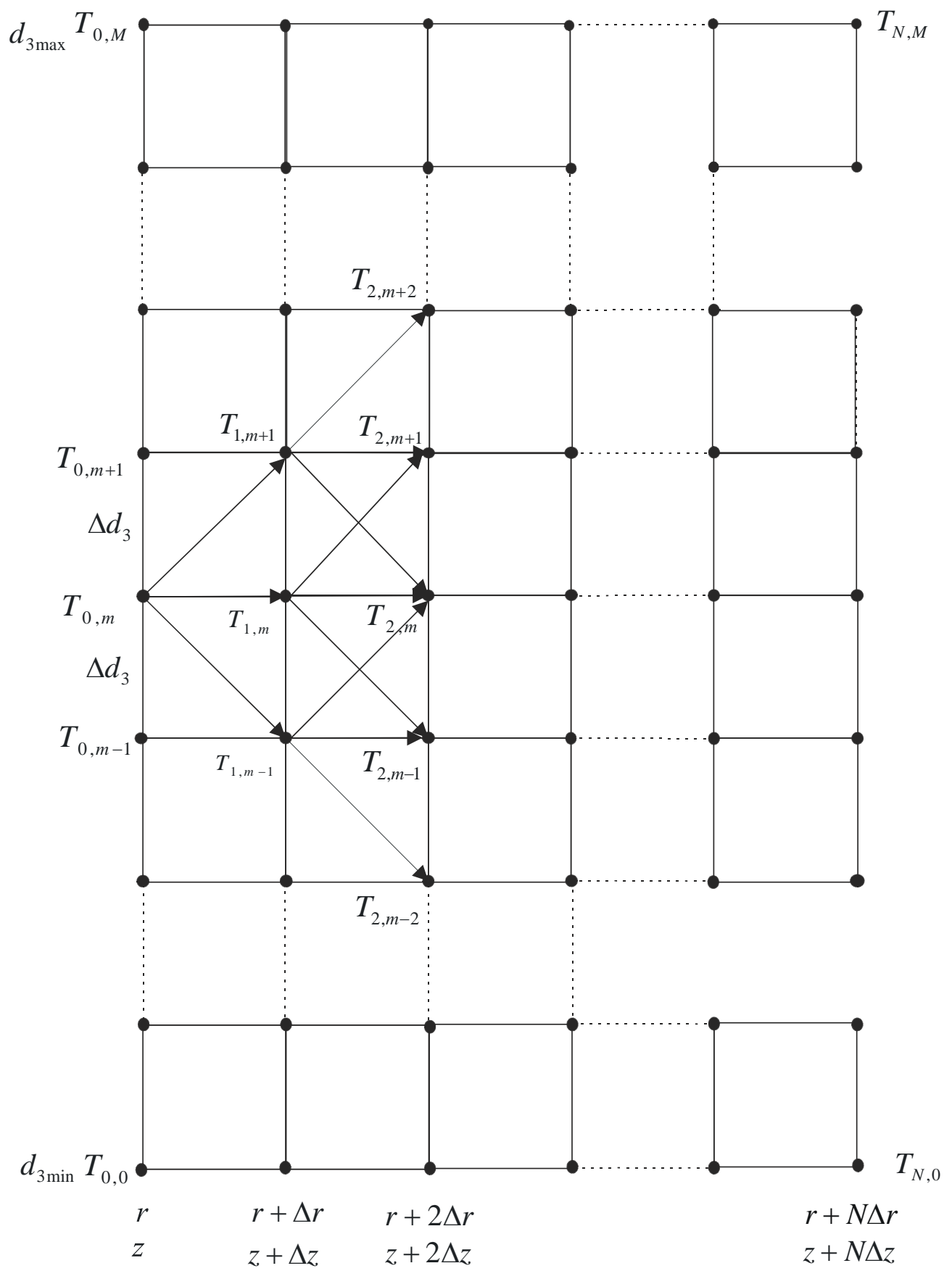

Figure 7.1 A node network in the manipulator workspace.

If we choose a $\Delta d_{3}$ that is larger than the increment of the TCP, $d_{3}$ will in most cases not move. We have chosen the value of $\Delta d_{3}$ to one tenth of the increment in the TCP path, i.e. from one stage to the next. 


\section{Chapter 8}

\section{SIMULATIONS}

The three kinematic control algorithms have been tested through simulations in a program developed especially for this thesis. The simulations are carried out for a common hydraulic manipulator driven by hydraulic actuators shown in figure 8.1. We have limited the simulations to one typical task. The task describes a normal working cycle which occurs when a forwarder is loading and unloading logs from the ground and off/on the carrier. The task consists of three linear segments in the workspace as shown (ABC) in figure 8.2.

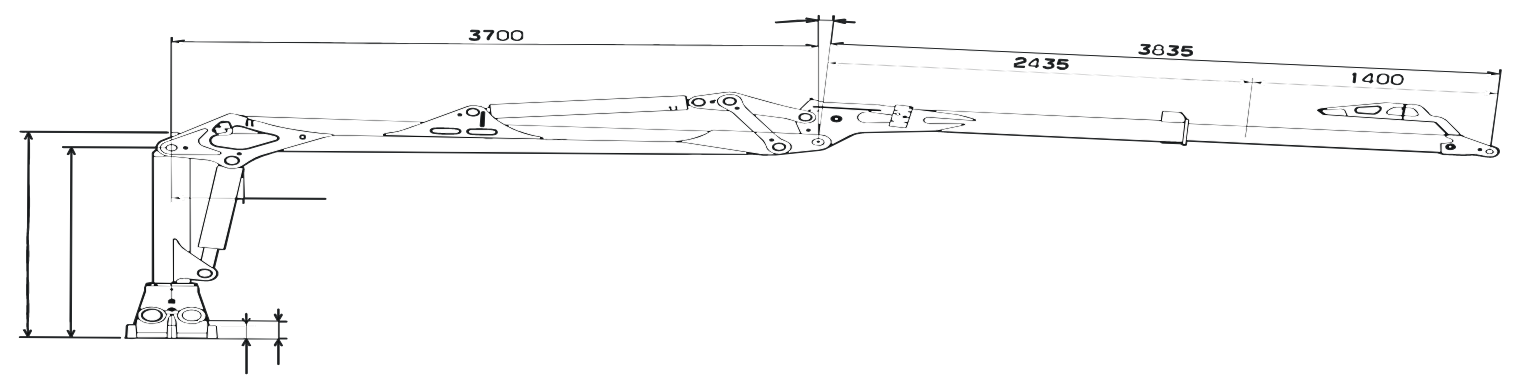

Figure 8.1 Hydraulic knuckle boom Cranab 850

The paths are as follows: $\mathrm{A}-\mathrm{B}, \mathrm{B}-\mathrm{C}$ and $\mathrm{A}-\mathrm{C}$. For each path the position and velocity of the joints are analysed. The coordinates for each point in the work space are:
A $(1.5,1.0)$
B $(5.5,1.0)$
$\mathrm{C}(5.5,-3.0)$ 


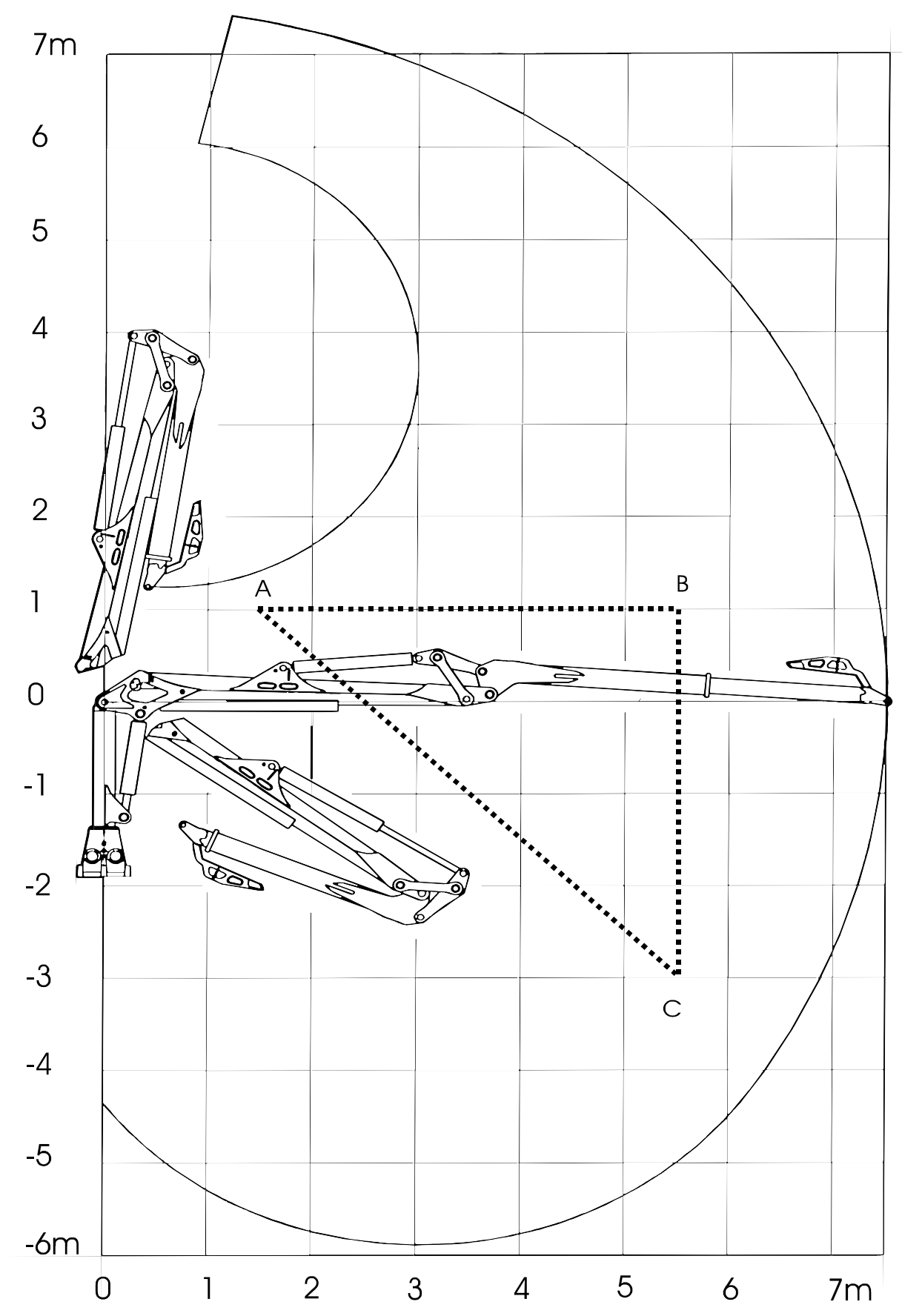

Figure 8.2 Work space and simulation task. 


\subsection{Parameters}

For the simulations we have used following data. Mechanical data of the boom Cranab 850 are seen in figure 8.1. The joint limits are:

$$
\begin{aligned}
& \theta_{1 \text { min }}=8 \mathrm{deg} \\
& \theta_{1 \max }=123 \mathrm{deg} \\
& \theta_{2 \min }=2 \mathrm{deg} \\
& \theta_{2 \max }=178 \mathrm{deg} \\
& d_{3 \min }=0 \mathrm{~m} \\
& d_{3 \max }=1.4 \mathrm{~m} \\
& r_{c}=3.5 \mathrm{~m} \\
& z_{c}=0.65 \mathrm{~m} \\
& \rho_{\text {min }}=3.5 \mathrm{~m} \\
& \rho_{\text {max }}=4.9 \mathrm{~m}
\end{aligned}
$$

The maximum velocities for the different joints which are used for all simulations are:

$$
\begin{aligned}
& \dot{\theta}_{1 \max }=0.88 \mathrm{rad} / \mathrm{s} \\
& \dot{\theta}_{2 \max }=1,23 \mathrm{rad} / \mathrm{s} \\
& \dot{d}_{3 \max }=0.42 \mathrm{~m} / \mathrm{s}
\end{aligned}
$$

The joints speeds are set to equal in both directions. This is due to that for each machine application the hydraulic pressure and flow are different. Therefore the joint speeds are set to suit one typical pressure and flow.

In the dynamic programming simulations the parameters are set to:

$$
\begin{aligned}
& \Delta r=0.01 \\
& \Delta z=0.01 \\
& \Delta d_{3}=0.01 \\
& q=5
\end{aligned}
$$


The weighting matrix $\mathrm{W}$, based on empirical data, se equation (5.5), is set to

$$
W=\left[\begin{array}{ccc}
1.5 & 0 & 0 \\
0 & 1 & 0 \\
0 & 0 & 8
\end{array}\right]
$$

\subsection{Simulations with maximum lifting capacity and maximum velocity}

The following figures from the simulations show the time records of $\theta_{1}, \theta_{2}, d_{3}, \dot{\theta}_{1}, \dot{\theta}_{2}$ and $\dot{d}_{3}$ when the TCP (Tool Centre Point) moves from point A to B, B to C and A to $\mathrm{C}$ in the work space at two different velocities, 1.0 and $2.5 \mathrm{~m} / \mathrm{s}$. The ideal positioning times at these speeds are as follows:

A to $\mathrm{B}$ and $\mathrm{B}$ to $\mathrm{C}$ : $\quad 4 \mathrm{~s}$ and $1.6 \mathrm{~s}$ respectively

C to A: $\quad 5.66 \mathrm{~s}$ and 2.26 s respectively

If these times are not met it is an indication that one or more of the DOF:s are saturated.

The dynamic programming will show the shortest time that the TCP can move between two points. The joints are limited to maximum allowed velocities.

To be able to display $d_{3}$ on the same plot as $\theta_{1}$ and $\theta_{2}, d_{3}$ has been multiplied with a constant set to 100 . 


\subsubsection{TCP velocity $1.0 \mathrm{~m} / \mathrm{s}$}

TCP moves from point $A$ to $B$.

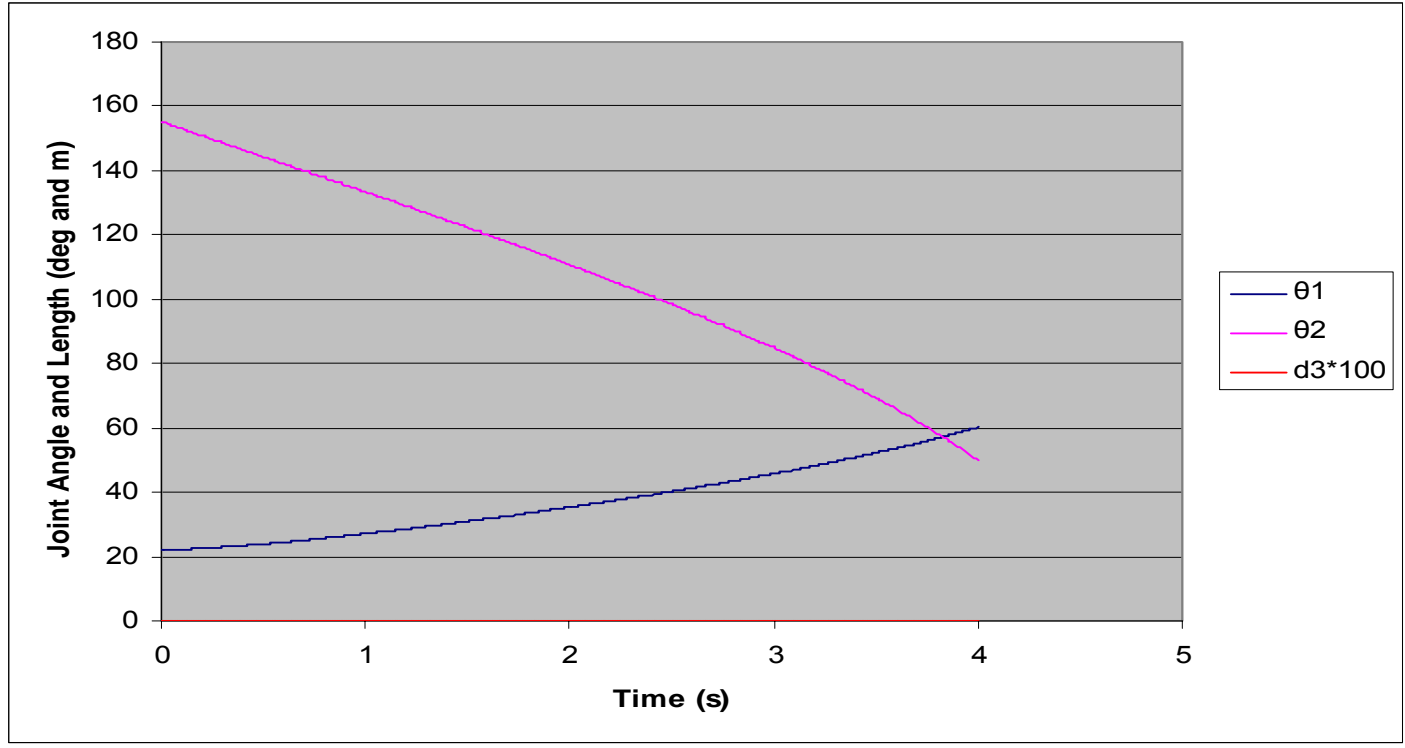

Figure 8.2.1.1 Maximum lifting capacity algorithm. TCP moves from $A$ to $B$ with a speed of $1.0 \mathrm{~m} / \mathrm{s}$. Variations in $\theta_{1}, \theta_{2}$ and $d_{3}$.

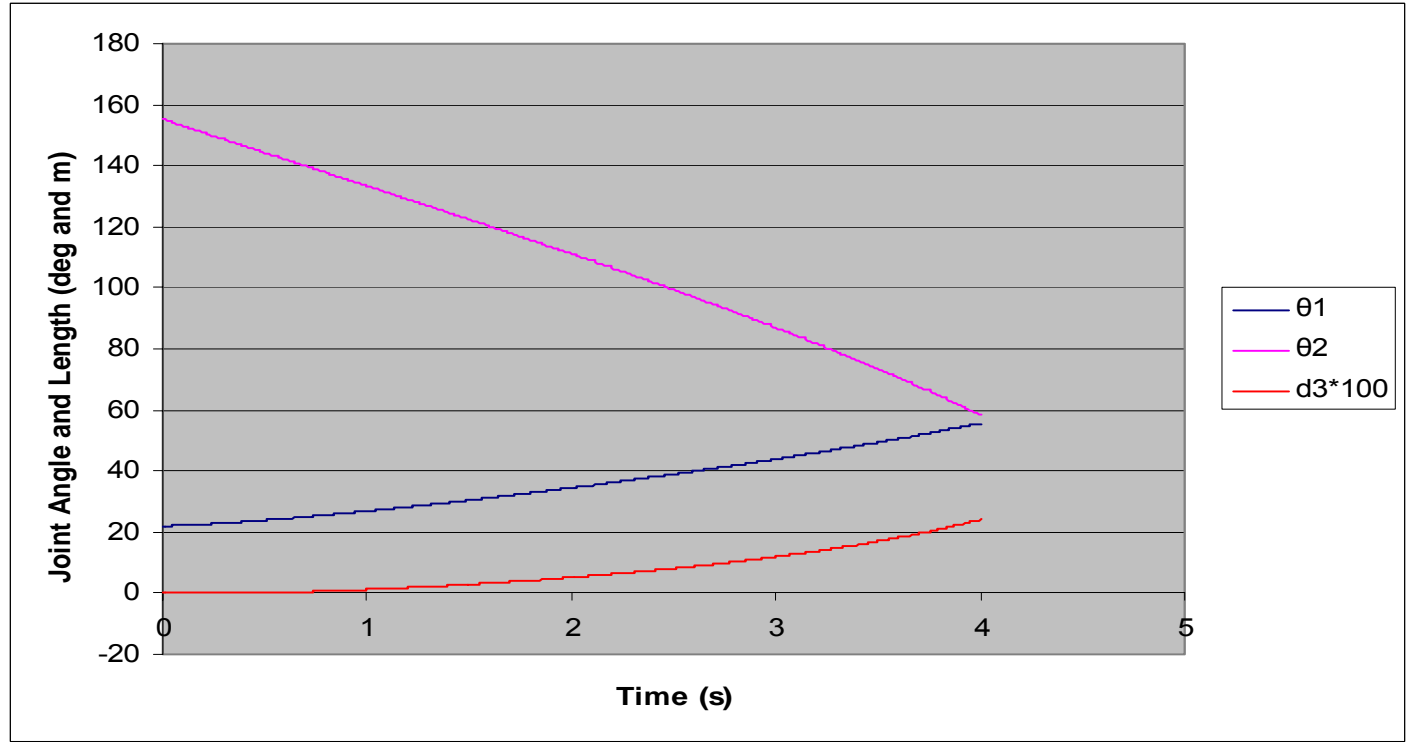

Figure 8.2.1.2 Maximum velocity algorithm. TCP moves from A to B with a speed of $1.0 \mathrm{~m} / \mathrm{s}$. Variations in $\theta_{1}, \theta_{2}$ and $d_{3}$. 


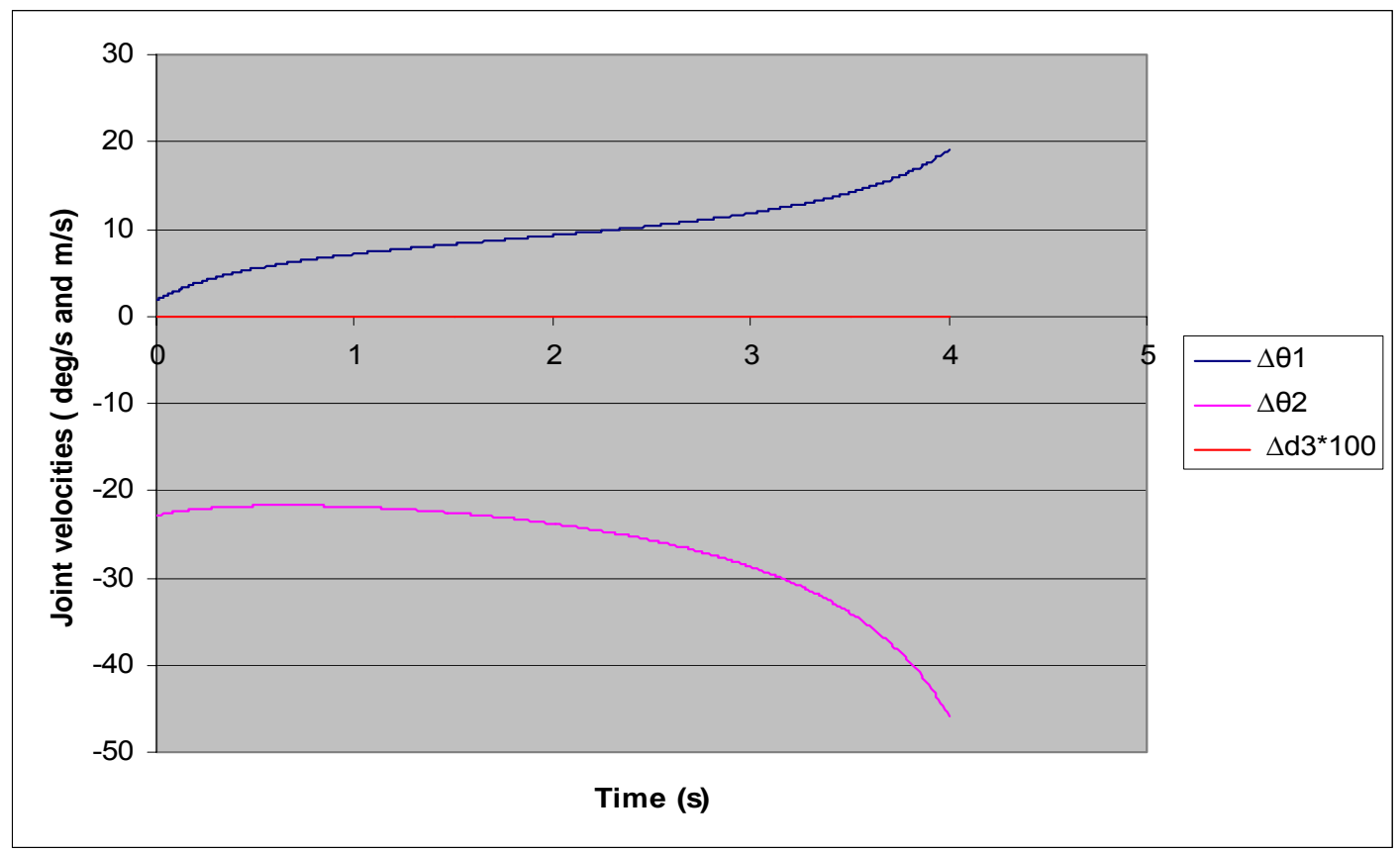

Figure 8.2.1.3 Maximum lifting capacity algorithm. TCP moves from A to B with a speed of $1.0 \mathrm{~m} / \mathrm{s}$. Variations in $\dot{\theta}_{1}, \dot{\theta}_{2}$ and $\dot{d}_{3}$.

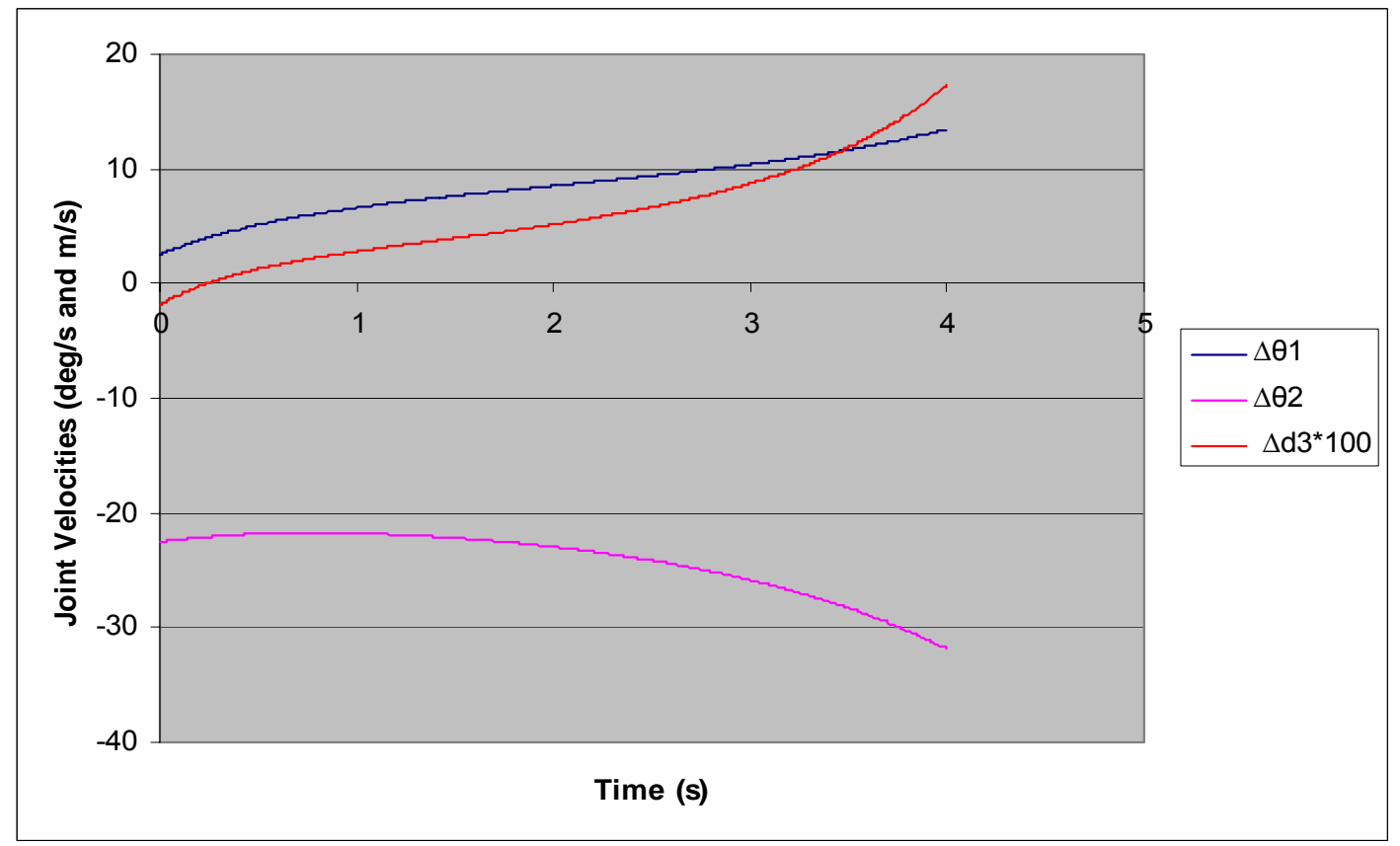

Figure 8.2.1.4 Maximum velocity algorithm. TCP moves from A to $B$ with a speed of $1.0 \mathrm{~m} / \mathrm{s}$. Variations in joint velocities $\dot{\theta}_{1}, \dot{\theta}_{2}$ and $\dot{d}_{3}$.

Both the maximum lifting capacity and maximum velocity algorithm need the same time to go from point A to B, $4.0 \mathrm{~s}$. The velocities of the joints change smoothly in both cases. None of the joint velocities reach their speed limits. 
TCP moves from point B to C.

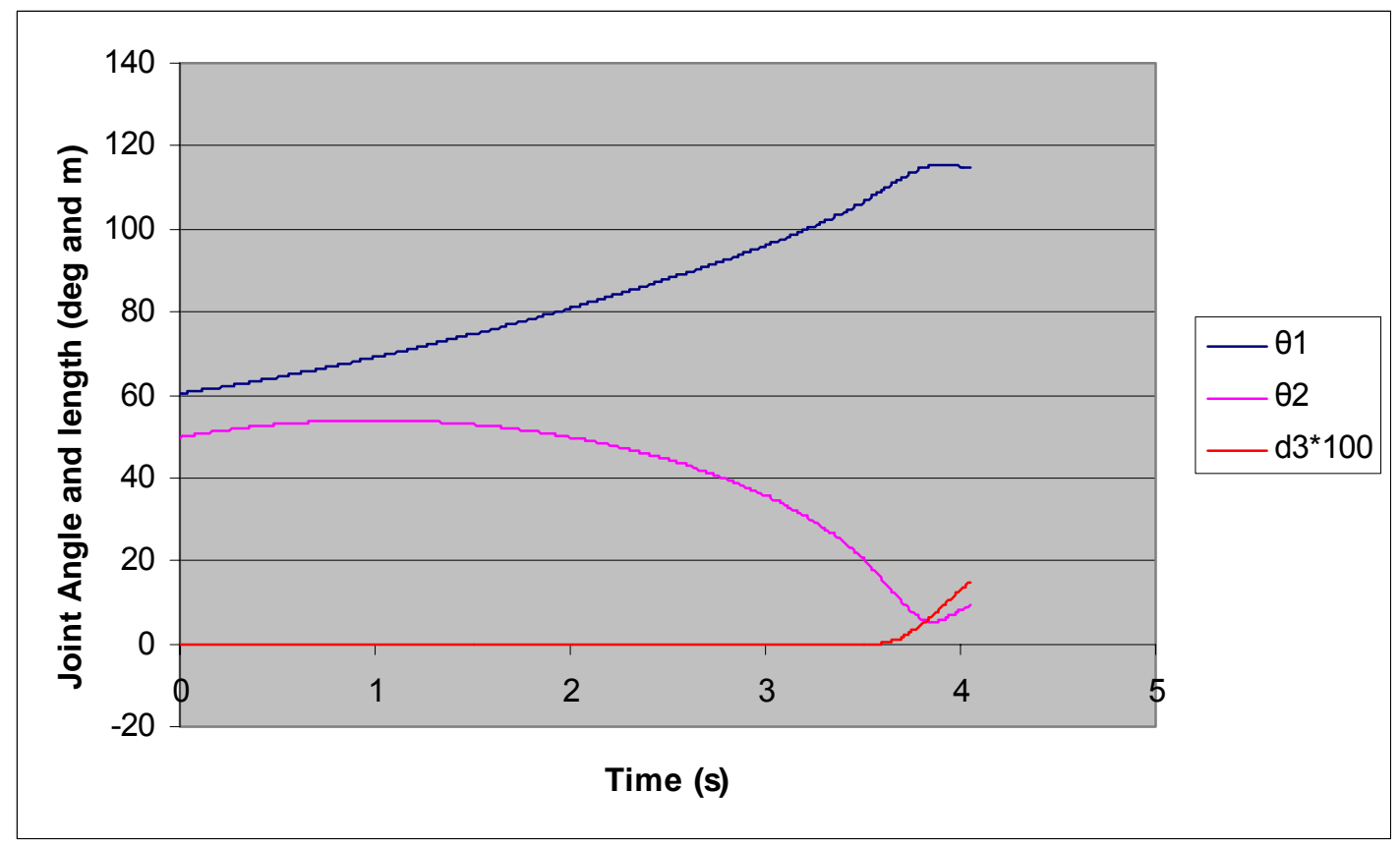

Figure 8.2.1.5 Maximum lifting capacity algorithm. TCP moves from $B$ to $C$ with a speed of $1.0 \mathrm{~m} / \mathrm{s}$. Variations $\theta_{1}, \theta_{2}$ and $d_{3}$.

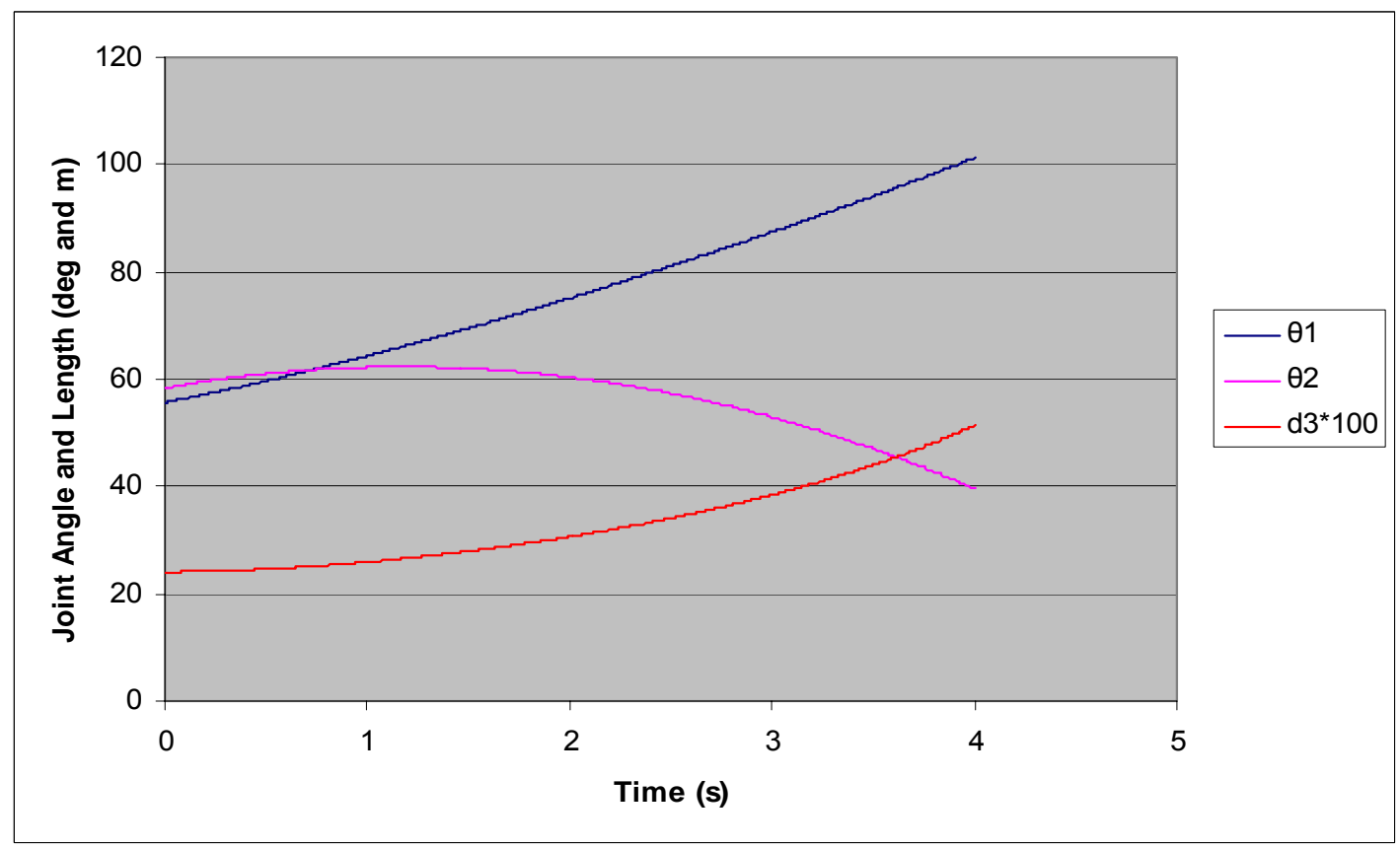

Figure 8.2.1.6 Maximum velocity algorithm. TCP moves from $B$ to $C$ with a speed of $1.0 \mathrm{~m} / \mathrm{s}$. Variations in $\theta_{1}, \theta_{2}$ and $d_{3}$. 


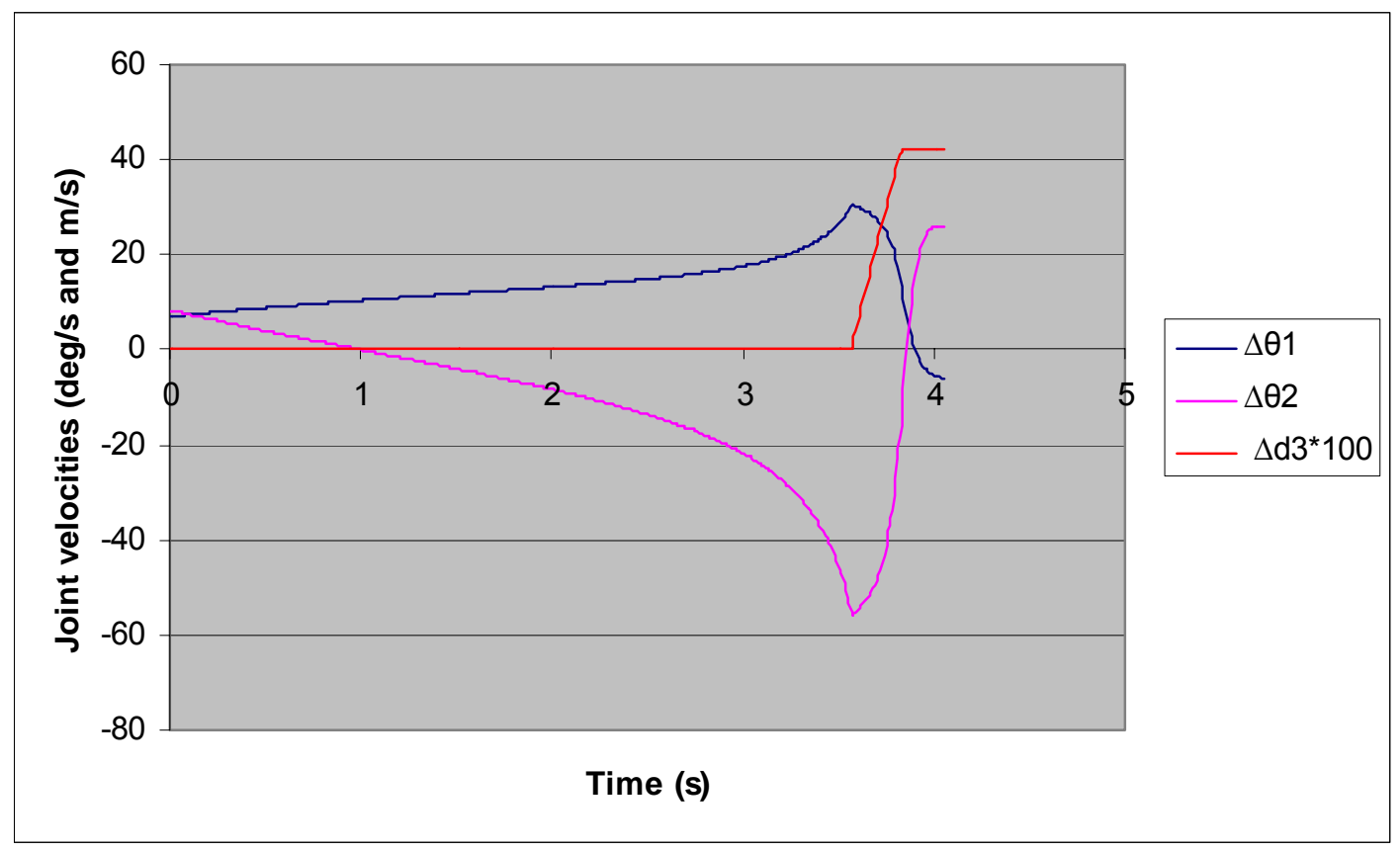

Figure 8.2.1.7 Maximum lifting capacity algorithm. TCP moves from $B$ to $C$ with a speed of $1.0 \mathrm{~m} / \mathrm{s}$. Variations in $\dot{\theta}_{1}, \dot{\theta}_{2}$ and $\dot{d}_{3}$.

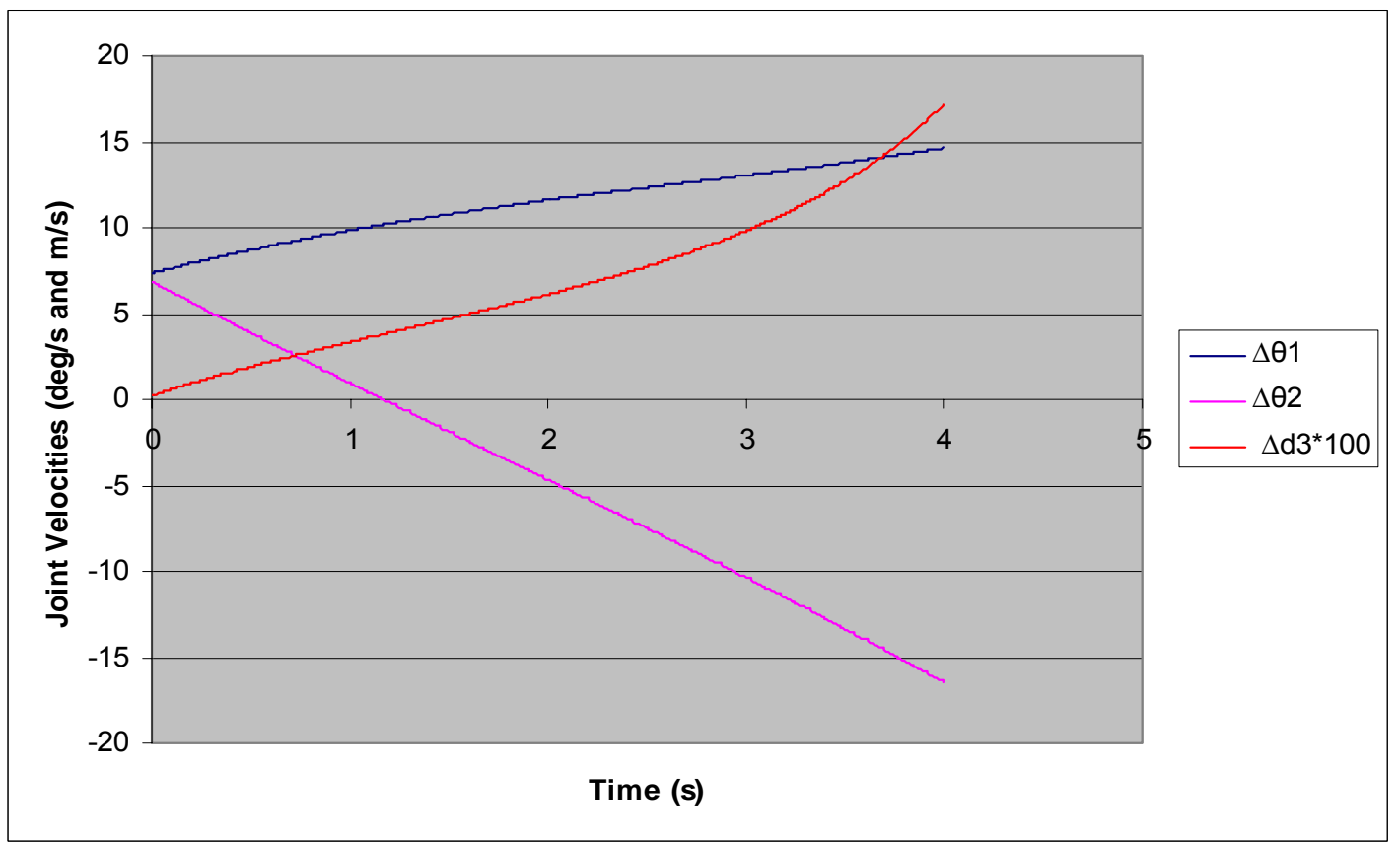

Figure 8.2.1.8 Maximum velocity algorithm. TCP moves from $B$ to $C$ with a speed of $1.0 \mathrm{~m} / \mathrm{s}$. Variations in $\dot{\theta}_{1}, \dot{\theta}_{2}$ and $\dot{d}_{3}$.

The maximum lifting capacity needs $4.05 \mathrm{~s}$ to go from point B to C. $\dot{d}_{3}$ reaches its maximum velocity limit. According to section 6.2, a scaling of the commanded 
signal is necessary, which increases the time consumption. During the scaling, the path is followed, but a lower velocity than $1.0 \mathrm{~m} / \mathrm{s}$, and $\dot{d}_{3}$ is saturated.

The maximum lifting capacity 1 needs $5.66 \mathrm{~s}$ to go from A to C. The velocities of the joints do not reach their limits. 
TCP moves from point $A$ to $C$.

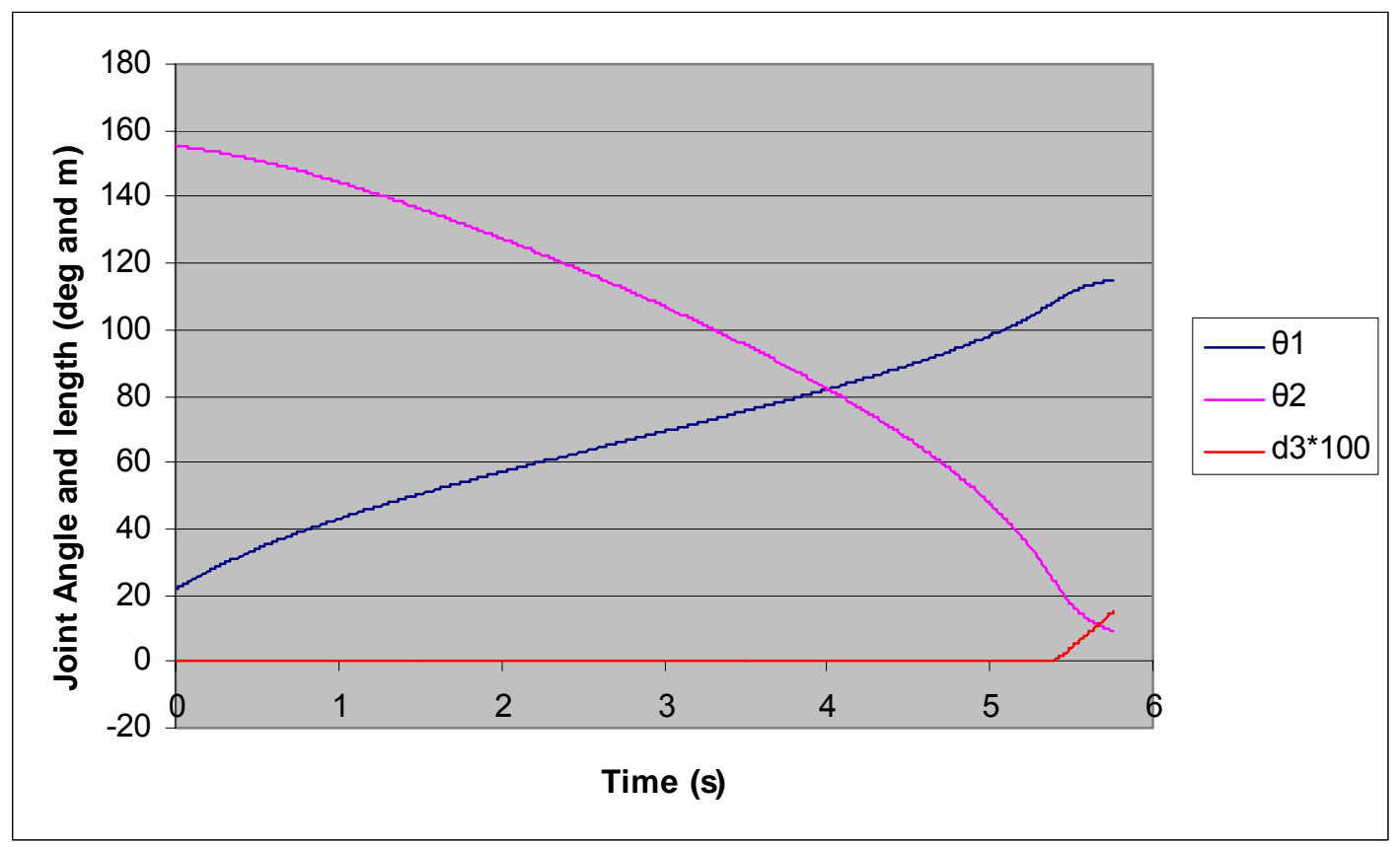

Figure 8.2.1.9 Maximum lifting capacity algorithm. TCP moves from $A$ to $C$ with a speed of $1.0 \mathrm{~m} / \mathrm{s}$. Variations in $\theta_{1}, \theta_{2}$ and $d_{3}$.

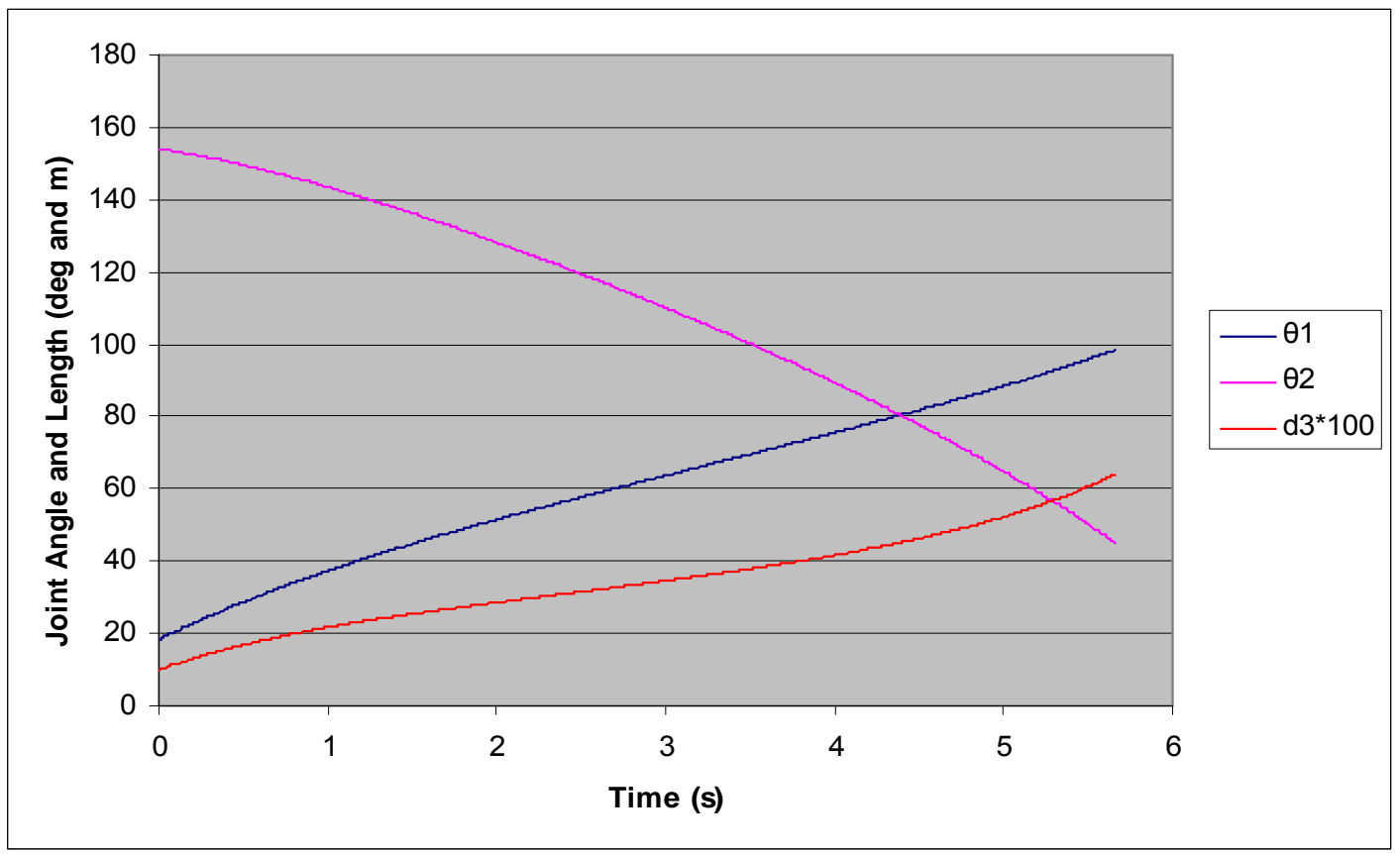

Figure 8.2.1.10 Maximum velocity algorithm. TCP moves from $A$ to $C$ with a speed of $1.0 \mathrm{~m} / \mathrm{s}$. Variations in $\theta_{1}, \theta_{2}$ and $d_{3}$. 


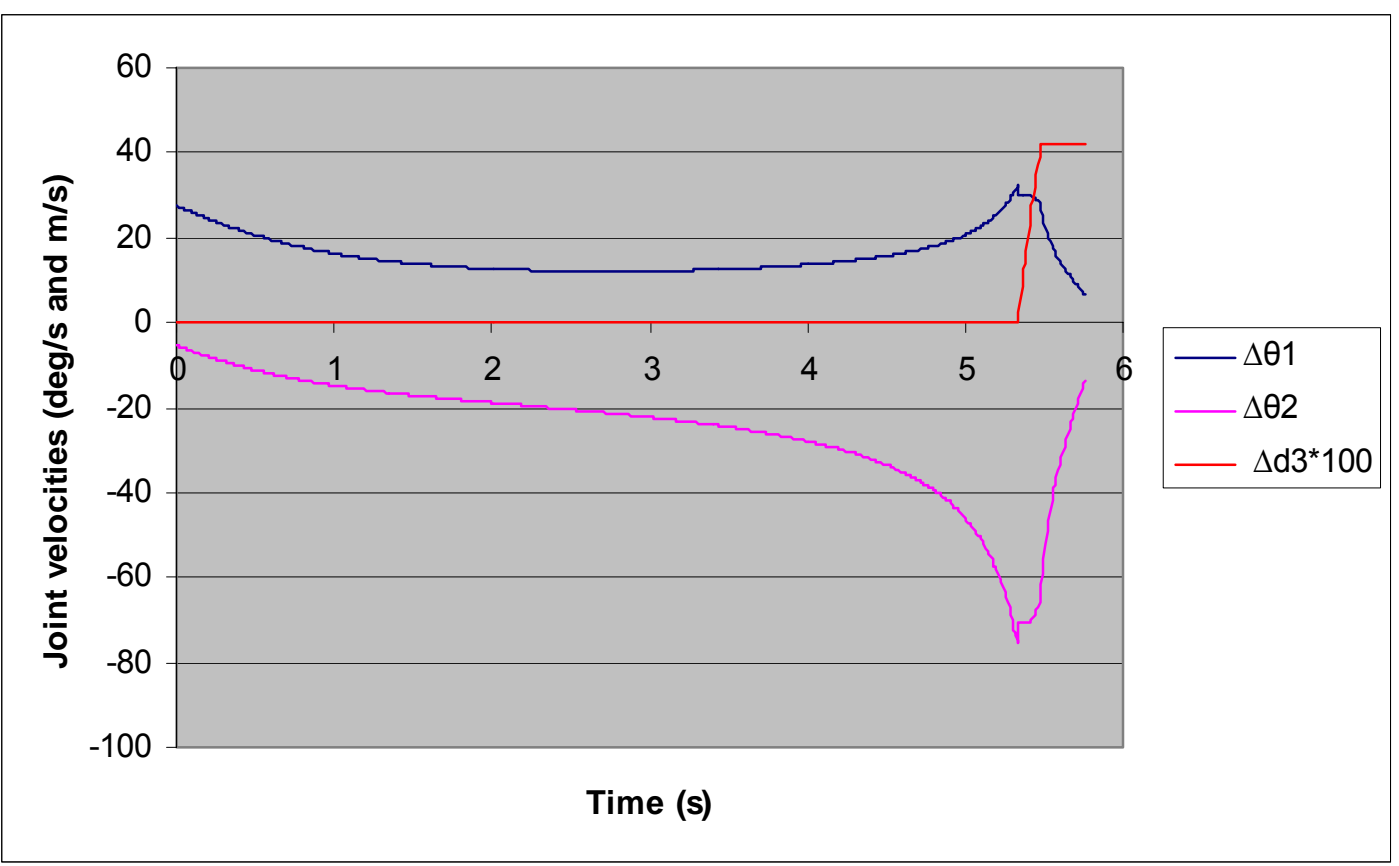

Figure 8.2.1.11 Maximum lifting capacity algorithm. TCP moves from A to $\mathrm{C}$ with a speed of $1.0 \mathrm{~m} / \mathrm{s}$. Variations in $\dot{\theta}_{1}, \dot{\theta}_{2}$ and $\dot{d}_{3}$.

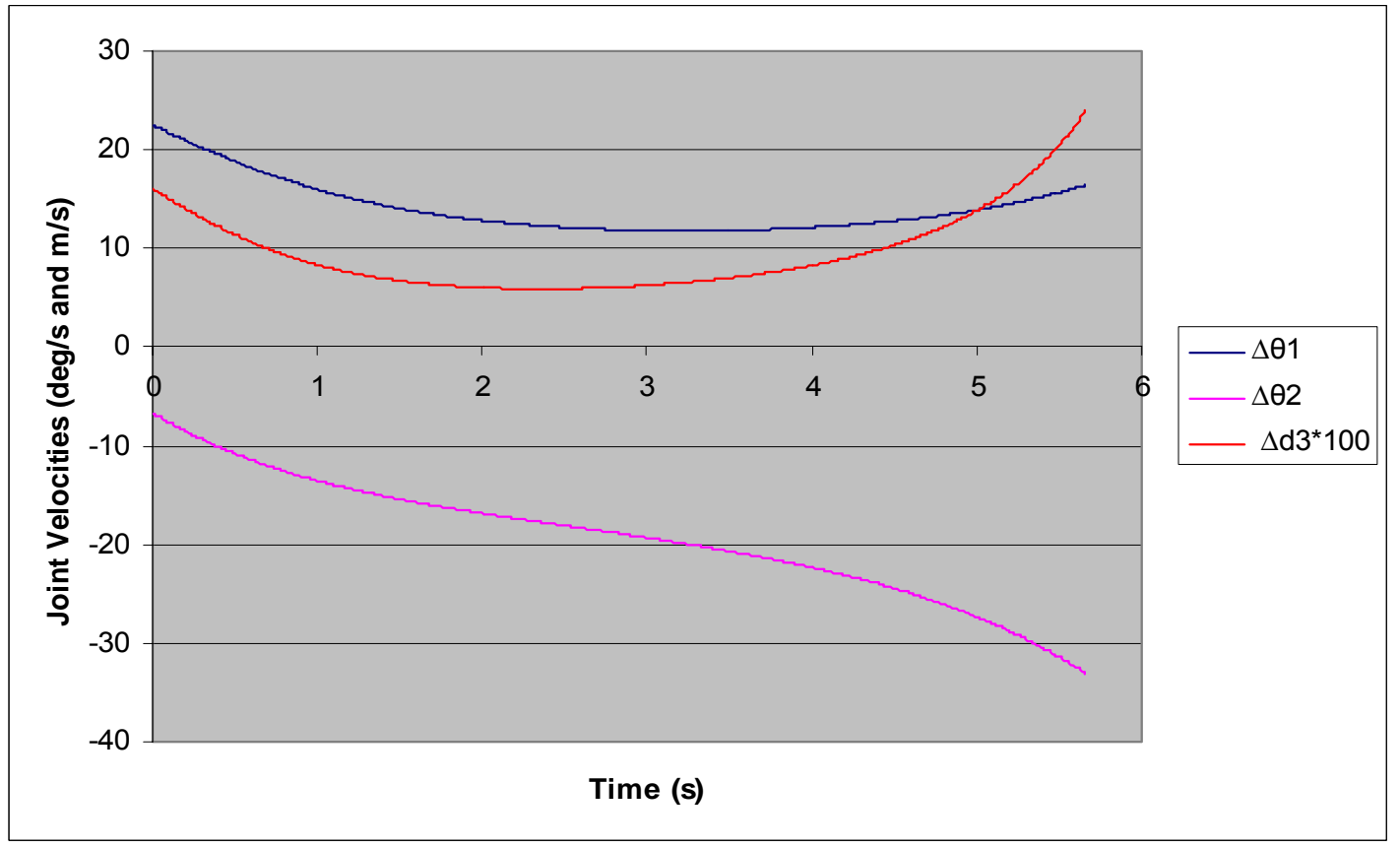

Figure 8.2.1.12 Maximum velocity algorithm. TCP moves from $A$ to $C$ with a speed of $1.0 \mathrm{~m} / \mathrm{s}$. Variations in $\dot{\theta}_{1}, \dot{\theta}_{2}$ and $\dot{d}_{3}$. 
The maximum lifting capacity needs $5.77 \mathrm{~s}$ to go from point A to C. $\dot{\theta}_{2}$ and $\dot{d}_{3}$ reach their maximum velocity limits, but not simultaneously. According to section 6.2 , a scaling of the commanded signal is necessary, which increases the time consumption. During the scaling, the path is followed, but a lower velocity than 1.0 $\mathrm{m} / \mathrm{s}, \dot{\theta}_{2}$ and $\dot{d}_{3}$ is saturated.

The maximum lifting capacity 1 needs $5.66 \mathrm{~s}$ to go from A to C. The velocities of the joints do not reach their limits. 


\subsubsection{TCP velocity $2.5 \mathrm{~m} / \mathrm{s}$}

TCP moves from point A to $B$.

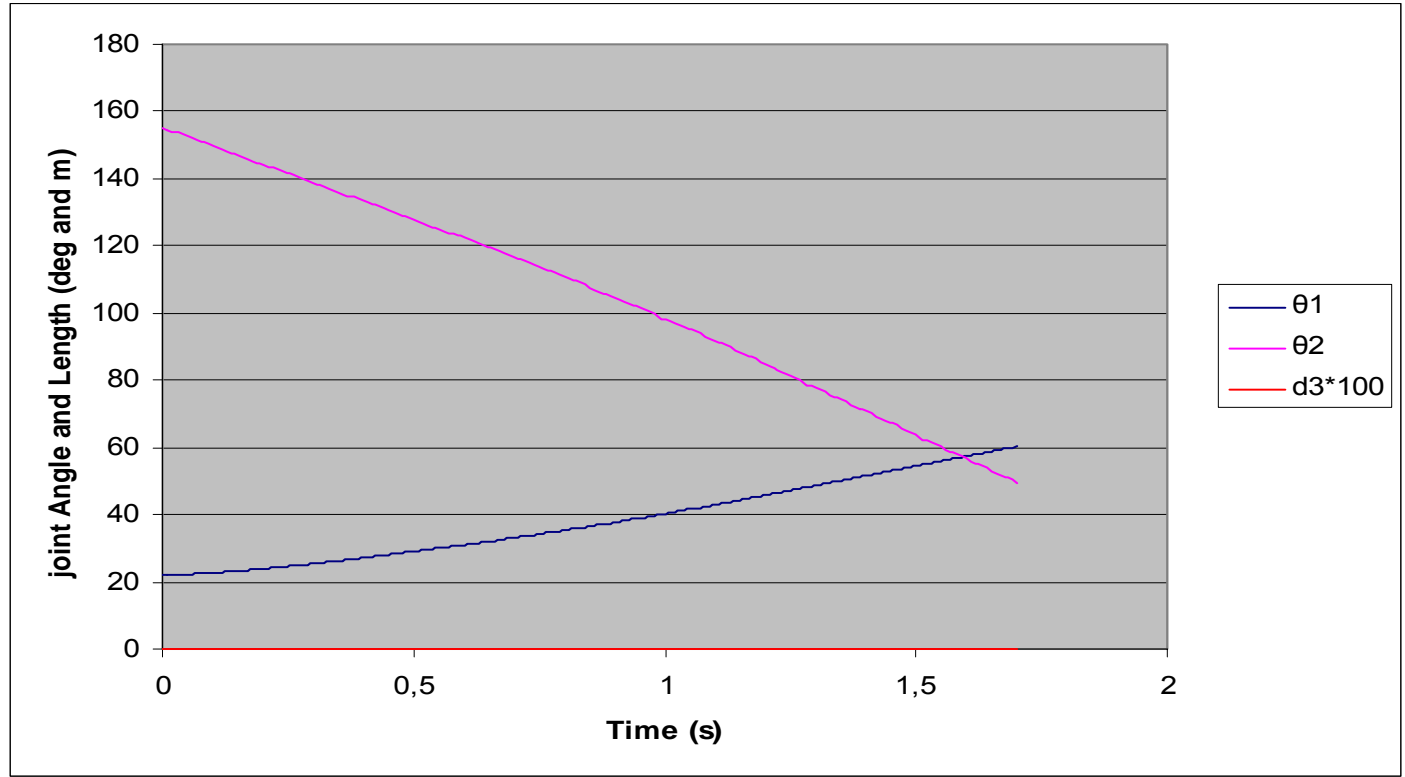

Figure 8.2.2.1 Maximum lifting capacity algorithm. TCP moves from A to $B$ with a speed of $2.5 \mathrm{~m} / \mathrm{s}$. Variations in $\theta_{1}, \theta_{2}$ and $d_{3}$.

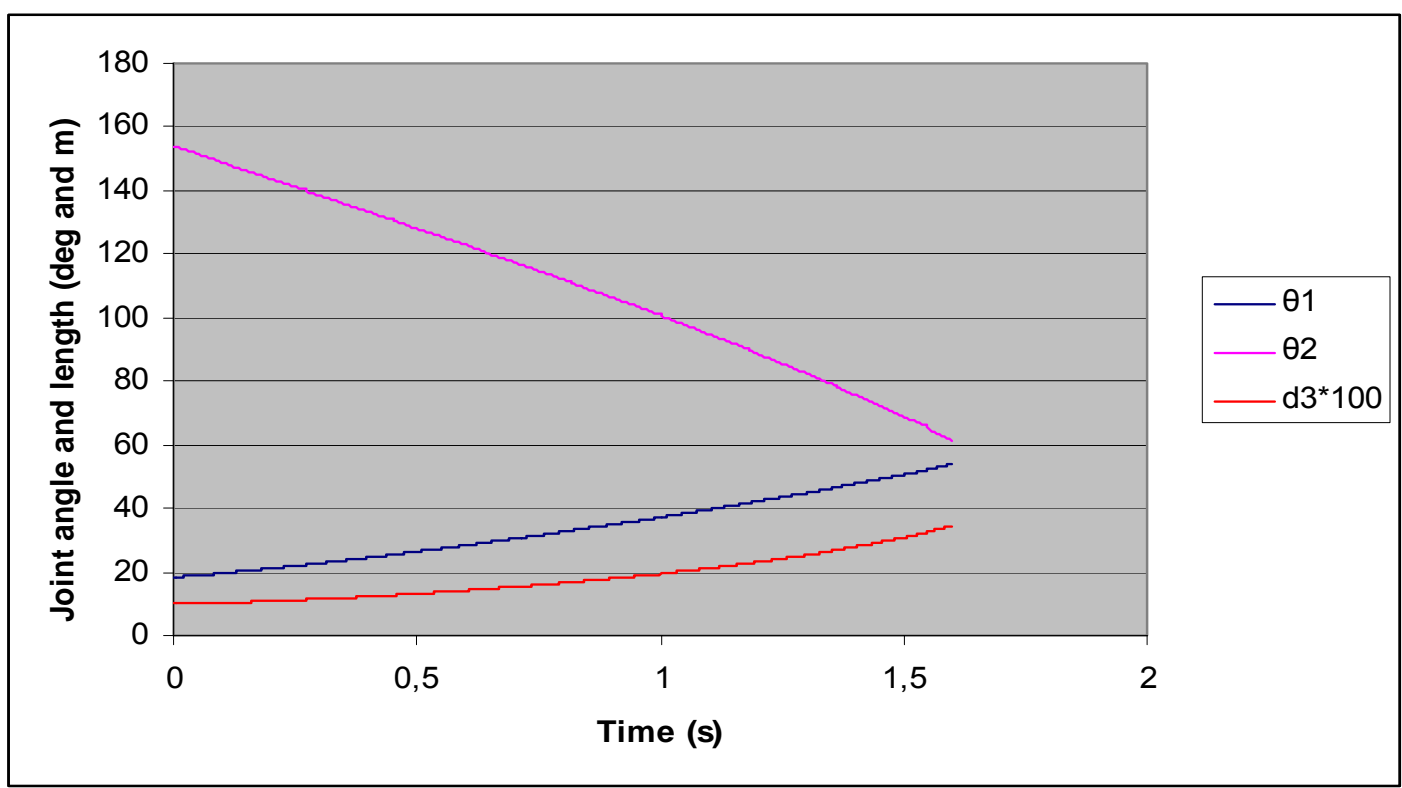

Figure 8.2.2.2 Maximum velocity algorithm. TCP moves from $A$ to $B$ with a speed of $2.5 \mathrm{~m} / \mathrm{s}$. Variations in $\theta_{1}, \theta_{2}$ and $d_{3}$. 


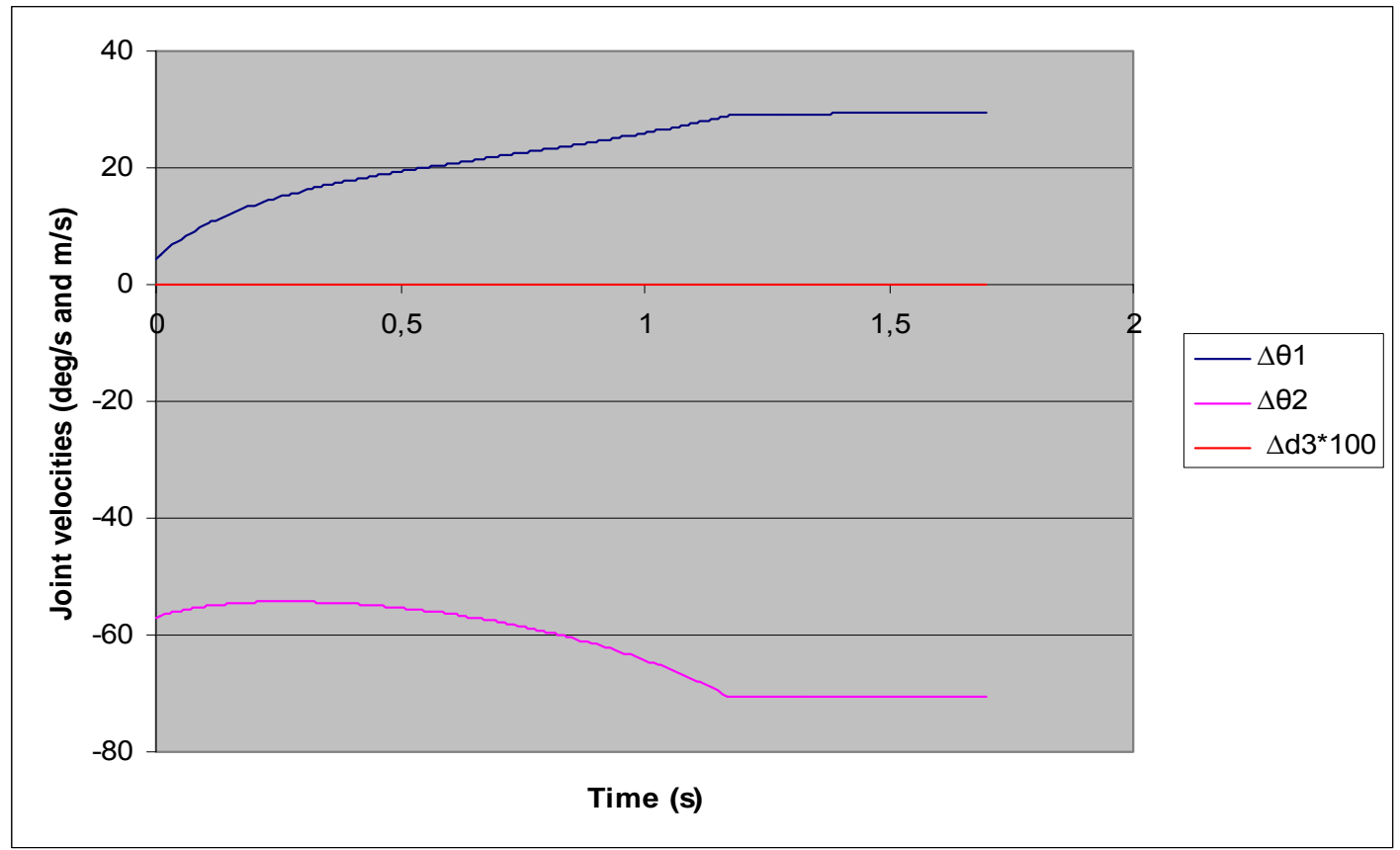

Figure 8.2.2.3 Maximum lifting capacity algorithm. TCP moves from A to $B$ with a speed of $2.5 \mathrm{~m} / \mathrm{s}$. Variations in $\dot{\theta}_{1}, \dot{\theta}_{2}$ and $\dot{d}_{3}$.

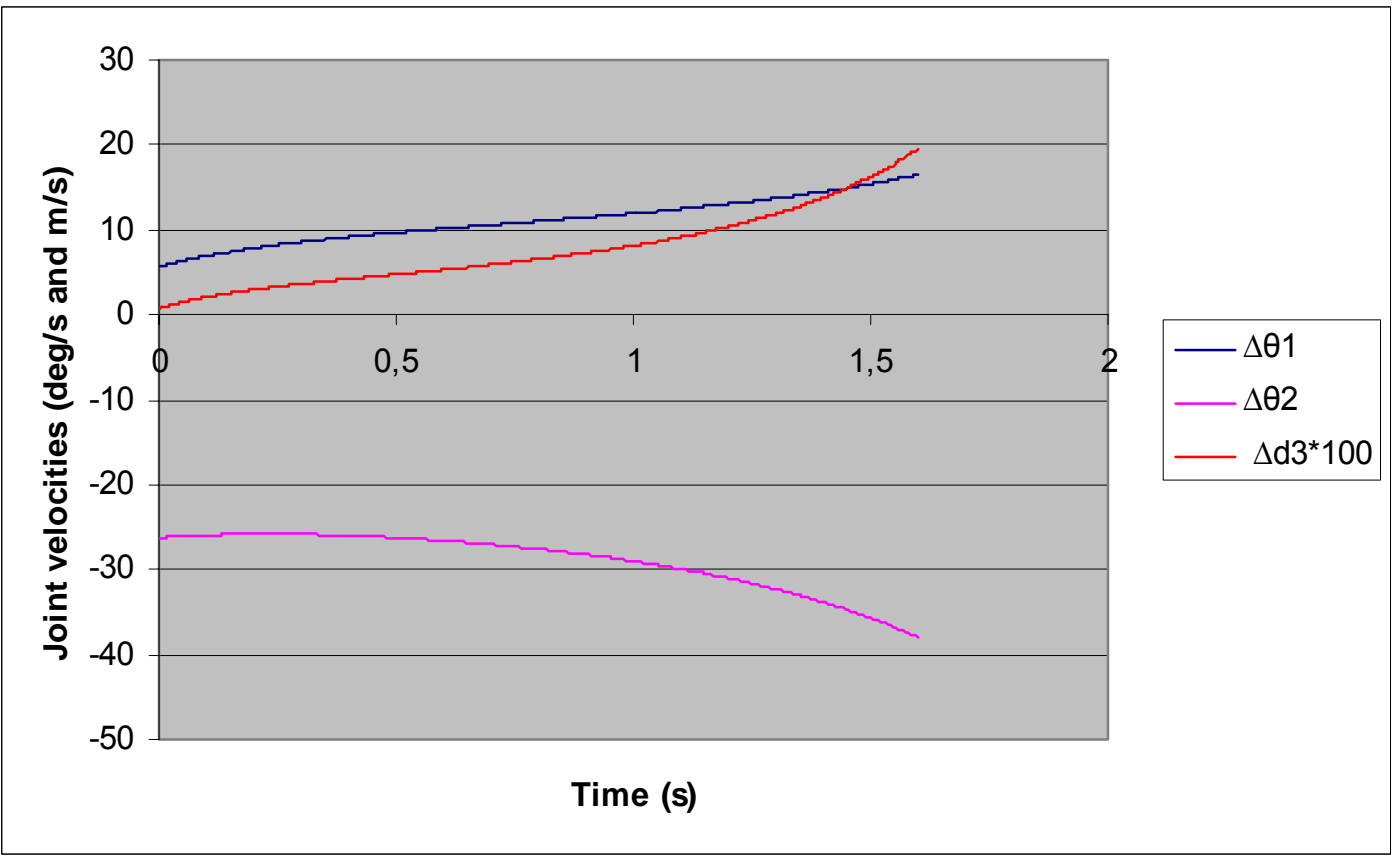

Figure 8.2.2.4 Maximum velocity algorithm. TCP moves from A to $B$ with a speed of $2.5 \mathrm{~m} / \mathrm{s}$. Variations in $\dot{\theta}_{1}, \dot{\theta}_{2}$ and $\dot{d}_{3}$. 
The maximum lifting capacity needs $1.70 \mathrm{~s}$ to go from point A to B. $\dot{\theta}_{2}$ reaches its maximum velocity limit. According to section 6.2, a scaling of the commanded signal is necessary, which increases the time consumption. During the scaling, the path is followed, but a lower velocity than $2.5 \mathrm{~m} / \mathrm{s}, \dot{\theta}_{2}$ is saturated.

The maximum lifting capacity 1 needs $1.60 \mathrm{~s}$ to go from $\mathrm{A}$ to $\mathrm{B}$. The velocities of the joints do not reach their limits. 
TCP moves from point B to C.

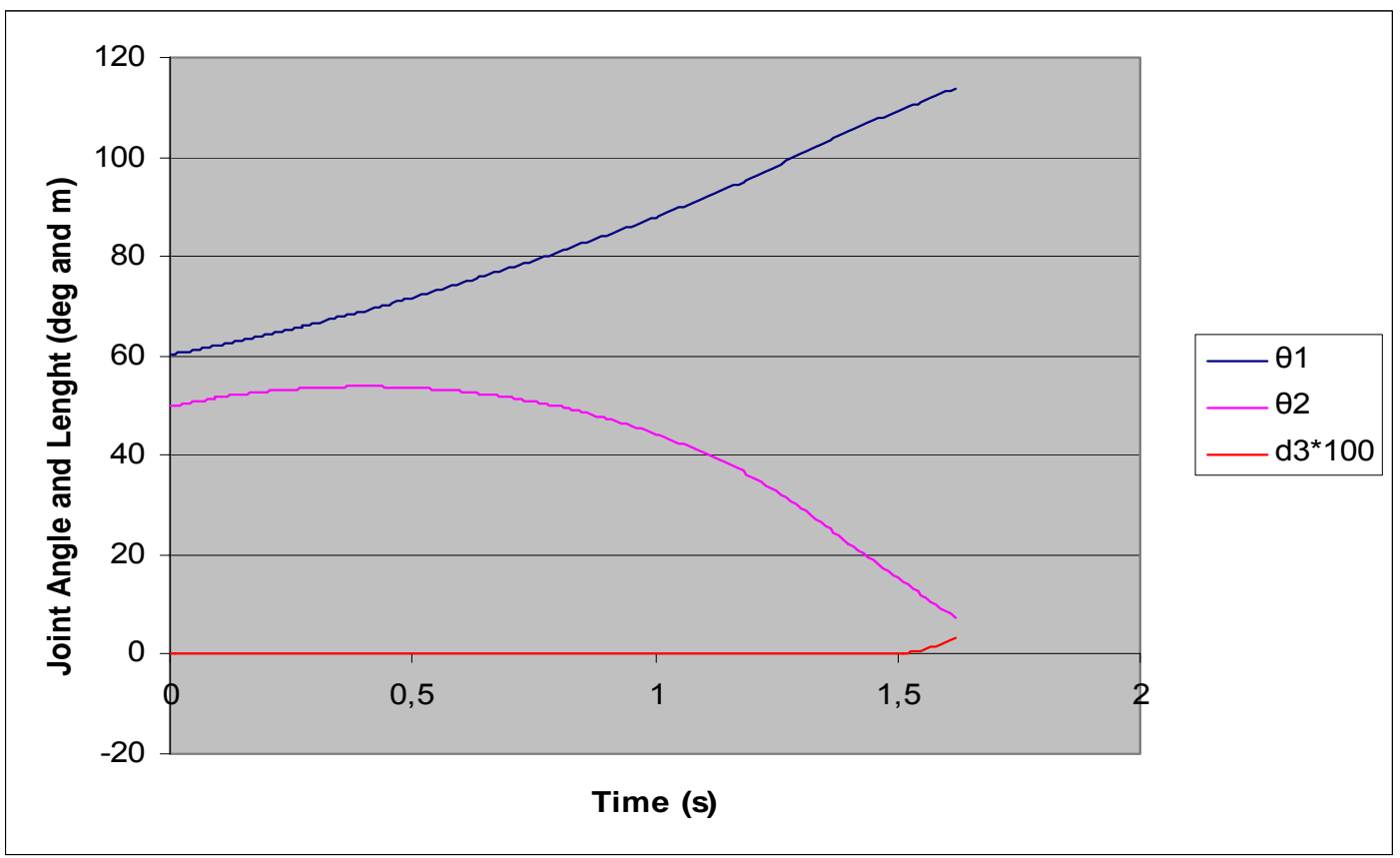

Figure 8.2.2.5 Maximum lifting capacity algorithm. TCP moves from $B$ to $C$ with a speed of $2.5 \mathrm{~m} / \mathrm{s}$. Variations in $\theta_{1}, \theta_{2}$ and $d_{3}$.

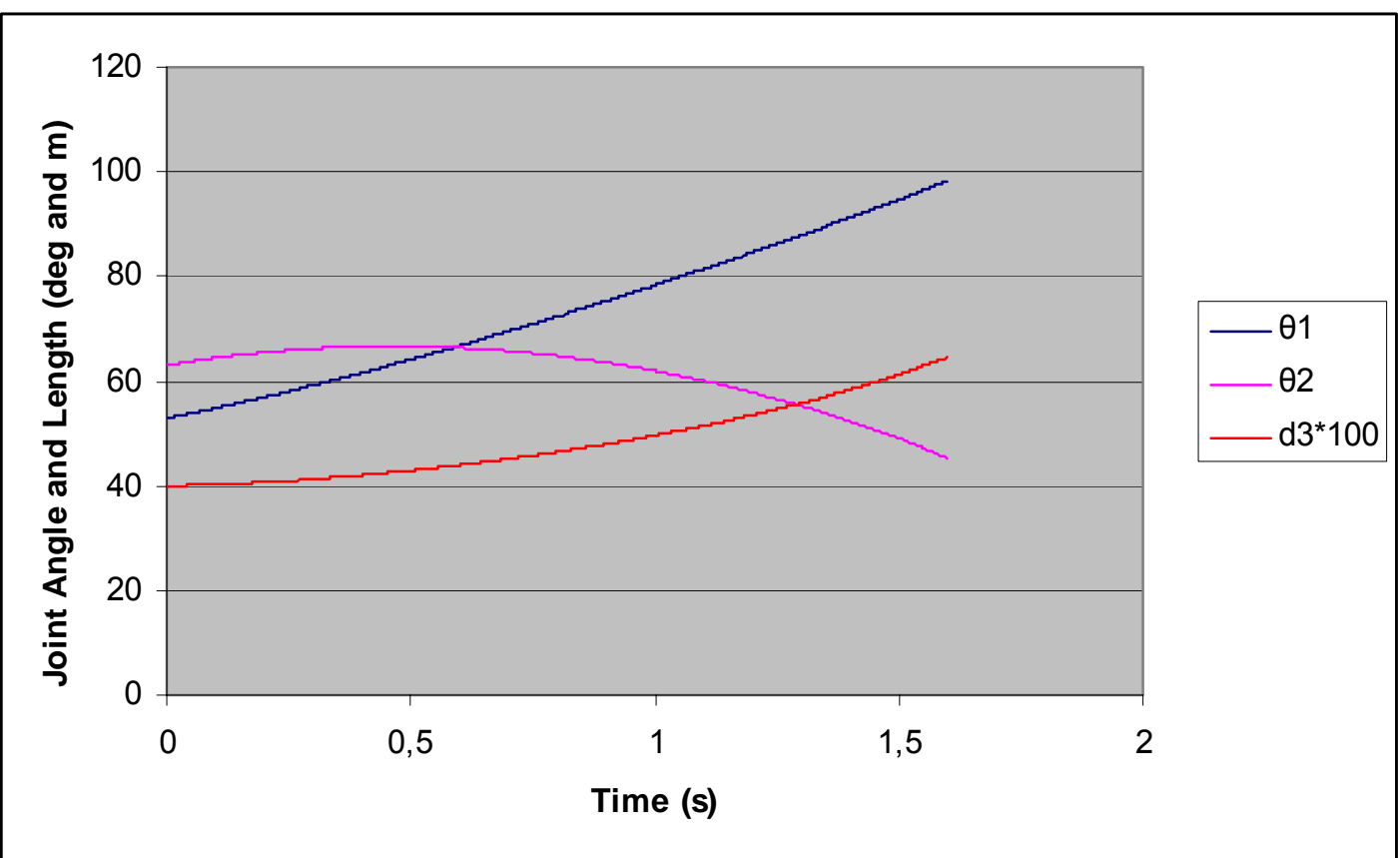

Figure 8.2.2.6 Maximum velocity algorithm. TCP moves from $B$ to $C$ with a speed of $2.5 \mathrm{~m} / \mathrm{s}$. Variations in $\theta_{1}, \theta_{2}$ and $d_{3}$. 


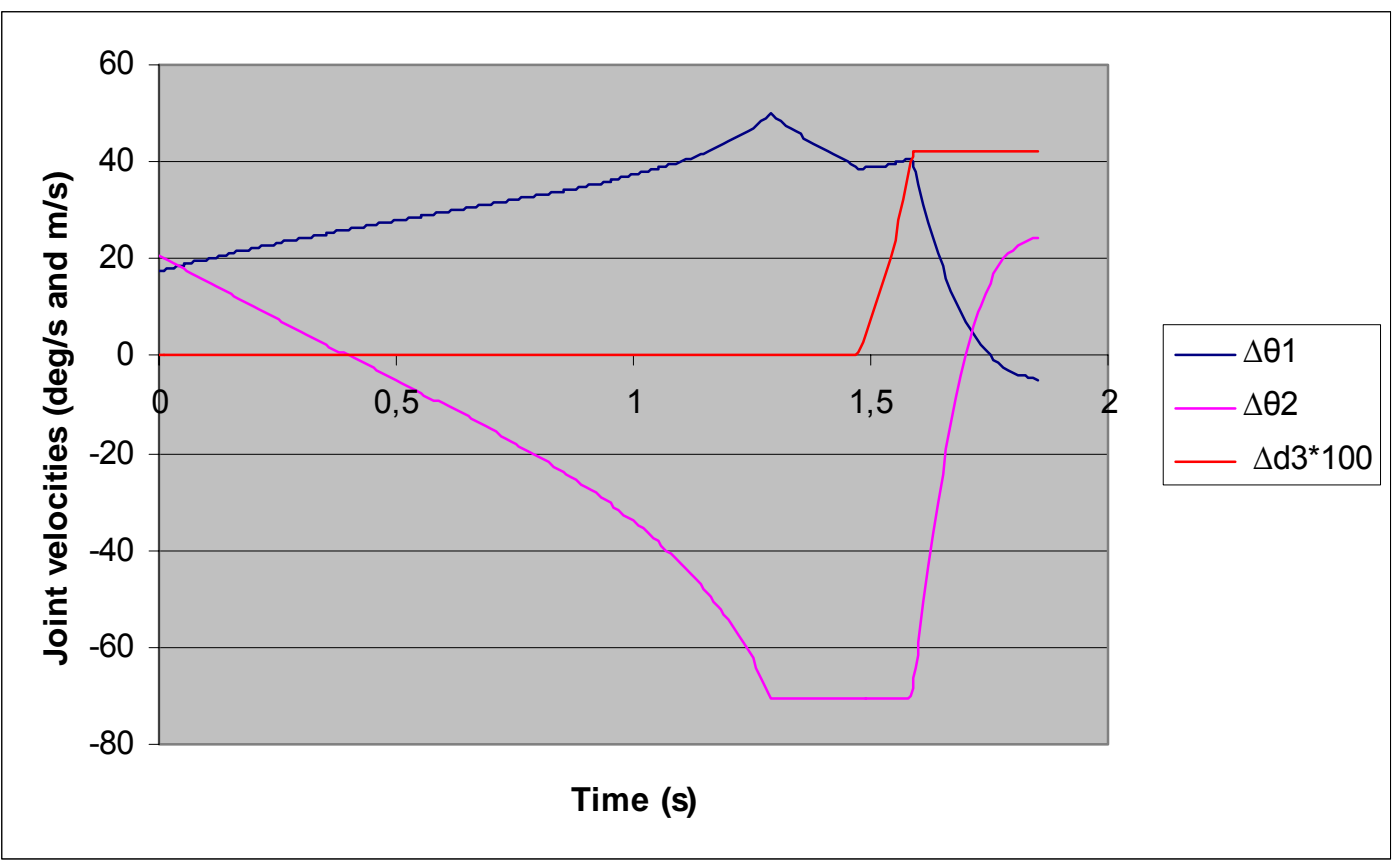

Figure 8.2.2.7 Maximum lifting capacity algorithm. TCP moves from B to $\mathrm{C}$ with a speed of $2.5 \mathrm{~m} / \mathrm{s}$. Variations in $\dot{\theta}_{1}, \dot{\theta}_{2}$ and $\dot{d}_{3}$.

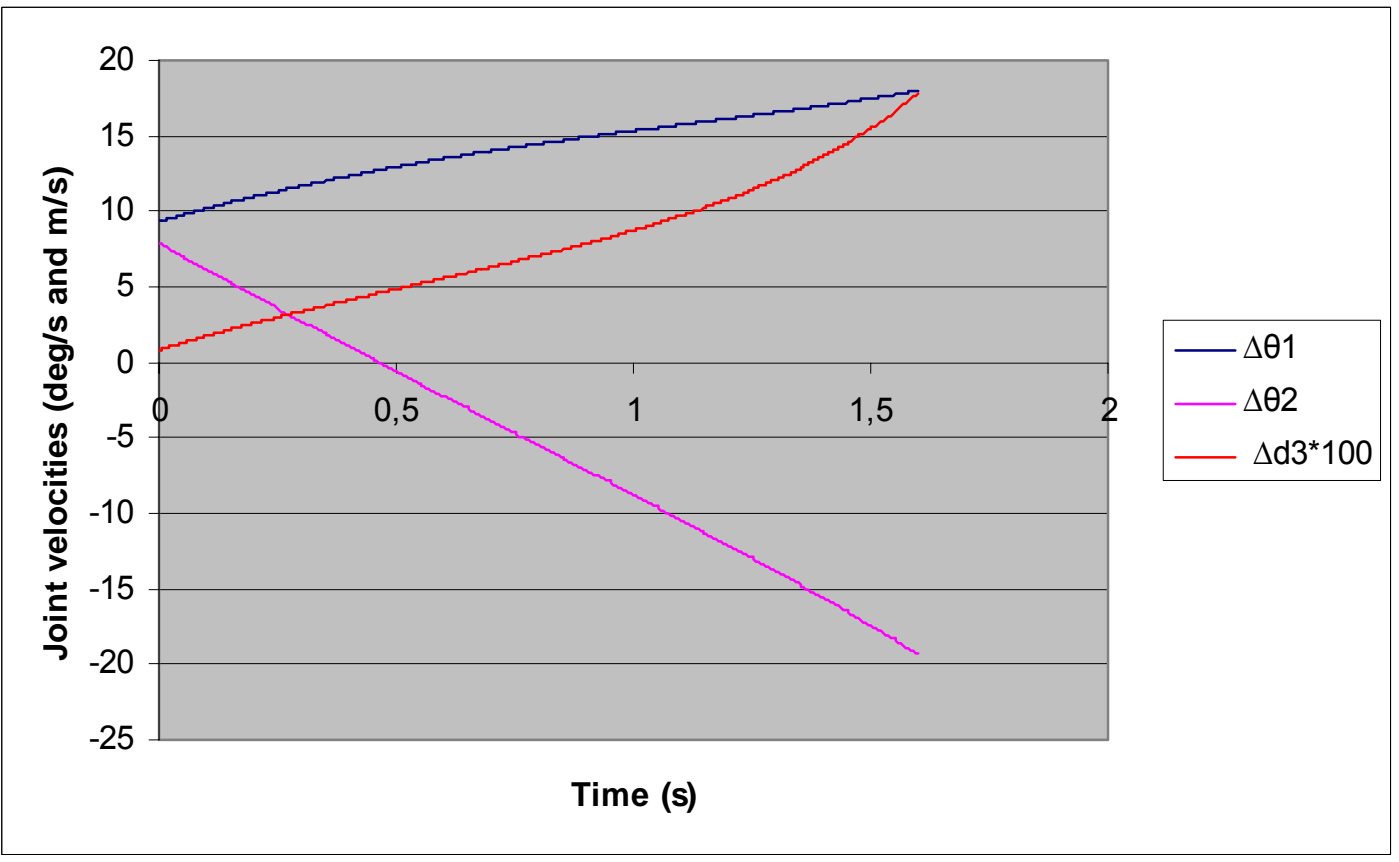

Figure 8.2.2.8 Maximum velocity algorithm. TCP moves from $B$ to $C$ with a speed of $2.5 \mathrm{~m} / \mathrm{s}$. Variations in $\dot{\theta}_{1}, \dot{\theta}_{2}$ and $\dot{d}_{3}$. 
The maximum lifting capacity algorithm needs more time, $1.89 \mathrm{~s}$, than the maximum velocity algorithm, $1.60 \mathrm{~s}$, to go from point $\mathrm{B}$ to $\mathrm{C}$. The velocities of the joints change smoothly in both cases. $\dot{\theta}_{1}, \dot{\theta}_{2}$ and $\dot{d}_{3}$ reach their maximum velocity limits in the maximum lifting capacity algorithm, but not simultaneously. According to section 6.2, a scaling of the command signal is necessary, which increases the time consumption. 
TCP moves from point $A$ to $C$.

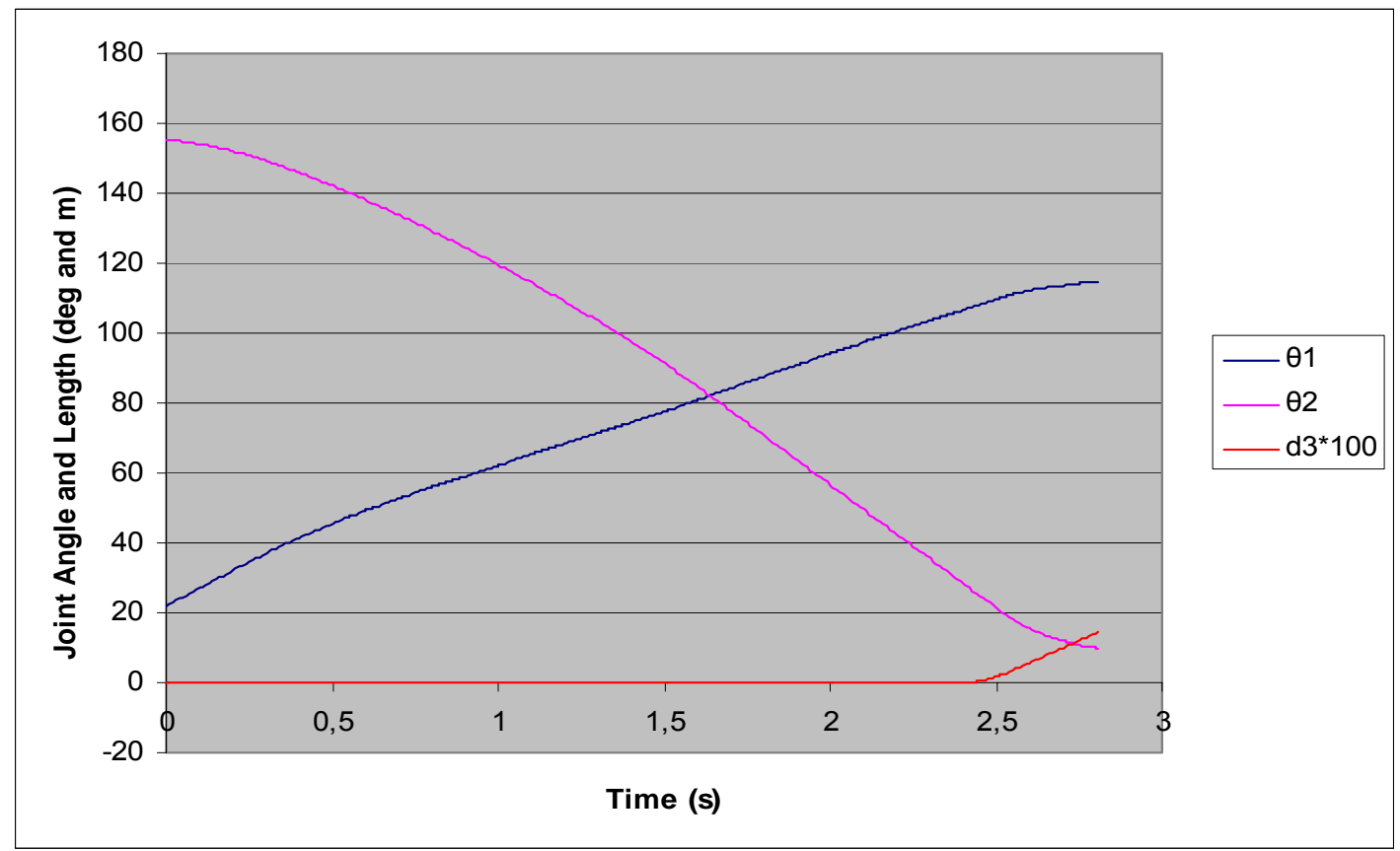

Figure 8.2.2.9 Maximum lifting capacity algorithm. TCP moves from A to $\mathrm{C}$ with a speed of $2.5 \mathrm{~m} / \mathrm{s}$. Variations in $\theta_{1}, \theta_{2}$ and $d_{3}$.

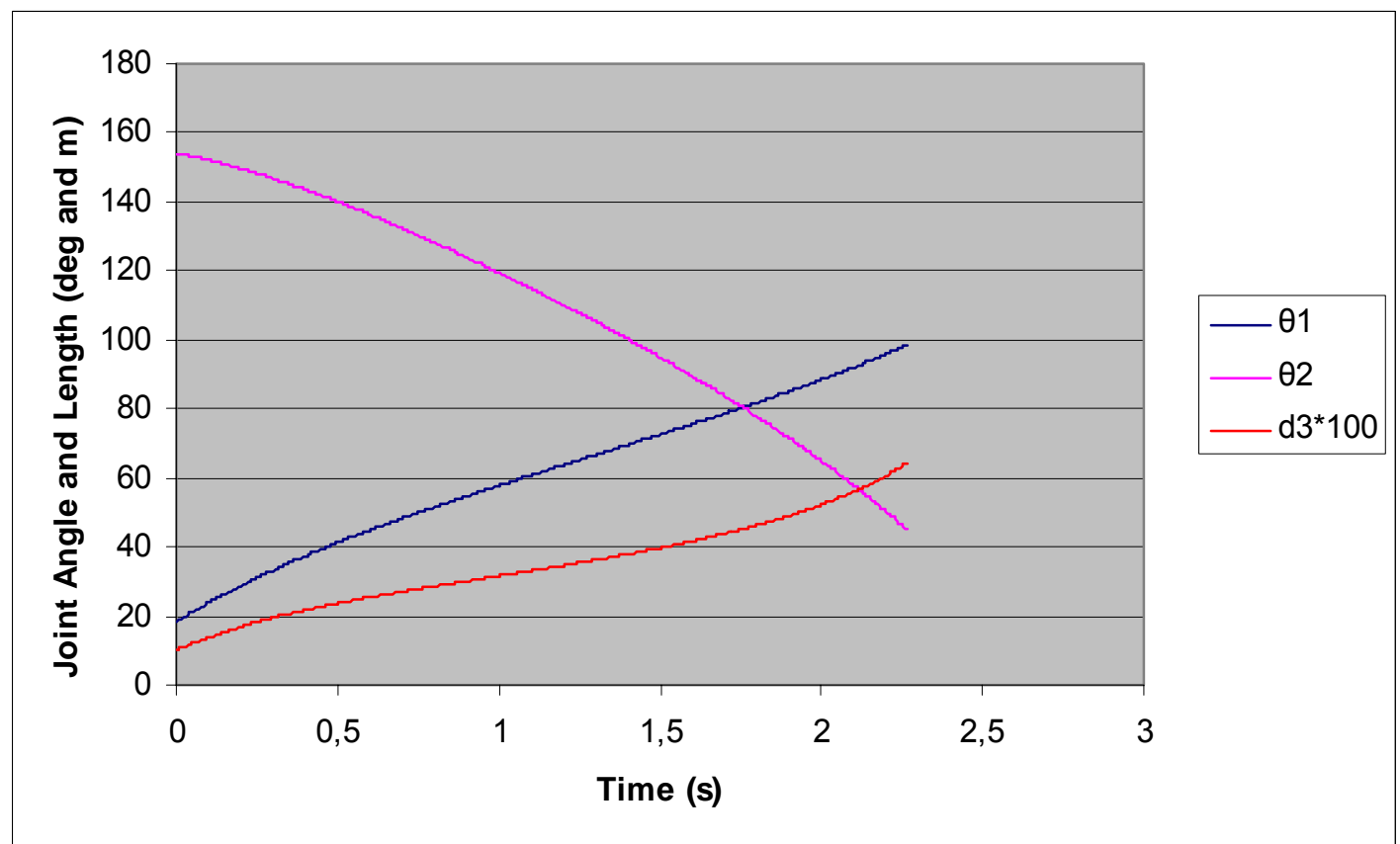

Figure 8.2.2.10 Maximum velocity algorithm. TCP moves from $A$ to $C$ with a speed of $2.5 \mathrm{~m} / \mathrm{s}$. Variations in $\theta_{1}, \theta_{2}$ and $d_{3}$. 


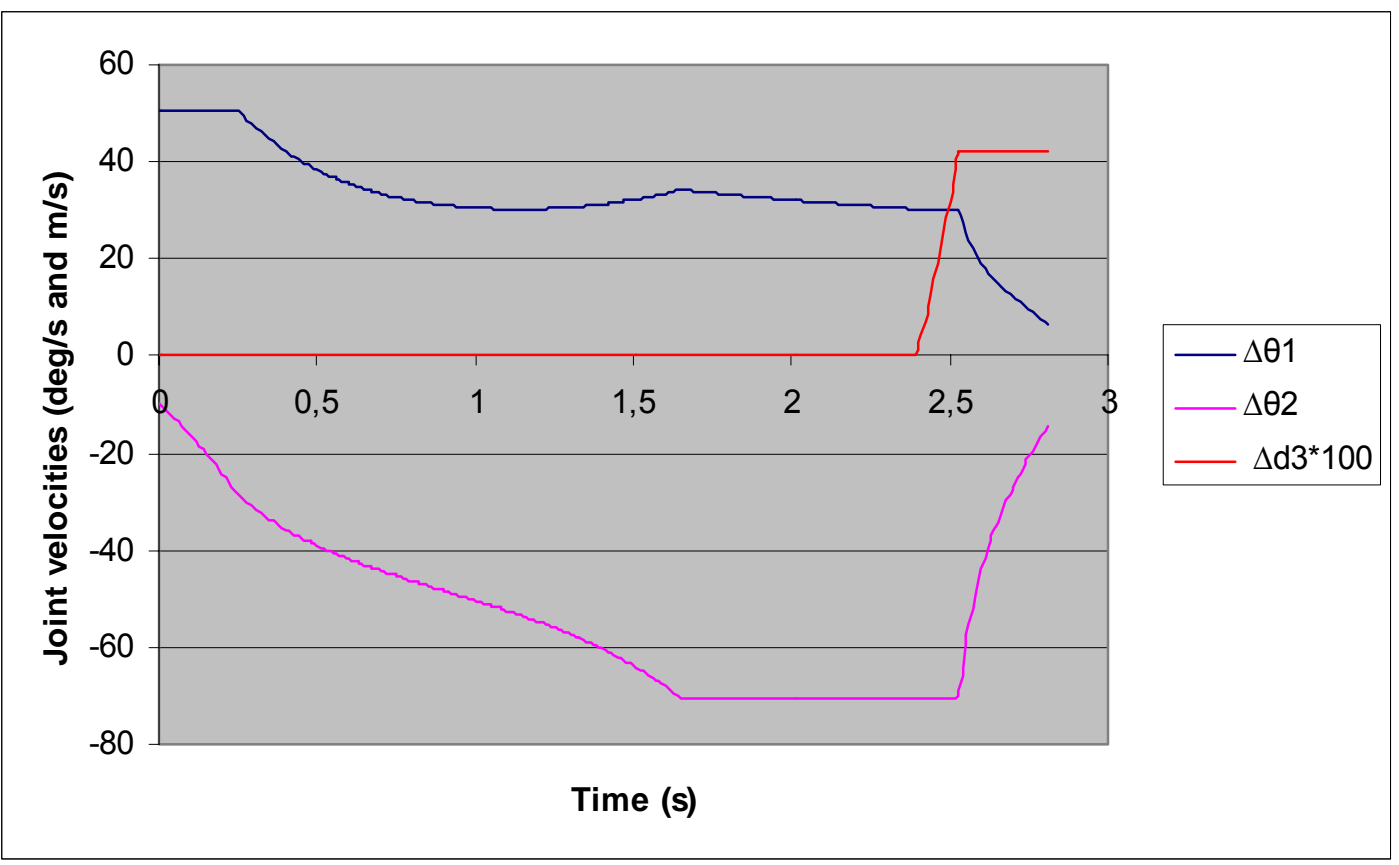

Figure 8.2.2.11 Maximum lifting capacity algorithm. TCP moves from A to $\mathrm{C}$ with a speed of $2.5 \mathrm{~m} / \mathrm{s}$. Variations in $\dot{\theta}_{1}, \dot{\theta}_{2}$ and $\dot{d}_{3}$.

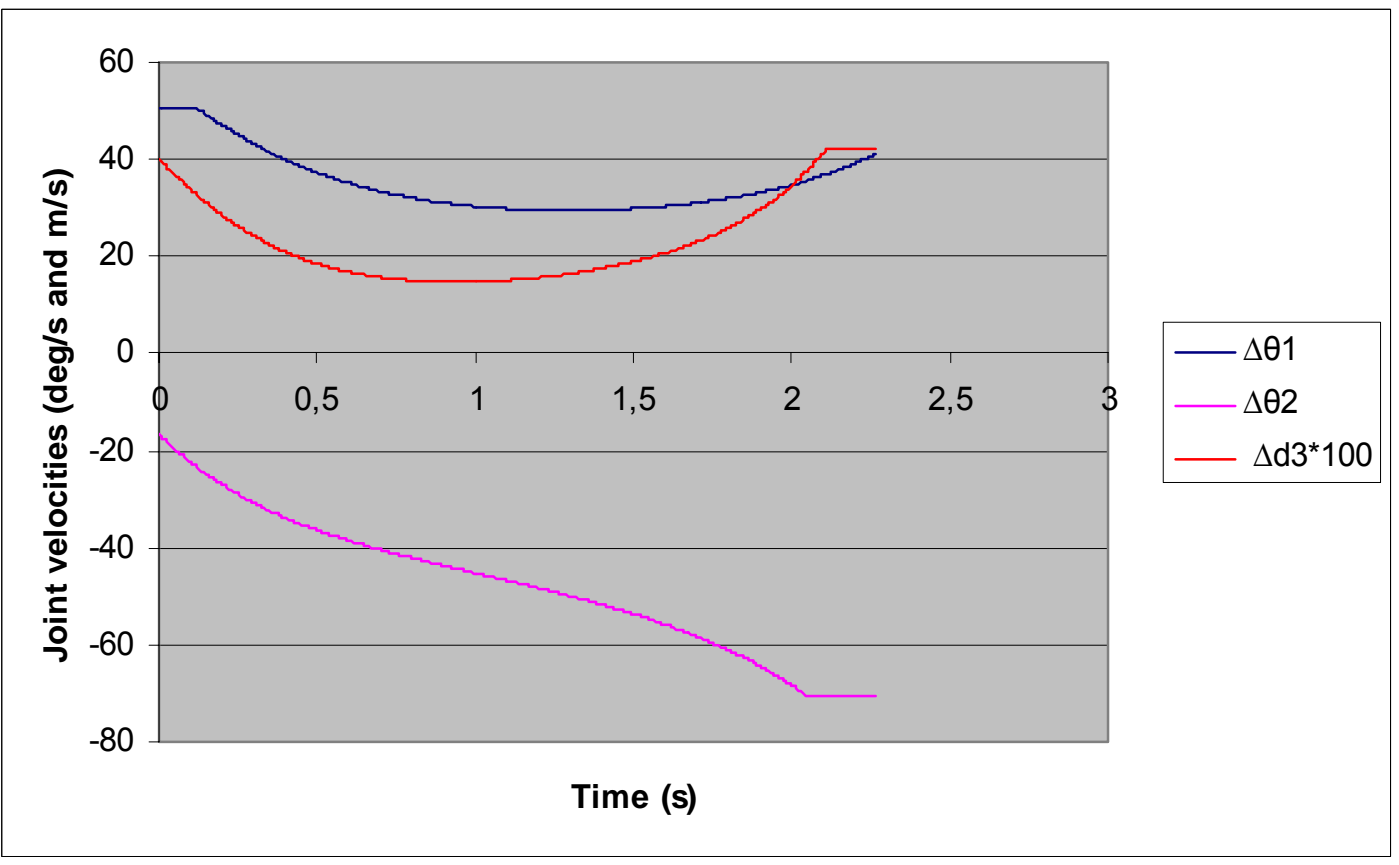

Figure 8.2.2.12 Maximum velocity algorithm. TCP moves from $A$ to $C$ with a speed of $2.5 \mathrm{~m} / \mathrm{s}$. Variations in $\dot{\theta}_{1}, \dot{\theta}_{2}$ and $\dot{d}_{3}$. 
The maximum lifting capacity needs $2.81 \mathrm{~s}$ to go from point A to C. $\dot{\theta}_{1}, \dot{\theta}_{2}$ and $\dot{d}_{3}$ reach their maximum velocity limits, but not simultaneously. According to section 6.2, a scaling of the command signal is necessary, which increases the time consumption.

Also in the maximum velocity case, $\dot{\theta}_{1}, \dot{\theta}_{2}$ and $\dot{d}_{3}$ reach their maximum velocity, and at the end of the trajectory, $\dot{\theta}_{2}$ and $\dot{d}_{3}$ do it almost simultaneously, which causes a scaling of the command signal, according to section 5.2.1.2, and a small increase in time consumption, $2.28 \mathrm{~s}$, compared to $2.26 \mathrm{~s}$ if no saturation occurs. During the scaling, the commanded path is followed, but with a slightly lower velocity than $1.5 \mathrm{~m} / \mathrm{s}$, and $\dot{\theta}_{2}$ and $\dot{d}_{3}$ are saturated. 


\subsection{Simulations with the dynamic programming algorithm}

The following figures show how $\theta_{1}, \theta_{2}, d_{3}, \dot{\theta}_{1}, \dot{\theta}_{2}$ and $\dot{d}_{3}$ will change over time when the TCP moves from point $\mathrm{A}$ to $\mathrm{B}, \mathrm{B}$ to $\mathrm{C}$ and $\mathrm{A}$ to $\mathrm{C}$. As the dynamic program algorithm calculates the shortest time that the TCP can achieve given the design parameters $\Delta r, \Delta z, \Delta d_{3}$ and $q$ when it moves along the path given $\theta_{1 \max }, \theta_{2 \max }$ and $d_{3 \max }$ we don't need to simulate for different speeds.

\subsubsection{TCP moves from point $A$ to $B$.}

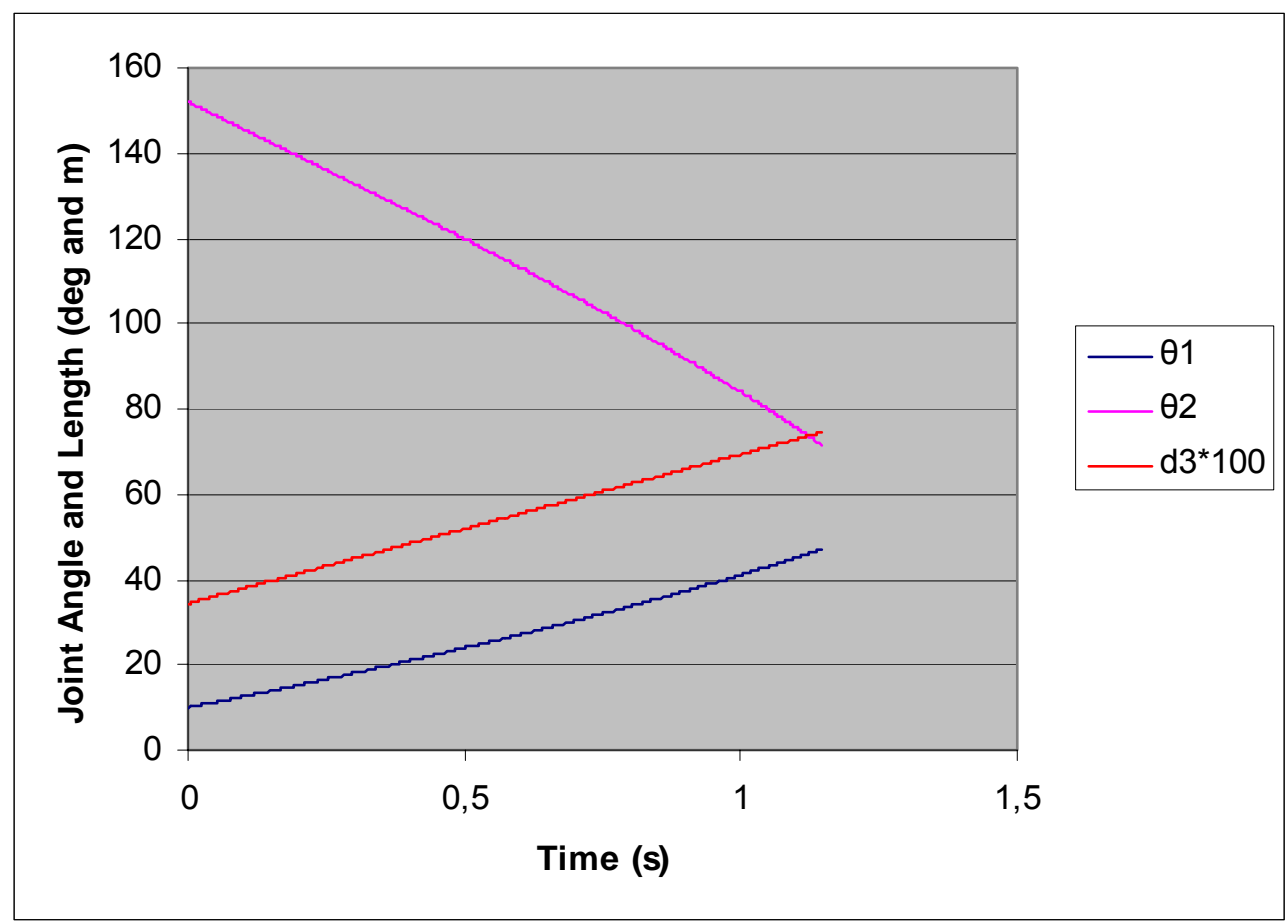

Figure 8.3.1.1 Dynamic programming algorithm. TCP moves from $A$ to $B$. Variations in $\theta_{1}, \theta_{2}$ and $d_{3}$. 


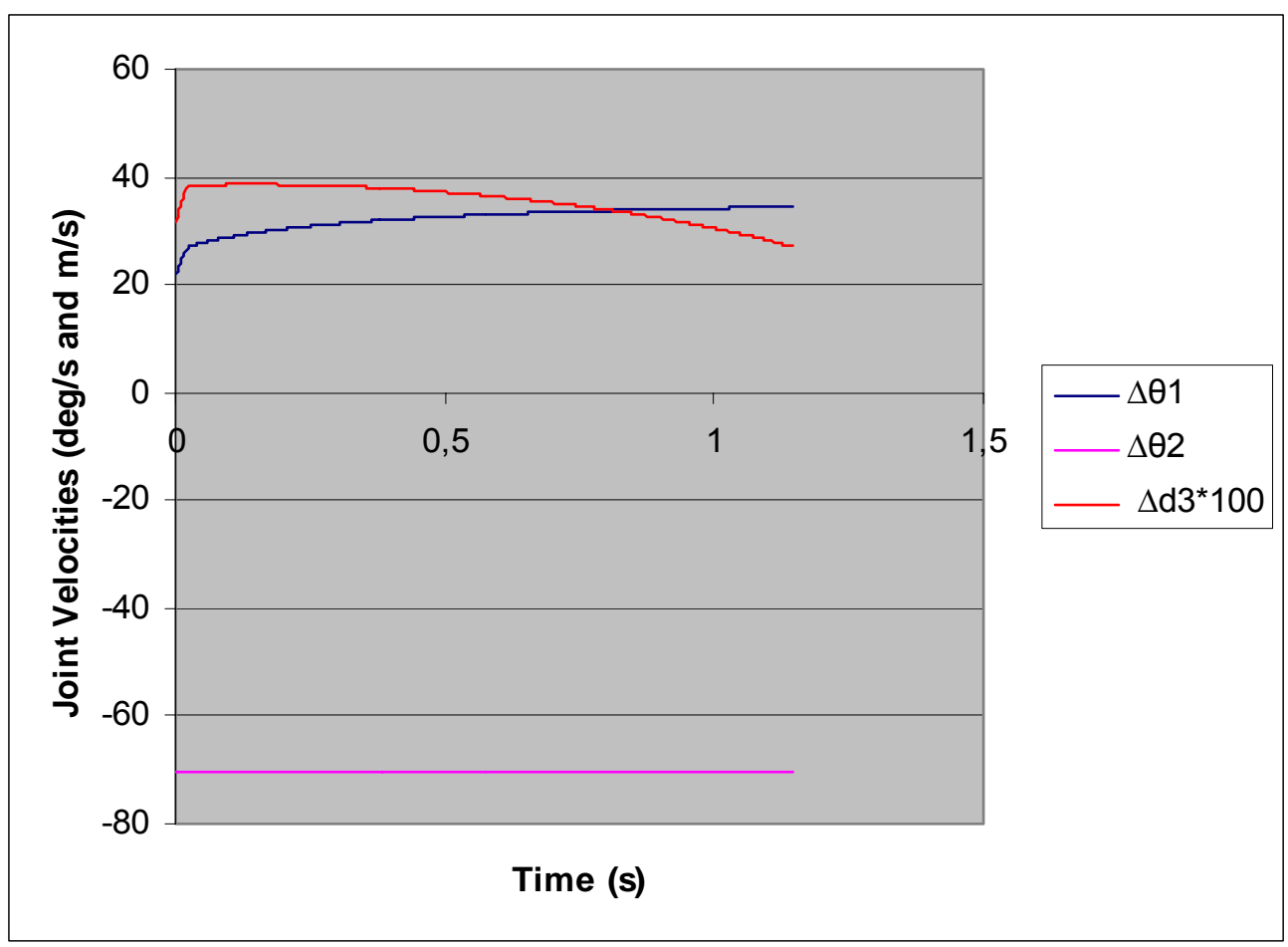

Figure 8.3.1.2 Dynamic programming algorithm. TCP moves from A to B. Variations in $\dot{\theta}_{1}, \dot{\theta}_{2}$ and $\dot{d}_{3}$.

The shortest time which is possible to achieve between A and B is $1.15 \mathrm{~s} . \dot{\theta}_{2}$ is at its maximum speed the whole time. $\dot{d}_{3}$ is almost at maximum speed. 


\subsubsection{TCP moves from point B to $C$.}

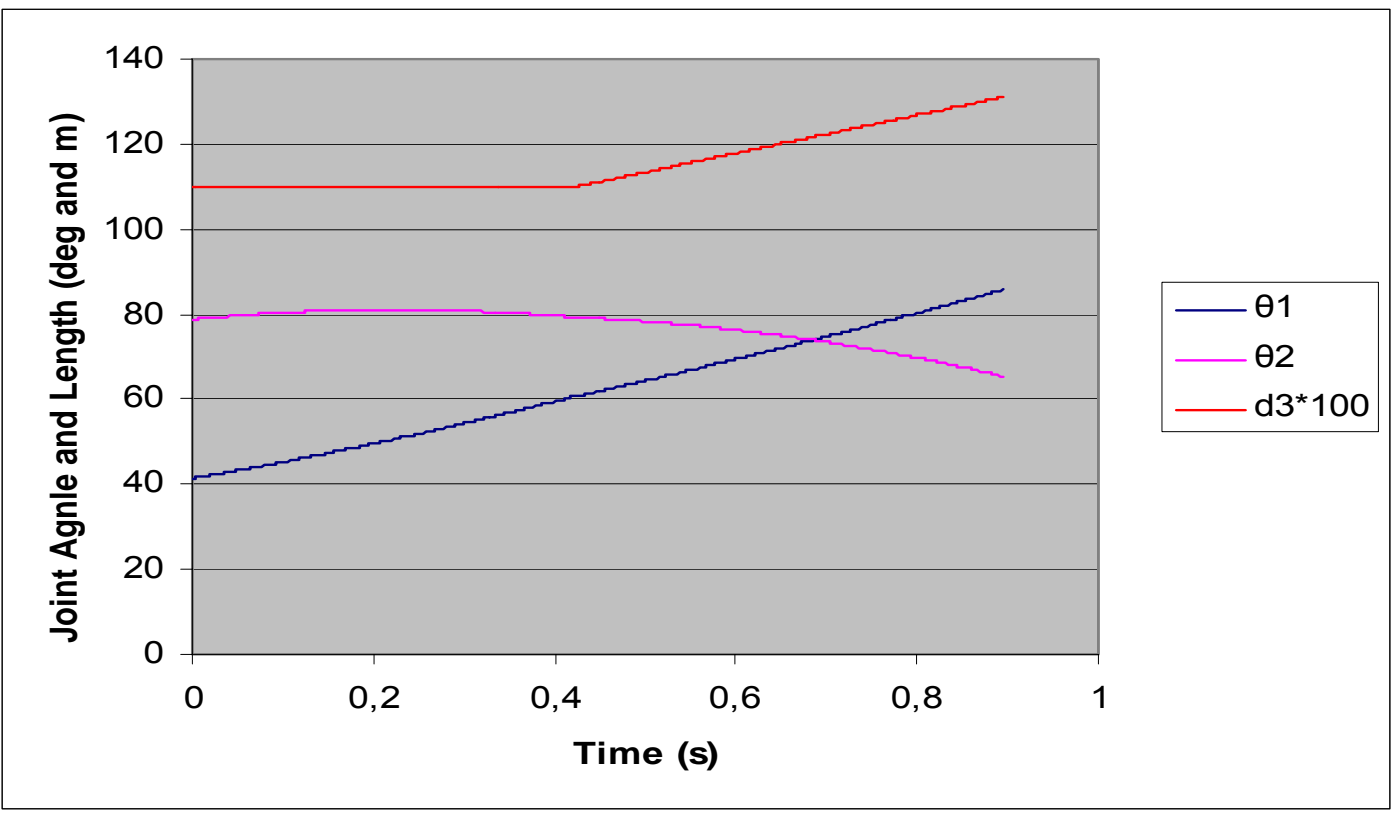

Figure 8.3.2.1 Dynamic programming algorithm. TCP moves from $B$ to $C$. Variations in $\theta_{1}, \theta_{2}$ and $d_{3}$.

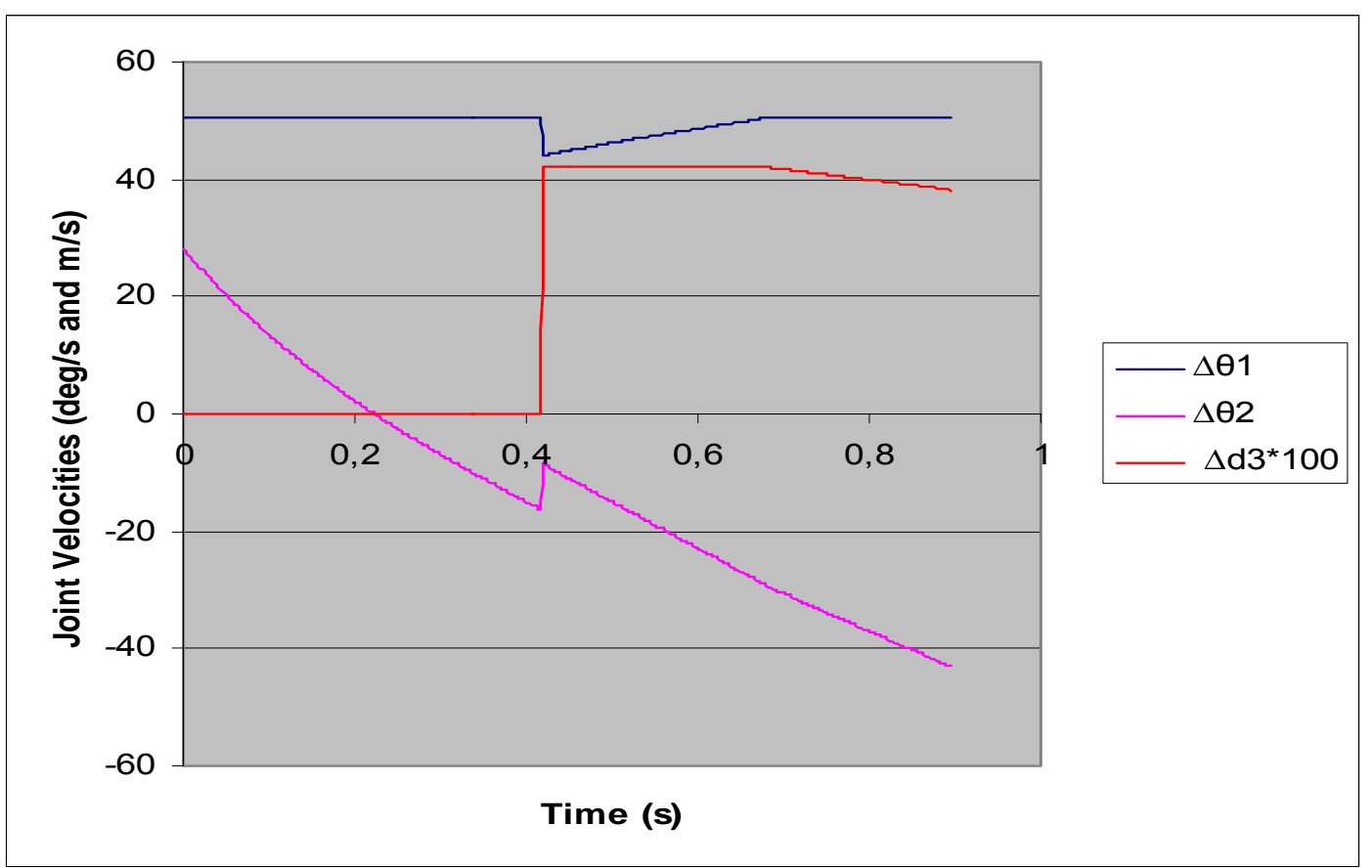

Figure 8.3.2.2 Dynamic programming algorithm. TCP moves from B to $\mathrm{C}$. Variations in $\dot{\theta}_{1}$, and $\dot{d}_{3}$. 
The shortest time which is possible to achieve between B and C is $0.89 \mathrm{~s}$. $\dot{\theta}_{1}$ is at its maximum speed from start up to approximately $0.4 \mathrm{~s}$ when $\dot{d}_{3}$ is activated at its maximum speed . $\dot{\theta}_{1}$ is at its maximum speed at the end of the path.

\subsubsection{TCP moves from point $A$ to $C$.}

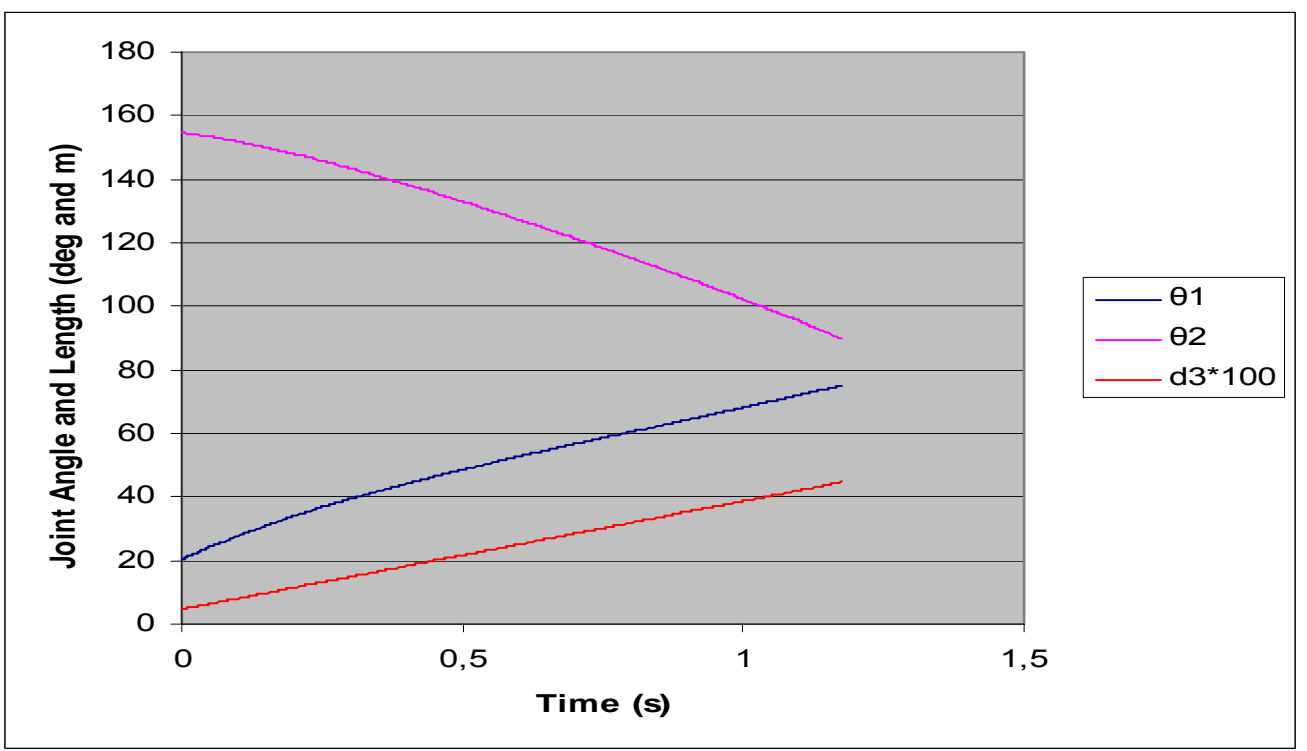

Figure 8.3.3.1 Dynamic programming algorithm. TCP moves from $A$ to $C$. Variations in $\theta_{1}, \theta_{2}$ and $d_{3}$.

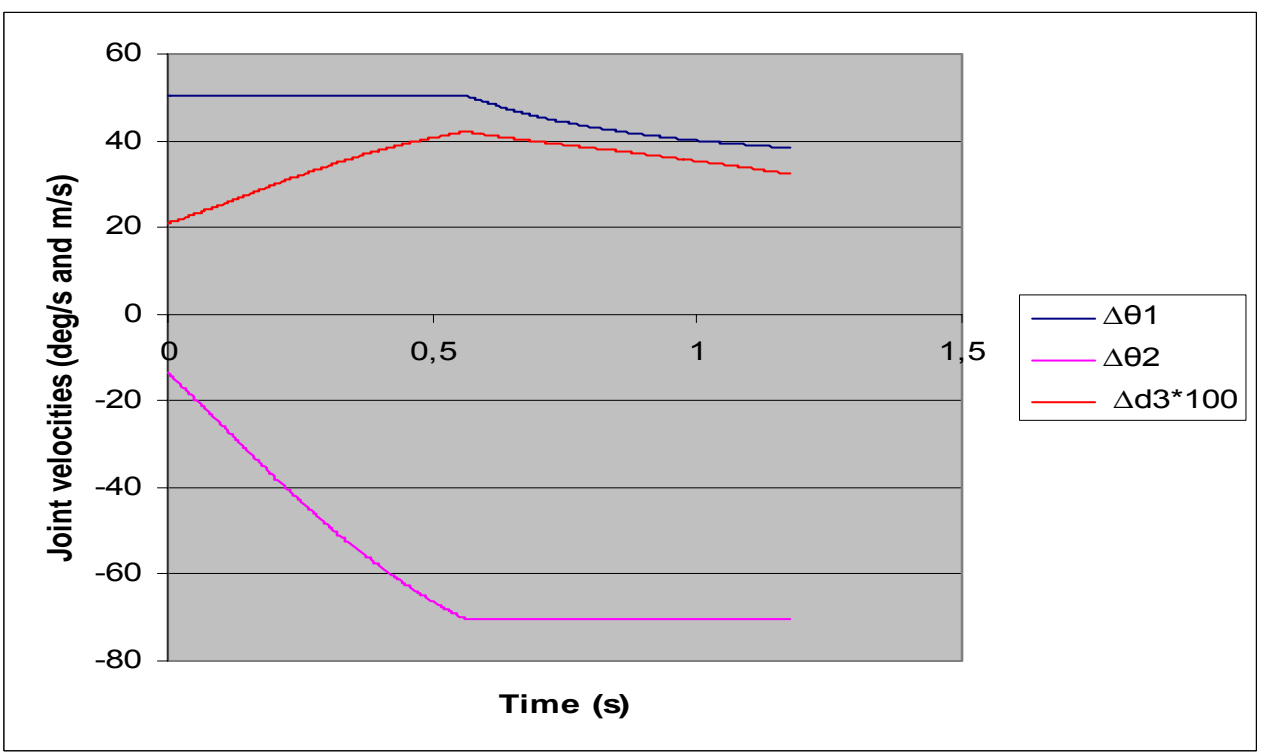


Figure 8.3.3.2 Dynamic programming algorithm. TCP moves from $A$ to $C$. Variations in $\dot{\theta}_{1}, \dot{\theta}_{2}$ and $\dot{d}_{3}$.

The shortest time which is possible to achieve between $\mathrm{A}$ and $\mathrm{C}$ is $1.18 \mathrm{~s}$. $\dot{\theta}_{1}$ is at its maximum speed from start up to ca $0.6 \mathrm{~s}$ and then $\dot{\theta}_{2}$ is at its maximum speed up to the end of the path.

To get a better picture of the time consumption the results from all simulations are put together in tables 8.1 and 8.2 . In table 8.1 we have the TCP velocity $1.0 \mathrm{~m} / \mathrm{s}$ and in table 8.2 we have the TCP velocity $2.5 \mathrm{~m} / \mathrm{s}$.

Table 8.1 Time consumption in seconds for the TCP velocity $1.0 \mathrm{~m} / \mathrm{s}$.

\begin{tabular}{|c|c|c|c|}
\hline Control Law & A - B & B - C & A - C \\
\hline Maximum lifting capacity & 4.00 & 4.05 & 5.76 \\
\hline Maximum velocity & 4.00 & 4.00 & 5.67 \\
\hline Dynamic programming $^{*}$ & 1.15 & 0.89 & 1.18 \\
\hline
\end{tabular}

*) TCP velocity not constant

Table 8.2 Time consumption in seconds for the TCP velocity $2.5 \mathrm{~m} / \mathrm{s}$.

\begin{tabular}{|l|c|c|c|}
\hline Control Law & A - B & B - C & A - C \\
\hline Maximum lifting capacity & 1.7 & 1.89 & 2.81 \\
\hline Maximum velocity & 1.6 & 1.6 & 2.28 \\
\hline Dynamic programming $^{*}$ & 1.15 & 0.89 & 1.18 \\
\hline
\end{tabular}

*) TCP velocity not constant

The maximum velocity algorithm is capable of keeping the commanded velocity in all cases whereas the maximum lifting capacity is not. Presumably, the lifting capacity of the latter method is superior , but the verification of this is outside the scope of this thesis. 


\section{Chapter 9}

\section{CONCLUSION}

Algorithms for computation of the inverse kinematics of kinematically redundant hydraulic manipulators have been investigated. The hydraulic manipulator used in the simulation study consists of a 4-DOF hydraulic forestry machine manipulator. The aim was to compare kinematic control algorithms that would control the manipulator arm.

Three methods resolving the manipulator redundancy at the velocity level were examined, maximum lifting capacity, maximum velocity (local optimization) and dynamic programming (global optimization).

The simulations show the necessary speed requirements for all joints when performing straight paths in the manipulator work area. The simulations also show the difference in time consumptions between the three control algorithms and also what happens when the joints reach their maximum velocity limit.

Although this work was an attempt to propose complete algorithms that directly could be applicable to a real system, it is still only a simulation study which lacks the qualities of implementation on a real hydraulic manipulator.

The dynamic programming is not practical due to that the algorithm needs to know the start and the end position, which is unusual in a practical application when the manipulator is controlled by an operator.

In our simulation example, the maximum velocity algorithm gives shorter cycle time than the maximum lifting capacity algorithm, but this is not a general conclusion. In other applications the two methods should be carefully compared, since there are many parameters to play with. In the maximum lifting capacity method we have $r_{c}, z_{c}, \rho_{\min }, \rho_{\max }$ and in the maximum velocity method $w_{11}, w_{22}, w_{33}$.

The dynamic programming demonstrates the shortest possible cycle times when relaxing the requirements of constant TCP velocity along the path, but must know the start and the end position of the trajectories. It may be useful in future applications where automated functions are used.

In future work the maximum lifting capacity method will be tested in a forestry real time simulator. The method will be evaluated by forestry machine operators to see if the boom tip control could increase the productivity. Semi automated functions will also be tested. 


\section{References}

[1] Ahlgren, T., Brundin, L., Jonsson, B., Löfroth, C., Morenius, B., Myhrman, D., 1982. Manöversystem för hydraulkranar. Skogforsk Redogörelse nr 6.

[2] Beiner, L., Mattila, J., An improved pseudo-inverse solution for redundant hydraulic manipulators. Robotica, Vol. 17, 1999 (pp. 173-179).

[3] Bellman, R., Dynamic Programming. Princeton, New Jersey, 1957.

[4] Honzik, B. and Zezulka, F., Redundancy Resolution Techniques for Mobile manipulators. AMPTS '99. 1999.

[5] Chan, T. F. and Dubey, R. V., A Weighted Least-Norm Solution Based Scheme for Avoiding Joint Limits for Redundant Joint Manipulators, IEEE Trans. on Robotics and Automation, Vol. 11, no.2, 1995 (pp286-292).

[6] Chen, W., Zhang, Q., and Yang, Z., Gruver, W. A.., Optimizing Multiple Performance Criteria in Redundant Manipulators by Subtask-Priority Control, Proc. of the 1995 IEEE International Conference on Systems, Man, and Cybernetics, Vancouver, Canada, October 1995, (pp 2534-2539).

[7] Chen, W., Zhang, Q., and Yang, Z., Gruver, W. A.., A New Approach to the Kinematic Control of Redundant Manipulators, Proc. of the 1995 IEEE International Conference on Systems, Man, and Cybernetics, Vancouver, Canada, October 1995, (pp 2528-2533).

[8] Cleary, K., Tesar, C., Incorporating Multiple Criteria in the Operation of Redundant Manipulators, IEEE Int. Conf. Robotics and Automation, Cincinnati, 1990, (pp. 618623).

[9] Erikson, G. \& Thor, M. 1999. Interaktion människa-skogsmaskin. Rapport från ett SLO-projekt (in Swedish). Skogforsk Arbetsrapport 423.

[10] Gellerstedt, S. Att gallra med skogsmaskin - den mentala och fysiska belastningen (in Swedish). Uppsatser och resultat nr 244. Inst. F. Skogsteknik. Sveriges Lantbruks universitet.

[11] Hollerbach, J. M., Suh, K. C., Redundancy Resolution of Manipulators through Torque Optimization, A. I. Memo 882, Massachusetts Institute of Technology, January 1986. 
[12] Honegger, M., Codourey, A., Redundancy Resolution of a Cartesian space operated heavy industrial Manipulator. Int. Conf. on Robotics and Automation, May 16-21, 1998.

[13] Klein, C. A, " Use of Redundancy in the design of robotic systems," in: Robotic Research: The Second Int. Symposium, H. Hanafusa and H. Inoue, Eds., MIT Press, 1985 , (pp. 208-214), Cambridge, MA,.

[14] Klein, Charles A., Kee, Koh-Boon, The Nature of Drift in Pseudo inverse Control of Kinematically Redundant Manipulators. IEEE Transactions on Robotics and Automation. 1989, Vol. 5, No. 2, (pp. 231-234).

[15] Klein, Charles A., Ahmed, Shamim, Repeatable Pseudo inverse Control for Planar Kinematically Redundant Manipulators. IEEE Transaction on System, Man, and Cybernetics, 1995, Vol. 25, No. 12, (pp. 1657-1662).

[16] Klein, C. A., Chu-Jenq, C. and Ahmed. S, Use of an extended Jacobian Method to Map Algorithmic Singularities. IEEE 1993 (pp 632-637).

[17] Li, L., Gruver, W. A.., Zhang, Q., Kinematic control of redundant robots based on the motion optimizability measure, IEEE Transactions on Systems, Man and Cybernetics, 2001, Part B, Vol. 31, No. 1,.

[18] Löfgren, B., Boom Tip Control (in Swedish). Skogforsk. Meddelande No. 18, Forest research institute of Sweden, 1989.

[19] Löfgren, B., Landström, M., Atterbrandt, M., Pettersson, N., Nordén, B., Kranspetsstyrning - en utvärdering (in Swedish). Skogforsk. Redogörelse, Nr.1, 1994.

[20] Martin, D. P., Baillieul, J. and Hollerbach, J. M., Resolution of Kinematic Redundancy Using Optimization Techniques, IEEE Transaction on Robotics and Automation, 1989. Vol. 5., No. 4 (pp 529-533).

[21] McGee, S., Chan, T. F. and Dubey, R. V., Probability Weighting of Performance Criteria for a Redundant Manipulator, IEEE 1994, (pp 1887-1894).

[22] Nakamura, Y., Advanced Robotics, Redundancy and Optimization, AddisonWesley, 1991.

[23] Nedungadi, A., Kazerounian, K. A local solution with global characteristics for the joint torque optimization of a redundant manipulator, J. of Rob. Systems, 1989, vol. 6(5), (pp. 631-654).

[24] Nedungadi, A. Torque optimization of redundant manipulators, Int. Symp. on Intelligent Robotics, 1987, (pp. 10.65-10.83). 
[25] Nenchev, D. N. Redundancy resolution through local optimization: A review, J. of Rob. Systems, 1989, vol. 6 (6), (pp. 769-798).

[26] Noble, B., Methods for Computing the Moore-Penrose Generalized Inverse, and Related matters. M.Z. Nashed ed, New York Academic Press, 1975, (pp. 254-301).

[27] Sciavicco, L. and Siciliano, B., A Dynamic Solution to the Inverse Kinematic Problem for Redundant Manipulators, Proc. IEEE Int. Conf. Robotics and Automation, 1987 (pp. 1081-1087), Raleigh, North Carolina.

[28] Siciliano, B. Kinematic control of redundant manipulators: A tutorial, J. of Int. and Rob. Systems, 1990, Vol. 3, (pp. 201-212).

[29] SkogForsk. A number of productivity and time studies under the period 1970-2002. Brunberg, T. Westerlund, M. Studie av Timberjack 1270, Timberjack 1880 och Valmet 911 vid Djupdal, SCA Skog AB. 1994

[30] Suh, K. C., Hollerbach, J. M. Local versus global torque optimization of redundant manipulators, IEEE Int. Conf. Robotics and Automation, 1987, (pp. 619-624). 


\section{Appendix 1: Knuckle boom market}

The annual sales of knuckle booms are about 10000 - 11000 pieces in the world. The distribution between different areas is

$\begin{array}{ll}\text { Trucks } & 41 \% \\ \text { Forwarder } & 12 \% \\ \text { Harvester } & 7 \% \\ \text { Stationary } & 20 \% \\ \text { Others } & 20 \%\end{array}$

\begin{tabular}{|c|c|c|c|}
\hline Name & Manufacturer & Type of boom & Area of use \\
\hline FASSI & $\begin{array}{l}\text { FASSI Gru Idrauliche- } \\
\text { S.p.A } \\
\text { Italy }\end{array}$ & Knuckle boom & Trucks \\
\hline HIAB & $\begin{array}{l}\text { HIAB AB } \\
\text { Sweden }\end{array}$ & Knuckle boom & Trucks, Stationary \\
\hline HMF & $\begin{array}{l}\text { HÖJBERGS Maskinfabrik } \\
\text { A/S } \\
\text { Denmark }\end{array}$ & Knuckle boom & Trucks, Stationary \\
\hline LOGLIFT & $\begin{array}{l}\text { Loglift OY } \\
\text { Finland }\end{array}$ & Knuckle boom & Forestry machines, Trucks \\
\hline PALFINGER & $\begin{array}{l}\text { Palfinger AG } \\
\text { Austria }\end{array}$ & Knuckle boom & Trucks, Tractors, Stationary \\
\hline CRANAB & $\begin{array}{l}\text { CRANAB AB } \\
\text { Sweden }\end{array}$ & $\begin{array}{l}\text { Knuckle boom, Telescope } \\
\text { boom Parallel boom }\end{array}$ & Forestry machines \\
\hline MOWI & $\begin{array}{l}\text { MOWI System AB } \\
\text { Sweden }\end{array}$ & Parallel boom & Forestry machines \\
\hline MOHEDA & $\begin{array}{l}\text { Moheda System AB } \\
\text { Sweden }\end{array}$ & Knuckle boom & Forestry Wagons; Tractors \\
\hline FARMI & $\begin{array}{l}\text { Farmi-Normet } \\
\text { Corporation OY, Finland }\end{array}$ & Knuckle boom & Forestry Wagons \\
\hline KTS & $\begin{array}{l}\text { Kumla Traktorservice AB } \\
\text { Sweden }\end{array}$ & Knuckle boom & Forestry Wagons \\
\hline Sonnys & $\begin{array}{l}\text { Sonnys Maskiner AB } \\
\text { Sweden }\end{array}$ & Knuckle boom & Forestry Wagons \\
\hline SP & $\begin{array}{l}\text { SP Maskiner AB } \\
\text { Sweden }\end{array}$ & Knuckle boom & $\begin{array}{l}\text { Forestry Wagons, Forestry } \\
\text { machines, Stationary }\end{array}$ \\
\hline Timberjack & $\begin{array}{l}\text { John Deere -Timberjack } \\
\text { Finland }\end{array}$ & Knuckle boom & Forestry machines \\
\hline Ponsse & $\begin{array}{l}\text { Ponsse OY } \\
\text { Finland }\end{array}$ & $\begin{array}{l}\text { Knuckle boom, Parallel } \\
\text { boom }\end{array}$ & Forestry machines \\
\hline Rottne & $\begin{array}{l}\text { Rottne Industri AB } \\
\text { Sweden }\end{array}$ & $\begin{array}{l}\text { Knuckle boom Parallel } \\
\text { boom }\end{array}$ & Forestry machines \\
\hline Epsilon & $\begin{array}{l}\text { Epsilon Kran GmbH \& Co } \\
\text { KG } \\
\text { Austria }\end{array}$ & Knuckle boom & Trucks, Stationary \\
\hline PATU & $\begin{array}{l}\text { KESLA OYJ } \\
\text { Finland }\end{array}$ & Knuckle boom & $\begin{array}{l}\text { Trucks, Forestry machines, } \\
\text { Stationary }\end{array}$ \\
\hline Fuchs & Fuchs-Bagger & Knuckle boom & Skrothantering \\
\hline
\end{tabular}




\begin{tabular}{|c|c|c|c|}
\hline & Germany & & Wood handling \\
\hline Penz & $\begin{array}{l}\text { Rochus Penz GmbH } \\
\text { Kranbau, Germany }\end{array}$ & Knuckle boom & Loading wagons, Trucks \\
\hline Vreten & Vreten AB Sweden & Knuckle boom & Loading wagons \\
\hline Weimer & $\begin{array}{l}\text { Weimer Skogsteknik AB, } \\
\text { Sweden }\end{array}$ & Knuckle boom & Loading wagons \\
\hline Kronos & $\begin{array}{l}\text { Kronos/Wikar OY, } \\
\text { Finland }\end{array}$ & Knuckle boom & Loading wagons \\
\hline Tigerlift & $\begin{array}{l}\text { Intermercato } \\
\text { Sweden }\end{array}$ & Knuckle boom & Loading wagons, Tractors, \\
\hline Logmer & $\begin{array}{l}\text { Logmer Forest OY } \\
\text { Finland }\end{array}$ & Parallel boom & Forestry machines \\
\hline Waratah & $\begin{array}{l}\text { Waratah Forestry } \\
\text { Attachment Finland }\end{array}$ & Knuckle boom & Forestry machines \\
\hline Nokka & Nokka-Tume OY, Finland & Knuckle boom & Loading wagons \\
\hline Jonsered & $\begin{array}{l}\text { Jonsered Cranes AB } \\
\text { Sweden }\end{array}$ & Knuckle boom & $\begin{array}{l}\text { Trucks, Loading wagons, } \\
\text { Stationary }\end{array}$ \\
\hline Guerra & $\begin{array}{l}\text { Industrias Guerra S.A. } \\
\text { Spain }\end{array}$ & Knuckle boom & $\begin{array}{l}\text { Marina applikationer, Trucks, } \\
\text { Loading wagons, stationär }\end{array}$ \\
\hline Vimek & $\begin{array}{l}\text { Vimek AB } \\
\text { Sweden }\end{array}$ & Knuckle boom & Loading wagons \\
\hline Patruuna & Pellonpaja OY, Finland & Knuckle boom & Loading wagons \\
\hline Jonsered & Jonsered Cranes Sweden & Knuckle boom & Trucks, Stationär, \\
\hline EFFER & EFFER, Italy & $\begin{array}{l}\text { Knuckle boom, Telescope } \\
\text { boom, }\end{array}$ & Trucks, marine applications, \\
\hline $\begin{array}{l}\text { Epsilon } \\
\text { Palfinger } \\
\text { Stepa }\end{array}$ & $\begin{array}{l}\text { Palfinger } \\
\text { Germany }\end{array}$ & $\begin{array}{l}\text { Knuckle boom, Telescope } \\
\text { boom }\end{array}$ & Trucks, Stationary, farming, \\
\hline Prentice & $\begin{array}{l}\text { Blount } \\
\text { Prentice Plant } \\
\text { USA }\end{array}$ & Knuckle boom & Trucks, Stationary \\
\hline National & National Cranes, USA & $\begin{array}{l}\text { Knuckle boom, Telescope } \\
\text { boom }\end{array}$ & Trucks, Stationary \\
\hline Steco & $\begin{array}{l}\text { Stedt Hydraulic Cranes } \\
\text { co, USA }\end{array}$ & $\begin{array}{l}\text { Knuckle boom, Telescope } \\
\text { boom }\end{array}$ & Trucks, Stationary \\
\hline Cormach & Cormach Cranes, Italy & Knuckle boom & Trucks \\
\hline
\end{tabular}

